University of Chicago Law School

Chicago Unbound

Journal Articles

Faculty Scholarship

2001

\title{
Beyond Exit and Voice: User Participation in the Production of Local Public Goods
}

Lee Anne Fennell

Follow this and additional works at: https://chicagounbound.uchicago.edu/journal_articles

Part of the Law Commons

\section{Recommended Citation}

Lee Anne Fennell, "Beyond Exit and Voice: User Participation in the Production of Local Public Goods," 80 Texas Law Review 1 (2001).

This Article is brought to you for free and open access by the Faculty Scholarship at Chicago Unbound. It has been accepted for inclusion in Journal Articles by an authorized administrator of Chicago Unbound. For more information, please contact unbound@law.uchicago.edu. 


\title{
Texas Law Review
}

Volume 80, Number 1, November 2001

\author{
Articles
}

\section{Beyond Exit and Voice: User Participation in the Production of Local Public Goods}

\section{Lee Anne Fennell*}

I. The Role of User Participation ...........................................................6

A. Rethinking Education and Neighborhood Security ..............................6

B. Participation, User Heterogeneity, and Critical Concentrations.........12

C. Beyond Voice and Exit.....................................................................23

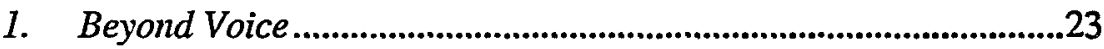

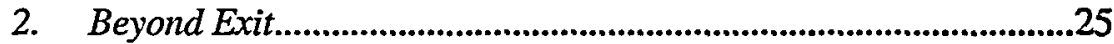

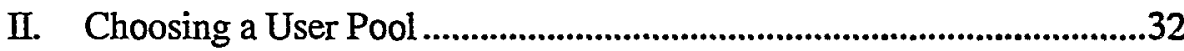

A. Cooperation and Consumption ........................................................32

B. The "Choice of Pool" Game.................................................................36

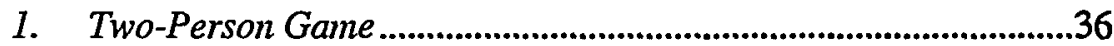

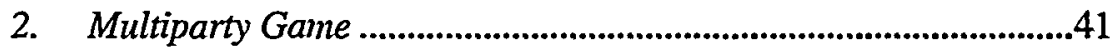

C. Locks, Bribes, Norms, and Pacts......................................................45

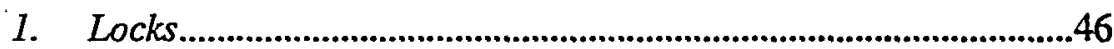

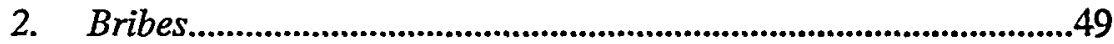

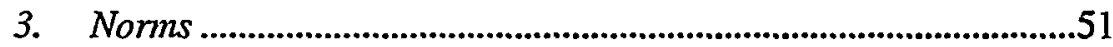

Assistant Professor, University of Texas School of Law. I would like to thank Lynn Baker, Dhammika Dharmapala, Richard Epstein, William Fischel, Christopher Fennell, Elizabeth Garrett, Mark Gergen, William Henderson, Douglas Laycock, Daryl Levinson, Saul Levmore, James Madigan, Jonathan Nash, Eric Rasmusen, Julie Roin, Steven Salop, Warren Schwartz, Heathcote Wales, and Amy Wax for providing helpful input on this project. I am also grateful for the many thoughtful comments provided at presentations of this paper at the University of Texas School of Law, Georgetown University Law Center's Law and Economics Workshop, and the 2001 Annual Meeting of the American Law and Economics Association. Finally, I would like to thank the Virginia Center for the Humanities for providing me with office space and research suppon during the summer of 2000. All errors are mine. 
4. Pacts 52

III. Choosing Actions Within the User Pool..........................................53

A. Quality-Enhancing Behavior and Intrapool Spillovers........................53

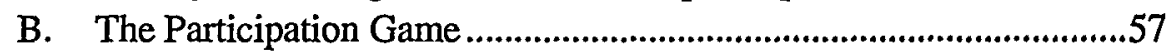

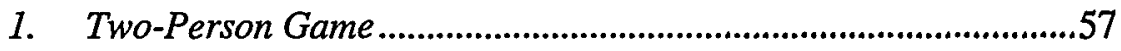

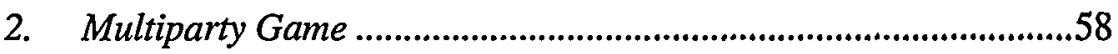

C. Strategies for Improving Intrapool Outcomes ...................................60

IV. The Interdependence of Interpool and Intrapool Decisions.....................64

A. Achieving a Critical Mass ...............................................................64

B. Signaling and Screening ...................................................................66

C. Pool Characteristics and the Dynamics of Cooperation .....................69

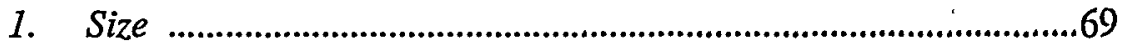

2. Homogeneity and Diversity .......................................................70

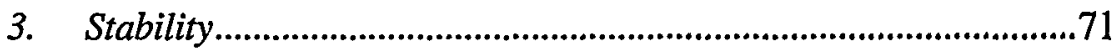

V. User Pools and Legal Rules: Two Examples..........................................74

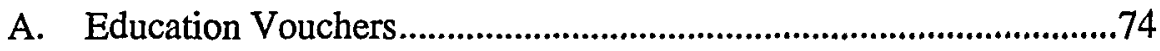

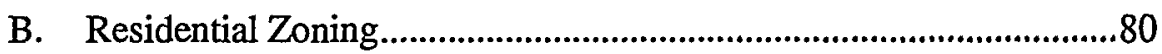

1. Zoning as Exclusion .........................................................................80

2. The Other Side of the Fence: Zoning as Forced Inclusion..............85

VI. Conclusion.

Two goods commonly provided by local governments-education and neighborhood security - have an enormous impact on day-to-day quality of life. Not surprisingly, these goods generate a great deal of debate. Currently, widespread controversy surrounds proposals to restructure the provision and consumption of education through vouchers. Likewise, private alternatives to public security, such as gated communities, produce reactions ranging from outrage to enthusiasm. School finance and zoning, both of which bear directly on the provision of these goods, are perpetual sources of discussion and dissension. These issues, as well as the larger theoretical questions underlying them, should be of particular interest and importance to legal scholars. After all, legal structures, institutions, and rules determine how these goods will be provided, funded, and consumed. ${ }^{1}$ Yet legal scholars

1. See Clayton P. Gillette, Opting Out of Public Provision, 73 DENV. U. L. REv. 1185, 1185 (1996) (observing that law is pervasively involved in dividing up responsibility for the provision of various goods between governments, markets, and households "by creating incentives, prohibitions, and mandates for one or more of these groups to provide a particular good or service"). Statc constitutions, for example, mandate the public provision of education, see id. at $1185 \mathrm{n} .2$ (citing Peter Enrich, Leaving Equality Behind: New Directions in School Finance Reform, 48 VAND. L. REV. 101 (1995)), and state laws govern its delivery. Similarly, local zoning laws determino how neighborhoods will form, thereby determining how goods such as education and neighborhood secnrity will be consumed. See Jerry Frug, The Geography of Community, 48 STAN. L. REV, 1047, 1081 (1996) (discussing state zoning enabling acts and other laws that empower cities to regulate residential options). 
have failed to generate a convincing descriptive account of how the quality of these goods is determined and how people make choices about consuming them. ${ }^{2}$ This failure has limited the legal academy's contribution to the public discourse.

Legal scholarship has typically assumed that the quality of locally provided goods is driven by some combination of market-like consumer behavior ("exit") and political activity ("voice"). ${ }^{3}$ Although the "exit-voice" framework is useful, it is incomplete with respect to certain kinds of locally provided goods, such as education and neighborhood security. It overlooks the critical role of user behavior-the acts and omissions of the school's students and the neighborhood's residents-in determining the quality of these goods. Everyone imtuitively recognizes that the participation of users in "consuming" a good like education or neighborhood security profoundly influences the quality of that good, and in some sense "produces" the good. Indeed, there is significant empirical backing for this intuition, and economists have formalized this and related points. ${ }^{4}$ Nevertheless, the influence of user participation has not been adequately recognized in legal scholarship, nor have its implications for law been fully explored. ${ }^{5}$ Because

2. There has been some interesting and important work in this area, however. See, e.g., Gerald E. Frug, City Services, 73 N.Y.U. L. REv. 23 (1998); Gillette, supra note 1; Michael J. Trebilcock, Ron Daniels \& Malcolm Thorburn, Govermment by Voucher, 80 B.U. L. REV. 205 (2000).

3. This framework was formalized in ALBERT O. HIRSCHMAN, EXIT, VOICE AND LOYALTY: RESPONSES TO DECLINE IN FIRMS, ORGANIZATIONS, AND STATES (1970), and is frequently applied in scholarly discussions of local public goods. See, e.g., CLAYTON P. GLLETIE \& LYNN A. BAKER, LOCAL GOVERNMENT LAW: CASES AND MATERIALS 376 (2d ed. 1999) (noting that the exit-voice "analysis has recently been adopted in much of the legal literature that discusses the capacity of residents to monitor the conduct of local officials" and collecting citations to such literature). For example, the controversy surrounding educational vouchers has been characterized as a dispute over which of these two quality-control mechanisms is more effective. See generally Janies S. Liebman, Voice, Not Choice, 101 YALE LJ. 259 (1991) (reviewing JOHN E. ChUBB \& TERRY M. MOE, POLTICS, MARKETS AND AMERICA'S SCHOOLS (1990)).

4. See Charles F. Manski, Educational Choice (Vouchers) and Social Mobilin, 11 ECON. EDUC. REV. 351, 356 (1992) (discussing the role of student interactions in the production of education). The relationship between population characteristics and the cost and quality of goods like education and neighborhood security has also been examined in the economic literature. See, e.g., Robert M. Scliwab \& Wallace E. Oates, Community Composition and the Provision of Local Public Goods: A Normative Analysis, 44 J. PUB. ECON. 217 (1991) (suggesting that community composition plays a central role in determining the level of outputs for key goods like education and public safety); Mark Dynarski, Robert Schwab \& Emest Zampelli, Local Characteristics and Public Production: The Case of Education, 26 J. URB. ECON. 250 (1989) (finding that local population cbaracteristics, such as socioeconomic status, have an impact on the costs of producing educational achievement); Wallace E. Oates, The Use of Local Zoning Ordinances to Regulate Population Flows and the Quality of Local Services, in ESSAYS IN LABOR MARKET ANALYSIS 201 (Orley C. Ashenfelter \& Wallace E. Oates eds., 1977) (observing that the quality of local services such as education and public safety depends on the characteristics of the community, and discussing empirical support for this idea).

5. For example, Clayton Gillette makes only passing mention of this point in an article addressing the implications of decisions about local public goods, before moving on to discuss general notions of community and equality. See Gillette, supra note 1, at 1213-14 ("If we believe that those who are inost likely to leave low-quality public schools for higher quality private ones are 
participation is central to quality and users are heterogeneous in their participation, the formation, membership, and internal behavior of user pools should be of great interest for law and policy. An approach that emphasizes user dynamics will yield policy prescriptions that are very different from those generated by the usual exit-voice approach. Moreover, such an approach offers a new vocabulary that can facilitate a more meaningful dialogue about schools and neighborhoods.

To develop a useful new way of thinking about local public goods, it is necessary to pin down the nature of the goods themselves: Are education and neighborhood security ordinary consumption goods which consumers should be free to select at will, or are they in some important sense true "public goods"? $?^{6}$ I argue here that they are both and that this dual nature generates an interesting set of strategic dilemmas. Although these goods are consumed by individuals in much the same way as are other consumer goods, they are also "public goods" in the economic sense. For this reason it is appropriate to refer to them, as I do in this Article, as "local public goods."7 The composite pattern of consumption of education or security across an entire community generates a public good-an educated populace, or a safe populace-that is distinct from the consumption good that each individual student or resident obtains by attending a particular school or living in a particular neighborhood. The community as a whole has an interest in ensuring the quality of these goods because everyone in the relevant community experiences (imdeed, cannot escape experiencing) their impact. ${ }^{8}$ These goods, therefore, hold both consumption value and public value. ${ }^{9}$

individuals who would have been 'better' peers of those who remain, then opting out imposes real, but less measurable, costs.").

6. See infra notes 15-16 (defining public goods).

7. Some authors use the phrase "local public goods" to refer to any goods that are typically provided pubhicly by local governments. See HUGH STRETTON \& LIONEL ORCHARD, PUBLIC GOODS, PUBLIC ENTERPRISE, PUBLIC CHOICE 54 (1994) ("[W]e will treat as public goods all those whose supply is determined not by individual market demand but by collective politieal choice, i.e. any goods and services which governments decide to supply free or below cost to their users."). Moreover, the goods that are the focus of this paper-education and neighborhood security-also have characteristics of "public goods" as that term is used by economists, making the term "local public goods" even more apt. See infra notes 15-16 and accompanying text (discussing criteria for "pubhic goods").

8. I will not attempt to determine precisely how broadly or narrowly one should define the "relevant community," except to observe that it will often be broader than an individual municipality or other discrete user pool and may, for example, encompass an entirc inctropolitan area. If the relevant community were defined very broadly (say, to encompass the entire nation), the term "local public good" would become a bit of a misnomer. See RICHARD CORNES \& TODD SANDleR, THE THEORY OF EXTERnAlities, Public GOODS, AND Club GOODS 24 (1986) (defining "local public goods" as those public goods "whose benefits involve only a small jurisdiction such as a municipality or town").

9. I will term this public value "conıposite value" to distinguish it from consumption value and to emphasize that it is determined by the composite pattern of consumption throughout the relevant community. See infra text accompanying notes 13-27 (discussing and distinguishing these two sources of value). 
My approach thus makes explicit two points that are often suppressed or glossed over in current analyses: that users (students and residents) are themselves involved in producing education and neighborhood security, and that what they are producing is critically important, not only for themselves as consumers but also for everyone else within the larger community. ${ }^{10}$ In tandem, these two points illuminate both the way in which the quality of these goods is determined and the strategic dilemmas that are involved in their provision.

This Article uses game theory to systematically work through the implications of user participation for education and neighborhood security. The analysis proceeds in five parts. Part I argues that existing models for understanding these goods are inadequate. Existing approaches do not carefully separate the two distinct sources of value associated with these goods, and they do not fully take into account the role of user participation in producing thein. I argue that users affect quality not only through the exercise of "voice" but also through their everyday acts in consuming education and security. Likewise, "exit" means something different in the context of these local public goods than it does in the context of ordinary consumer goods. In an important sense, "exit" is not really possible; as long as one remains im the relevant community, one will be affected by the quality of education and security in that community as a whole. ${ }^{11}$

Part II turns to game theory for guidance. It sets out the first of two collective-action problems highlighted by a focus on user participation. This first collective-action problem involves a particular user's choice of a consumption community, or "user pool." One can choose to remain in what I will term the "default pool"12 (for example, an inner-city public-school systein) or one can opt for a private alternative or move to a different jurisdiction (e.g., a suburb) im which to consume the good. Well-off participants may be able to increase their consumption value by opting for a private or suburban alternative, but if too many quality-enhancing players choose this strategy, the public value associated with the composite consumption of the good is likely to decline significantly.

Part III addresses a second collective-action problem-one's choice of behavior within a given user pool. The things one does (or fails to do) as a member of a user pool generate spillover effects within that pool. Being a good student or an alert neighborhood resident will have a positive impact on

10. Both of these points have, of course, been recognized at some level in the existing literature. See infra notes 13-27 and accompanying text (discussing the two sources of value associated with goods such as education and neighborhood security); see infra notes 37-4l and accompanying text (discussing consumers as coproducers).

11. HIRSCHMAN, supra note 3, at 101 (noting that the key feature of public goods is that "there is no escape from consuming them unless one were to leave the community by which they are provided").

12. The use of "default" terminology in this context is borrowed from Clayton Gillette. See Gillette, supra note 1, at 1193-98 (applying contractual-default theory to local public goods). 
the quality of education or neighborhood security; being a disruptive student or an inattentive neighbor will have the opposite impact. These intrapool choices can be conceptualized as decisions of whether to cooperate or defect. User heterogeneity has important consequences here: some participants may be better equipped than others to generate positive spillovers for their fellow pool members. Such heterogeneity also points to an opportunity to increase cooperation by enabling users to participate more positively.

Part IV considers how the two "games" just described interact with each other and with legal rules to generate real-world outcomes. I open this Part by considering how various combinations of cooperative behavior in the two collective-action problems might achieve the critical concentrations necessary to a quality good. I then consider the possibility that attempting to solve one problem may make solving the other problem either easier or more difficult. For example, formation of exclusive user pools may be a viable way of solving the second collective-action problem, but it may lead to sorting effects that exacerbate the "choice of pool" dilemma. By the same token, certain characteristics of a given user pool, such as its size and stability, may make cooperative action easier or harder. Legal rules designed to address the "choice of pool" dilemma may impact these characteristics of user pools and may thus affect the amount of cooperation that takes place in the intrapool interaction.

In Part V, I consider some specific implications of refocusing attention on users and user pools. While my primary goal is to develop a more useful theoretical approach for understanding the dynamics involved in the provision of local public goods, there are some interesting real-world applications. I consider two legal mechanisms-education vouchers and residential zoning - through the lens of user participation.

\section{The Role of User Participation}

In this Part, I consider how a focus on user participation would alter conventional understandings of two local public goods-education and neighborhood security. In subpart A, I lay the groundwork for the remainder of the Article by defining terms, and briefly sketch how a user-participation approach would differ from prevailing models. In subpart $B, 1$ explore the implications of user participation in more detail, taking into account user heterogeneity and the shape of the production functions for local public goods. Subpart $\mathrm{C}$ details the ways in which a focus on user participation revises and augments our understanding of voice and exit.

\section{A. Rethinking Education and Neighborhood Security}

Publicly provided goods like education and security defy easy categorization. ${ }^{13}$ At one level, they look like ordinary consumption goods

13. They have been variously denoted "mixed goods," "impure public goods," or "merit goods." See, e.g., RICHARD A. MUSGRAVE, THE THEORY OF PUBLIC FINANCE 13 (1959) 
which the private market can (and often does) provide to individuals. People certainly obtain education and security for their own families' personal consumption, and they may indeed shop for these goods, much as they would for a consumer good like a toaster. Of course, goods like education (unlike commodities purchased off the sheif) may require group consumption for reasons of economy and logistics. This does not, in itself, suggest that public provision is desirable or that a public good is at stake. Private groups (or "clubs") can easily be formed to provide the benefits of joint consumption.

Viewed from the perspective of individual consumption, these local public goods lack the defining characteristics associated with the economist's notion of public goods. ${ }^{15}$ They are not "nourivalrous"-the enjoyment of a unit of education or police protection leaves less of that resource for others (e.g., through straining of imputs such as teachers, police cars, and facility space). Nor are they "nonexcludable"- -schoolhouse doors can be closed and police-protected enclaves can be created. ${ }^{16}$ Based on these features, education and neighborhood security look like private goods. ${ }^{17}$ Unless one recognizes a larger dimension to these goods that transcends the value that

(describing "merit wants" as public wants, such as "free education," that are "considered so meritorious that their satisfaction is provided for through the public budget, over and above what is provided for through the market and paid for by private buycrs"); Frug, supra note 2, at 26 n.6 and sources cited therein; KIERON WALSH, PUBLIC SERVICES AND MARKET MECHANISMS 10 (1995) (discussing education and health as merit goods).

14. See Gillette, supra note 1, at 1188 (discussing situations in which residents can form private "clubs" to consume higher levels of service than those publicly provided).

15. Two features-nonrivalry of consumption and nonexcludability of benefits-are generally taken to be the defining characteristics of "pure public goods." CORNES \& SANDLER, supra note 8, at 6-7. See also ROBERT D. COOTER, THE STRATEGIC CONSTITUTION 105 (2000) (stating that pure public goods are "nonrivalrous" and "nonexcludable"); RUSSELL HARDIN, COLLECTIVE ACTION 17 (1982) ("Public goods are defined by two properties: jointness of supply and impossibility of exclusion."); ELINOR OSTROM, ROY GARDNER \& JAMES WALKER, RULES, GAMES, AND COMIMONPOOL RESOURCES 7 (1994) (noting that public goods exhibit low "subtractability" of benefits and difficult exclusion). Some definitions of public goods include only one or the other of these critcria. See, e.g., STEPHEN SHMANSKE, PUBLIC GOODS, MIXED GOODS, AND MONOPOLISTIC COMPETITION 6-7 (1991) (explaiming the split among economists on this point and the author's decision to focus only on the nonrivalry condition); id. at $191 \mathrm{n} .2$ (collecting and comparing economics texts on this issue); Joseph Raz, Right-Based Moralities, in THEORIES OF RIGHTS 182, 187 (Jeremy Waldron ed., 1984) (defining public goods by reference to nonexcludability).

16. It is often noted that no real-world good qualifies as a "pure" public good. See, e.g., JAMES M. BUCHANAN, THE DEMAND AND SUPPLY OF PUBLIC GOODS 49-50 (1968) ("Strictly speaking, no good or service fits the extrene or polar definition in any genuincly descriptive sense.... The standard examples such as national defense come reasonably close to descriptive purity, but cien here careful consideration normally dictates some relaxation of the strict polar assumption."); WALSH, supra note 13, at 7 (noting that pure public goods are "difficult to discover" and discussing the argument "that there is no such thing as a public good in an objective sense, and that it is a purely cultural construct") (citation omitted). Nevertheless, goods clearly vary in their degree of "publicness." See HARDIN, supra note 15, at 19 ("Although it is not casy to think of examples of physically consumed, pure public goods, one can easily list goods that seem similar to public goods over some range of the number of customers.").

17. See OSTROM, GARDNER \& WALKER, supra notc 15, at 7 (catcgorizing goods with casy exclusion and high subtractability of benefits as "private goods"). 
individuals get from consuming them, it is difficult to account for their public provision. $^{18}$

This larger dimension is not difficult to detect. One can easily recognize that the local public goods under discussion here have meaning and value beyond the aggregated instances of personal consumption. ${ }^{19}$ The composite consumption of these goods throughout the relevant community generates larger public benefits-an educated populace or a safe populacethat can be considered apart from the sum of the benefits each individual user receives from consuming the good. ${ }^{20}$ These are true public goods experienced by the commumity as a whole, and their absence, or low quality, will be felt as a "public bad."21 They are, in true public-goods fashion, both nonrivalrous and nonexcludable. ${ }^{22}$ An educated populace provides benefits that are undiminished, no matter how many people enjoy them. Likewise, no one in the relevant community can be excluded from enjoying such a benefit (or from suffering from its absence). This second dimension of utility arising from local public goods gives society as a whole a large stake in the quality of goods like education and neighborhood security. The public aspect of these goods not only explains the existence of widespread public provision but also explains why people should care about the quality of that public provision. $^{23}$

18. See Frug, supra note 2, at 30 ("Once one adopts a consumer-oriented definition of city services and a voluntary association image of cities, transferring public services to the private sector seems easy and uncontroversial.").

19. See, e.g., BURTON A. WEISBROD, EXTERNAL BENEFITS OF PUBLIC EDUCATION 3 (1964) ("There seems to be a presumption that such external benefits do exist in some form. For if they do not, then education is merely another private consumption or investment good; and in that case why is it provided publicly?"); MUSGRAVE, supra note 13, at 13 (observing that education and health care have characteristics of "social wants" because "everyone stands to gain from living in a more educated or healthier community"); WALSH, supra note 13, at 7 (noting that many goods such as housing, health care, and edueation arguably have "publie goods characteristics, bccause of interaction effects").

20. To describe this more precisely, the consumption that takes place in each individual user pool generates externalities for people who are outside of that user pool, but within the larger community. All of these extra-pool externalities (that is, all of the spillovers from consumption that are not captured by the respective individual pool of consumers) together make up a public good (or public bad) that is shared by everyone within the entire relevant community. There are also spillovers that take place within the individual pool, based on the actions of pool members. See infra subpart I(B).

21. See WEISBROD, supra note 19, at 80 ("The real benefits of education are the real costs of non-education.").

22. Cf. MANCUR Olson, JR., THE LOGIC OF COLleCtive ACtion 15 (1971) ("The very faet that a goal or purpose is common to a group means that no one in the group is excluded from the benefit or satisfaction brought about by its achievement.").

23. The "public goods" aspect of education and security distinguishes the problcms discussed in this Article from many other situations involving user partieipation. For example, the participation of eniployees has a critical impact on the quality of the firms for which those employces work. Because employees are heterogeneous rather than fungible, movement between firms has impacts for both the "gaining" and "losing" firms. However, there is not a strong public interest associated with this movement, beeause society at large is not seriously affected by the quality of these various employee pools. In contrast, the consumption of a good like education across all user pools within a 
Thus, goods like education and neighborhood security have a rather interesting dual character, working both as articles of individual consumption and as public goods. These two distinct sources of value, while sometimes mentioned, are rarely isolated and formalized. ${ }^{24}$ Indeed, there is often a tendency to focus on one of these elements to the exclusion of the other. ${ }^{25}$ To consider both here, I will refer to the public value associated with the composite consumption of publicly provided goods as "composite value" to distinguish it from the "consumption value" one receives from one's own (or one's children's) imdividual use of goods such as public schools and public sidewalks. ${ }^{26}$ The imterplay between these two sources of value creates a strategic dilemma that I will examine in some detail. ${ }^{27}$ For now, it is sufficient to note that consumption value typically drives individual decisions about one's choice between competing local public goods (such as which

given community-such as a major metropolitan area-has quite profound implications for that entire community. In other words, a particularly low-quality inner-city school is a matter of concern for the entire metropolitan community, including those whose children attend a suhurban school; a particularly low-quality firm does not typically inflict similar externalities on the surrounding community.

24. See SHMANSKE, supra note 15, at 103-06 (noting that these two aspects of mixed goods have been at times recognized in the literature, but their implications have not been sufficiently explored); WEISBROD, supra note 19, at 3 (noting that the "external benefits" associated with the education of other people's children "have been relatively neglected by economists"). The two distinct sources of value associated with these goods have not gone wholly unremarked, of course. See, e.g., SHMANSKE, supra note 15, at 94-115 (distinguishing the "utilization dimension" of mixed goods from the "public goods dimension"); WEISBROD, supra note 19, at 3 (noting that demand for education may be divided into "demand by parents on behalf of their present and prospective school-age children" and "all other demand"); Robert D. Cooter \& James Gordley, The Cultural Justification of Uneamed Income: An Economic Model of Merit Goods Based on Aristorelian Ideas of Akrasia and Distributive Justice, in PROFITS AND MORALITY 150, 160 (Robin Cowan \& Mario J. Rizzo eds., 1995) (constructing an equation that recognizes the fact that merit goods "receive weight in their own right" apart from "their capacity to satisfy individual preferences"); BUCHANAN, supra note 16, at 176-77 (disenssing the "publicness and privateness" clements in a category of goods designated as "partially divisible goods and services, with interactions extending over groups of critically large size"); Henry M. Levin, The Economics of Educational Choice, in MARKET APPROACHES TO EDUCATION: VOUCHERS AND SCHOOL CHOICE 23, 26 (Elchanan Cohn cd., 1997) (discussing the "private" and "social" purposes of education).

25. For example, Gerald Frug has identified and criticized a tendency among commentators to view these goods as if they were ordinary articles of consumption. See generally Frug, supra note 2 , at $45-47$ (suggesting that the consumer-oriented vision of city services such as education and safety should be wholly replaced by one focusing on their community-building potential). Yet Frng's focus on these goods as "public" ones gives insufficient attention to the fact that these goods are also, in an important sense, consumer goods.

26. Both types of value are ultimately "consumed" by individuals, of course. See Paul A. Samuelson, The Pure Theory of Public Expenditure, 36 REv. Econ. \& STAT. 387, 387 (1954) ("1 assume no inystical collective mind that enjoys collective consumption goods...."). "Consumption value," as I use the term, refers to the value associated with the specific product one chooses to consume (by selecting a particular school or neighborhood), whereas "conposite value" represents a public good (or bad) that one cannot help consuming (that is, enjoying or suffering) as long as one remains within the relevant commumity. Thus, since "consumption value" relates to the direct and purposive acts of an individual as a consumer, it is directly analogous to the value one derives froin consuming a particular private good.

27. See infra Part II. 
school one's child will attend), while composite value tells us why we should care about the quality of all such goods within the relevant community.

Not only is the nature of education and neighborhood security inadequately parsed in existing accounts, but in addition, too little attention is paid to the way in which quality is determined. The question has not been completely ignored, of course, and much of the existing theory is helpful as far as it goes. But existing approaches lack descriptive power because they fail to properly account for the role of user participation in determining quality. Instead, they tend to focus on one or both of the classic qualitycontrol inechanisms in Albert Hirschman's framework: exit and voice. ${ }^{28}$

Much academic literature adopts what can loosely be called a "consumer choice" model that, consistent with a view of local public goods as ordinary consumer goods, focuses on the market-oriented mechanism of exit. ${ }^{29}$ This model envisions a Tiebout-inspired world in which citizenconsumers "vote with their feet" for the package of locally provided amenities that best suits their preferences. ${ }^{30}$ The work of James Buchanan and others on club theory ${ }^{31}$ coexists with the basic Tiebout nodel.$^{32}$ Under a club-theory approach, municipalities or other communities can be thought of as special-purpose consumption clubs whose members sort themselves by their demand for local public goods. ${ }^{33}$

Hirschman's work focuses not only on exit but also on the additional, and intrinsically political, mechanism of voice. ${ }^{34}$ The exit-voice framework is now an established fixture in legal scholarship, and is routinely applied to

28. HIRSCHMAN, supra note 3; see GLLLETE \& BAKER, supra note 3, at 376 (discussing applications of this framework). Hirschman also considers a third factor related to quality: loyalty. See infra note 248 and accompanying text.

29. See Frug, supra note 2, at 25-35 (describing and criticizing this view).

30. Charles Tiebout, A Pure Theory of Local Expenditures, 64 J. POL. ECON. 416 (1965); see WILLIAM A. FISCHEL, THE HOMEVOTER HYPOTHESIS (forthcoming Nov. 2001) (manuscript dated Oct. 2000 at § 3-12, on file with the Texas Law Review) (explaining Tiebout's theory, which posits that citizen-consumers "select the community that best matches their preferences"); Gillette, supra note 1, at 1192 ("One of the features that makes decentralized government most attractive is its capacity to offer different packages of goods and services and thus to appeal to the various preferences of different actors who can, with relative ease, migrate to jurisdictions that offer the package that is most attractive.").

31. See, e.g., James M. Buchanan, An Economic Theory of Clubs, 32 EconomiCA 125 (1965); CORNES \& SANDLER, supra note 8, at 3-4, 157-242; Todd Sandler \& John T. Tshirhart, The Economic Theory of Clubs: An Evaluative Survey, 18 J. ECoN. LIT. 1481 (1980).

32. See William A. Fischel, Municipal Corporations, Homeowners, and the Benefit View of the Property Tax, 18 ST. TAX NOTES 1781, 1784 (May 22, 2000) (noting that "[c]lub theory and the Tiebout hypothesis have largely had separate intellectual developments[,]" despite the connections between them).

33. See ROBERT H. NELSON, ZONING AND PROPERTY RIGHTS 41 (1977) ("Both the private club and the exclusive suburban community make it possible for groups of similar individuals to obtain goods and services that require collective provision and in the quantities and qualities suited to their closely shared means and preferences."); SHMANSKE, supra note 15, at 24 (observing that where "multiple, competing clubs" exist, "through self-selection consumers might end up in clubs whose members desire the same particular types and amounts of jointly shared goods" and noting that commumities might operate as such clubs).

34. HIRSCHMAN, supra note 3, at 15-20 (discussing categories of exit and voice and their relationships to economics and politics, respectively). 
questions involving goods provided by local governments. ${ }^{35}$ In this model, when people are unhappy with the package of amenities a particular local government is providing, they can opt for a different municipality or a private provider (exit), ${ }^{36}$ or they can agitate for change through the political process (voice).

Although this model is helpful, it rests on an assumption that does not hold true for education and neighborhood security-that the goods are produced exogenously by producers who are distinct from consumers ${ }^{37}$ and that declines in quality are the result of factors wholly external to the consumer. ${ }^{38}$ A paradigmatic example of such an exogenously produced good would be a widget produced in a distant factory. Such a widget might decline in quality because of a hole in the widget mold or a leak in the factory roof, but not because of anything the consumer did or failed to do. ${ }^{39}$

35. See GLLETIE \& BAKER, supra note 3, at 376 (describing the use of this framework in legal scholarship and collecting source citations); Liebman, supra note 3, at $295-98$ (using exit-voice analysis to critique education vouchers).

36. Exit can involve either leaving the jurisdiction for another more to one's liking- "voting with one's feet" in a literal sense-or physically staying within the jurisdiction while opting for a private alternative to the publicly provided good in question. See Gillette, supra note 1, at 1215 ("Opting out of the background level of service offers a private contractual analogue to a more traditional Tieboutian acquisition of the desired level of service through physical exit."); Liebman, supra note 3, at 276 (noting these two forms of exit in the education contex1). These two types of exit are not identical in their implications. One involves physical departure from the community and the direct withdrawal of tax money while the other does not. See James M. Buchanan, Principles of Urban Fiscal Strategy, 11 PUB. CHOICE 1 (1971) (discussing the fiscal effects of migration froin the city center to the suburbs). Moreover, privale altematives can be purchased on an "a la carte" basis (for example, one can choose to buy only private sehooling or private neighborhood security); in contrast, choosing a new ununicipality means rejecting one entire package in favor of a different one. Gillette, supra note 1, at 1215 .

37. In at least one place in Exit, Voice, and Loyalty, Hirschman does recognize that an individual could be sinultaneously involved in both consumption and production. HIRSCHLLAN, supra note 3, at 100 (explaining that "the "buyer' is now in reality a member and [that] as such be is involved in both the supply and the demand sides, in both production and consumption of the organization's output"). Yet Hirschman does not expand on this theme or explain how user participation contributes to quality. Elsewhere, Hirschman's schema suggests that user involvement in production is limited to the relatively indirect mechanism of voice. See id at 33 (stating that "[t]he voice option is the only way in which dissatisfied customers or members can react whenever the exit option is unavailable") (emphasis added); see also id. at 17 (opining that "[i]n a whole gamut of human institutions, from the state to the fanily, voice... is all their members normally have to work with"). A vivid example of the rhetorical implications of this assumed dichotomy between producers and consumers is found in Myron Lieberman's book advocating a market approacl to education. See MYRON LIEBERMLAN, PUBLC EDUCATION: AN AUTOPSY 45.66 (1993) (discussing "producer-consumer conflict" in education).

38. See HIRSCHMAN, supra note 3, at 4 (assuming that the performance of firms and organizations is "subject to deterioration for unspecified, random causes").

39. Although I am discussing publicly provided goods in this Article and am here contrasting then with a privately produced item, the distinction I am making does not break cleanly along private/public lines. There are many goods that are wholly private and for which the users share substantially in production: social gatherings, clubs, churches, singles bars, and restaurants are a few examples. See Michael Rothschild \& Lawrence J. White, The Analytics of the Pricing of Higher Education and Other Services in Which the Custamers are Inputs, 103 J. POLr. ECON. 573, 574 (1995) (noting that spectators at sporting events "consume not only the game but also the 
The exit-voice framework does recognize a role for the consumer, of course-the consumer can react to quality declines by buying someone else's product (exit) or by complaining (voice), either of which may spur the producers of the good to make improvements. For example, our widgetmaker might react to declining sales or customer complaints by repairing the widget mold or patching the factory roof.

This picture is incomplete as applied to education and neighborhood security. Clearly, users do influence these local public goods through exit (by forming, joining, or leaving user pools) and through voice (by conplaining about a good or agitating for nore funding). And, indeed, some aspects of these goods are exogenously provided-teachers, school buildings, police officers, and patrol cars are supplied through the appropriate governmental channels. But in a very important sense, users are also directly involved in producing the goods and determining the quality of the goods through their participation. ${ }^{40}$ Thus, their acts of consumption are also acts of production. ${ }^{41}$

\section{B. Participation, User Heterogeneity, and Critical Concentrations}

It is helpful at this point to spell out some of the more obvious impacts of user participation with respect to the two goods under discussion. In the case of education, studies have confirmed what common sense suggeststhat peers in school have a tremendous effect on a student's educational experience and achievement. ${ }^{42}$ The users of the educational product

experience of being part of the crowd" and that "[a]t theaters, amusement parks, resort cruises, private clubs, trendy restaurants, and charity balls, the other customers partially determine the quality of what each customer consumes"). There are also publicly provided goods, such as trash collection, that are not produced by users to any significant extent.

40. See Oates, supra note 4, at 205 (noting that "characteristics of the individuals of the community are themselves a critical determinant of the level of local services"); Manski, supra note 4 , at 356 (noting the role of student interactions in the production of education); Schwab \& Oates, supra note 4, at 218 (noting that many studies support the idea "that the level of attainment in a school system or the level of safety in a neighborhood depends not so much on the instructional staff or frequency of police patrols as on the characteristics of the residents of the jurisdiction"); Robert M. Schwab \& Emest M. Zampelli, Disentangling the Demand Function from the Production Function for Local Public Services: The Case of Public Safety, 33 J. PUB. ECON. 245, 254 (1987) (noting the role of income level of residents in producing public safety).

41. See Schwab \& Zampelli, supra note 40 , at $246-47$ (noting that the income of residents is a factor both in the production of public safety and the demand for it); $c f$. Denise Reaume, Individuals, Groups, and Rights to Public Goods, 38 U. TORONTO L.J. 1, 10, 15 (1988) (discussing goods such as culture which "unite production and consumption"). The fact that consumption and production are simultaneously occurring presents some interesting complexities. For example, Schwab and Zampelli suggest that "[i]t is plausible that for some goods, efficient consumption may require homogeneous communities, while efficient production may require heterogeneity; overall efficiency would then require a balancing of these two conflicting objectives." Schwab \& Zampelli, supra note 40, at 246.

42. See JOHN E. CHuBB \& TERRY M. MOE, POLITICS, MARKETS, AND AMERICA'S SCHOOLS 119 (1990) ("Researchers have found that student achievement is influenced by the attitudes and behavior of other students in a school-by the pressures from student peer groups.") (eitations omitted); see id. at 101 (discussing the dynamic whereby "children bring their [families'] values and 
therefore help determine its quality and content. Students can either enhance the quality of the educational product through high achievement, excellent work habits, and good behavior, or they can detract from it through problematic behavior and poor attitudes. Put another way, each student's participation (or lack thereof) generates spillover effccts that will have an impact on other students within the same user pool. Caroline Hoxby identifies several peer-effect spillovers:

A student's innate ability can affect his peers, not only through knowledge spillovers but through his influence on classroom standards. A student's environmentally determined behavior may affect his peers. For instance, a student who has not learned selfdiscipline at home may disrupt the classroom. Peer effects may follow lines like disability, race, gender, or family income: a learning disabled child may draw disproportionately on teacher time, racial or gender tension in the classroom may interfere with learning, richer parents may purchase learning resources that get spread over a classrooin. Peer effects may even work through the way in which teachers or administrators react to students. ${ }^{43}$

The quality of student participation may in part be a function of exogenous factors in the school setting (how engaging the teachers are, for example, or how well designed the classroom is), but the students themselves also bring in clusters of behaviors and attitudes that greatly impact the learning process. If we assume these behaviors and attitudes are largely learned in the home, this would explain empirical findings that academic results are highly correlated with the socioeconomic background (that is, the education level and income) of the students' families. In contrast, links between student achievement and other sorts of inputs-such as teacher salaries, student-teacher ratios, or expenditure levels-have not been consistently demonstrated. ${ }^{44}$ As Joln Chubb and Tcrry Moe observe, the importance of family background is "[o]ne of the strongest and most

habits [to school] and spread them among other children"); Vemon Henderson ct al., Peer Effects and Educational Production Functions, 10 J. PUB. ECON. 97, 97 (1978) (finding "that the principal variable or effect which is at the potential disposal of policy makers and which has a consistent and strong impact on the achievement of individual students is the quality (characteristics) of the typical or average student in a class"). A recent study found significant peer effects after controlling for the selection biases endemic to such inquiries. Caroline Hoxby, Peer Effects in the Classroom: Learning from Gender and Race Variation (Nat'l Bureau of Econ. Research, Working Paper No. 7867, Aug. 2000), available at http://www.nber.org/ papers/w7867.

43. Hoxby, supra note 42, at 5-6; see also Manski, supra notc 4, at 356 (noting that in addition to direct student interactions, students may influence the production of education indirectly by affecting such things as teachers' instructional decisions, teacher recruitment, and course offerings).

44. CHUBB \& MOE, supra note 42, at 101; Oates, supra note 4, at 208.09 (discussing empirical work, including the Coleman Report, consistently showing the significance of socioeconomic factors to scholastic achievement and finding no such relationship between other kinds of school inputs). This is not to dispute that such factors could have an important influence in certain instances. Indeed, some empirical evidence indicates that smaller classes result in better student performance. See, e.g., Douglas S. Wood, Do Smaller Classes Equal Better Students? (Oct. 31, 2000) (discussing 1999 follow-up study of Tennessee's Student Teacher Achiciement Ratio Study). at http://www.cnn.com/SPECIALS/2000/democracy/privateschools.publicmoney/stories/class.size. 
consistent finding[s] in research on student achievement," while "[b]y comparison, the influence that schools have on student achievement has often appeared weak.", This suggests that the consumers of education (the students and their families) may be among the most important factors of production, perhaps even eclipsing variations in monetary inputs. ${ }^{46}$ If, in fact, endogenous factors dominate the education-production process, exogenous improvements (better-designed facilities, smarter teachers, or more money) may not be sufficient on their own to improve educational quality.

Similar principles apply in the case of neighborhood security. While some aspects of security are provided exogenously by the local government (police officers, police cars, and the like) much of what makes a neighborhood safe or unsafe has to do with the residents of the community who are the consumers of neighborhood security. ${ }^{48}$ Obviously, if residents

45. CHUBB \& MOE, supra note 42 , at 101 . Chubb and Moe, apparently believing these endogenous influences to be insensitive to policy, focused their attention insteal on a cluster of factors relating to the "organization" of the school. See generally id. Finding these "organization" factors to be important to student outcomes, Chubb and Moe enthusiastically embraced the notion of school choice, which they felt would lead schools to improve their organization. See id. at 185 . 229. However, as James Liebman quite convincingly establishes in his review of their book, the factors they label "effective school organization," and which they characterize as the cause of student achievement, can in fact be better understood as the rcsult of that achievement and of parental and student sorting. See Liebman, supra note 3, at 261-77.

46. Oates, supra note 4, at 212 (observing that evidence suggests that effects of budgetary inputs on quality of education and public safety are "dwarfed in importance by the characteristics of the population itself'); $c f$. James E. Ryan, Schools, Race, and Money, 109 YALE L.J. 249, 290-91, 297-98 (1999) (discussing anecdotal and empirical evidence that questions the link between money and achievement and discussing studies showing a robust link between the socioeconomic status of one's peers and one's achievement levels).

47. See David F. Bradford \& Harry H. Kelejian, An Econometric Model of Flight to the Suburbs, 81 J. PoLrT. ECON. 566, 578 (1973) (arguing that "the findings of researchers into the causes of persistent poverty, and, in particular, the apparent difficulty of explaining the effectiveness of schooling in terms of anything other than the socioeconomic background of a child and his fellow students, suggest that public expenditures, even income transfers, are not sufficient to deal with important manifestations of poverty"); Ryan, supra note 46, at 308 (observing that "providing additional resources may not even be a particularly effective way for the state to remedy unequal or inadequate sclooling" and that "a more effective approach may entail ensuring that poorer students have access to more advantaged peers"); Oates, supra note 4, at 213 (noting that reforming school financing to equalize inputs "may have only modest effects on differentials in outputs" and noting differentials in achievement levels among Hawaii school districts, despite statelevel financing). Of course, one response to the realization that money makes only a small difference is to suggest that we apply a great deal more of it to the harder-to-serve populations. See Dynarski, Schwab \& Zampelli, supra note 4, at 262 ("Our results indicate that differences in local characteristics across [school] districts can be offset only by large variations in spending, because expenditure has a small effect on achievement relative to local characteristics."). This suggestion makes sense only if one assumes that the local population characteristics arc impervious to change. See Ryan, supra note 46, at 289 (noting that changing a school's composition may be a morc promising avenue for change than increasing expenditures, given the lack of evidence that even substantial increases in expenditures can overcome negative peer influences).

48. Empirical work suggests that population factors such as socioeconomic status and age are strongly associated with crime rates, while no strong relationship exists between crime rates and police inputs or expenditures. See Oates, supra note 4, at 209-12 (discussing previous studies and presenting statistical resnlts). 
are themselves involved in crime, this dilutes the quality of the community's security. But there are other very important aspects of user participation in the neighborhood setting. As Jane Jacobs convincingly argued forty years ago, the perceived security of a given area does not depend so much on police presence, but rather on how many law-abiding people are routinely out and about on the streets and engaged in casual observation and enforcement:

The first thing to understand is that the public peace-the sidewalk and street peace-of cities is not kept primarily by the police, necessary as police are. It is kept primarily by an intricate, almost unconscious, network of voluntary controls and standards among the people themselves, and enforced by the people themselves.... No amount of police can enforce civilization where the normal, casual enforcement of it has broken down. ${ }^{49}$

Recent sociological work in Chicago supports the prinacy of various sorts of "indigenous informal social control," such as "the willingness of residents to intervene to prevent acts such as truancy, drinking, vandalism, and street-corner disturbances (e.g., harassment, loitering, fighting)" in maintaining public order. ${ }^{50}$ Tenant groups in housing projects have made similar use of informal social controls and indigenous enforcement to reduce crime and maintain order. ${ }^{51}$

If neighbors' eyes-and wills-are the critical components of neighborhood security, exogenously provided factors may play a limited role. Features such as bright lights or video-camera surveillance may do little or nothing on their own to enhance security. ${ }^{52}$ Other externally imposed measures, such as harsher enforcemnent of existing laws, are also of questionable efficacy in reducing crime. ${ }^{53}$ Instead, it appears that

49. JANE JACOBS, THE DEATH AND LIFE OF GREAT AMERICAN CMIES 31-32 (1961).

50. Robert J. Sampson \& Stephen W. Raudenbush, Systematic Social Observation of Public Spaces: A New Look at Disorder in Urban Neighborhoods, 105 AM. J. SOC. 603, 612 (1999). Some of the forms of informal social control cited by Sampson and Raudenbush, such as "agilating for voting referendums" to close down bars where drugs are sold, or complaining until a "drug housc" is demolished, would fall under the rubric of "voice." Id.

51. SUdHIR ALladi VENKATESH, AMERICAN PROJeCt: THE RISE AND FALL OF A MOderN GHETTO 29-34, 77-83 (2000).

52. See JACOBS, supra note 49 , at 42 (explaining that while lights may make eyes more effective, "unless eyes are there, and unless in the brains behind those ejes is the almost unconscious reassurance of general street support in upholding civilization, lights can do no good"); Jason Ditton, Crime and the City: Public Attitudes Tossards Open-Street CCTV in Glasgow, 40 BRIT. J. CRIMINOL. 692 (2000) (finding that closed-circuit surveillance cameras in the center of Glasgow did not make people feel safer).

53. Sampson and Raudenbush's recent work in Chicago suggests that cren those law enforcement efforts directly targeted at controlling neighborhood disorder (i.e., "broken windows") may be of less value in fighting crime than has often been supposed. Sampson \& Raudenhush, supra note 50, at 638 (remarking that "the current fascination in policy circles on cleaning up disorder through law enforcement techniques appears simplistic and largely misplaced, at least in terms of directly fighting crime") (citations omitted). The original "broken windows" hypothesis suggested that disorder causes or attracts crime. See id. at 604 (citing James Q. Wilson \& George L. Kelling, The Police and Neighborhood Safery: Broken Windows, ATLANTIC MONTHLY, Mar. 1982, at 29). The Sampson and Raudenbush study shows that disorder is not correlated with higher crime 
cooperative action by the residents themselves offers the most promising avenue for making neighborhoods safer.

In this context, user participation may largely involve keeping an eye out for others and being out and about in the streets and parks oneself. While user participation could encompass such concerted actions as neighborhood watches or safety patrols, the concept extends to the most unplanned and everyday of activities, such as walking a dog, going for a jog, or taking a walk to the corner store or mailbox. Seemingly trivial individual decisions about whether and how to use the neighborhood sidewalks, streets, and parks may make a substantial qualitative difference in the aggregate. For example, the current trend towards wholly privatized play has undoubtedly had a negative impact on neighborhood safety. ${ }^{54}$

Clearly, users differ in the way they consume publicly provided goods like education and neighborhood security, and this heterogeneity has consequences. Some users make a habit of consuming these goods in a manner that enhances their quality. For simplicity, I will call these consumers "quality-enhancing users." Examples would include the attentive student who behaves and participates in class, the neighborhood resident who keeps eyes and ears open for trouble and makes frequent, purposeful use of the local sidewalks and streets, and a group of joggers that circumnavigates the public park every morning and evening.

Unfortunately, not all users-and not all uses-fit into the qualityenhancing mold. Some users make a habit of using publicly provided goods in a manner that detracts from their quality. For simplicity and symmetry, I will call these users "quality-detracting users." Examples would include students who bring drugs and violence into the school and people who use their local streets and public parks as venues for drug sales and gang activity. Many users fall in between these two extremes. For example, sone people are technically in the user pool, but are either physically absent or are, for all practical purposes, noncontributors. Here, think of the student who sits in the back of the classroom without speaking or of the neighborhood resident who stays behind barred windows and bolted doors, rarely venturing into the local streets. Other users may be relatively malleable and may follow the lead of

\footnotetext{
levels once one controls for the structural disadvantages of an area (e.g., concentrated poverty) and the "collective efficacy" of its residents. Sampson \& Raudenbush, supra note 50, at 638. The authors do suggest that neighborhood disorder may bave an indirect effect on crime by demoralizing citizens and thereby impeding their efforts to cooperate with each other and take a stand against crime, and by inducing people to leave the neighborhood (or keeping them from entering). ld. at 638. Moreover, a neighborhood that internally chooses to come together to address disorder may build social ties and demonstrate commitment that will have the effect of reducing crime. $1 d$. at 638 n.36. In other words, it is the endogenous process of neighborhood participation that holds value in addressing crime, not the presence or absence of disorder itself.

54. See RAY OldENBURG, THE GREAT GOOD PLACE 271 (1989) ("In our zeal to keep kids 'off the streets' and contain them within safer places, we contribute to the further deterioration of our public space. As we shuttle our children from one safe and certified adult to another, the strcets continue to deteriorate in accordance with the negative view held toward them.").
} 
the dominant users in the group, whether for good or ill. Young students in a classrooin are often particularly good examples of this phenomenon.

These categories are admittedly somewhat artificial. People are not immutably cast into one or another of these roles; individual students and residents may be quality enhancers at times and quality detractors or noncontributors at other times. Moreover, one of the most promising strategies for improving the quality of these goods is to assist people in becoming quality-enhancing users. ${ }^{55}$ But it is still helpful to formalize what is intuitively obvious-that users are heterogeneous, and that this heterogeneity has consequences for quality.

Users are not only heterogeneous as individuals, but they also influence others within their respective user pools. The nature and intensity of this influence will depend, in part, on the mix of other users already in a given pool. The way in which combimations and concentrations of heterogeneous users determine the quality of local public goods is not necessarily straightforward. ${ }^{56}$ In general terms, we know that peers influence each other in school and that neighborhoods are safest when lavv-abiding people are out and about in them. The recipe for success almost takes on the character of a paradox or a tautology. For example, law-abiding people will not be out and about in a neighborhood unless it is already the sort of neighborhood in which law-abiding people feel safe enough to move about freely.

The resolution of this problein requires a "critical mass" of qualityenhancing activity to establish a baseline level of quality upon which other quality-enhancing uses can build. ${ }^{57}$ While the dynamics of quality enhancement are not entirely clear and wonld be a matter for empirical study, casual observation suggests that quality improvements tend to snowball once a certain critical mass of quality-enhancing activity is established. Whether or not there are enough quality enhancers in the user pool at any one time depends not only on who is in the pool but also on what they are doing. This, in turn, depends on the combined outcome of two linked sets of individual

55. See infra subpart II(C) (describing possible ways to improve cooperation within the user pool). In this respect, my model differs from that of some economists who have explored the significance of population characteristics. See, e.g., Schwab \& Oates, supra notc 4, at 220-30 (presenting a model in which people are placed into two static catcgories: A and B).

56. See, e.g., Paul Glewwc, Estimating the Impact of Peer Group Effects on Socioeconomic Outcomes: Does the Distribution of Peer Group Characteristics Matter?, 16 ECON. EDUC. REV. 39, 43 (1997) (discussing the role of distribution of peer characteristies in determining peer impacts).

57. See, e.g., J. Douglas Wilms \& Frank Echols, Alert and Inert Clients: The Scottish Experience of Parental Choice of Schools, in MARKET APPROACHES TO EDUCATION: VOUCHERS AND SCHOOL CHOICE, supra note 24, at 425, 439 (recognizing the possibility "that there is a critical proportion of high-abihty and high-SES [sociocconomic status] pupils necessary to establish a favourable disciphinary climate and strong norms for academic success") (citation omitted): THOMAS C. SCHELLING, MiCROMOTIVES AND MACROBEHAVIOR 91-110 (1978) (diseussing and modeling "critical mass" in the context of various social phenomena); Pamela Oliver ct al., $A$ Theory of the Critical Mass. I. Interdependence, Group Heterogeneity, and the Production of Collective Action, 91 AM. J. SOC. 522, 522 (1985) (tracing the imporance of "critical mass" to successful collective action). 
decisions: the choice of a user pool and the choice of action within one's user pool.

Figure 1 illustrates how the quantity of quality-enhancing users in a given user pool might relate to quality. ${ }^{58}$

Figure 1 .

Quality

A

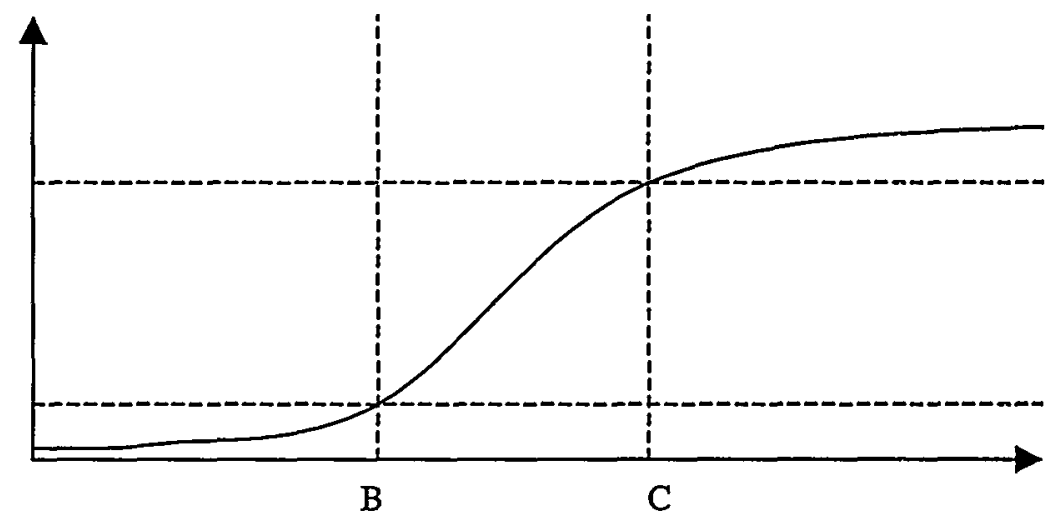

Number of Quality-Enhancing Users

The horizontal axis in Figure 1 represents the number of qualityenhancing users within a given user pool. I am making the simplifying assumption that each quality-enhancing user is identical in terms of her quality-enhancing propensities (although the effects of those propensities will differ in magnitude depending on the number of other quality-enhancing users already in the pool). ${ }^{59}$ The vertical axis represents the quality of the local public good-education or neighborhood security. To simplify matters, I am assuming that the range above the top dashed horizontal line (marked A) represents a level of quality that is unambiguously "acceptable" or "adequate" and that the range below the lower dashed horizontal line (marked U) represents a clearly "unacceptable" or "unsatisfactory" level of

58. Figure 1 is based on the S-shaped "general third-order" production function curve presented in Oliver et al., supra note 57, at 527-28 \& fig.1(a).

59. In reality, some users might be "super-enhancers" whose impact is several times greater than that of an underachieving quality enhancer. This reality is suppressed in my model; 1 am assuming that each quality enhancer is essentially fungible in terms of her quality-cnhancing capabihities. Additional quality enhancers added to the pool may have a larger or smaller marginal impact on quality than the ones added previously, but in my model this is wholly a function of the cumulative concentration of quality-enhancing users in the pool, not the result of any innate differences among the individual quality-enhancing users themselves. 
quality. In the quality range between these two dashed lines, some users would find the quality acceptable, and some would find it unacceptable.

The curve in Figure 1 is one possible depiction of the relationship between the number of quality-enhancing users and the quality of the local public good. ${ }^{60}$ The relationship is positive across the entire range: as more quality-enhancing users are added to the user pool, the quality increases. But the relationship between quality-enhancing users and quality is not steadily linear. ${ }^{61}$ In the range to the left of the leftmost vertical dashed line (point $B$ ), adding an additional quality-enhancing user makes little or no difference in quality. Likewise, subtracting a quality-enhancing user in this range does not result in any significant reduction of quality. This reflects the intuition that some schools and neighborhoods are in such bad shape that no individual quality-enhancing user can make a difference. ${ }^{62}$ In the range to the right of the rightmost vertical dashed line (point $\mathrm{C}$ ), a critical mass of qualityenhancing users exists to ensure an acceptable level of quality. Beyond point $\mathrm{C}$, eacl additional quality-enhancing user adds less and less in marginal terms to the overall quality of the good. This reflects the intuition that scliools and neighborhoods may reach a plateau where adding more wellprepared and disciplined students or inore safety-minded, law-abiding neighbors will not result in significant improvement.

The curve is steepest in the area between B and C. This steep part of the curve corresponds to quality levels that are neither unambiguously

60. Of course, the precise shape of the curve would be an empirical question and would be highly context-specific. See, e.g., Henderson et al., supra note 42, at 105 (finding, with respect to peer effects in education, that "achievement is a concave function of class quality"); Oliver et al., supra note 57, at 525-28 \& fig.1 (discussing various shapes of production functions for public goods). However, the S-shaped curve shown in Figure 1 seems intuitively plausible for goods like education and security. See id. at 528 (noting that this general type of curve tracks a common pattern for public goods: "a period of start-up costs or other sources of low but increasing marginal returns, which leads to a period of higher returns; then satiation sets in and produces diminishing marginal returns").

61. See Michael Taylor \& Hugh Ward, Chickens, Whales, and Lumpy Goods: Altemative Models of Public-Goods Provision, 30 POL. STUD, 350, 353 (1982) (discussing a type of "public good which is not provided in smoothly increasing amounts as the level of contributions increases").

62. This intuition is sometimes expressed rather inaccurately by saying that the school or neighborhood is "beyond saving" or "hopeless." Because of the interdependence of decisions, however, retaining even a few quality-enhancing users could make a tremendous difference in transforming a school or neighborhood. See SCHELIING, supra note 57, at 97 (observing that the fact that a particular collective enterprise ultimately fails does not tell us how close it came to succeeding or "[t]he number along the way who, if they could [have been] enticed or coerced into staying, would [have made] the whole thing viable"). Thus, a few quality cnhancers who committed themselves to "sticking" could set in motion a chain of events that would trigger and buttress behavioral changes among existing pool members and ultimately attract additional qnalityenhancing users. See id. at 97-98 (explaining how the behavior of people who act unconditionally can affect the behavior of those whose decisions are conditioned on what others do). Such a dynamic could, in time, pull the user pool up to the critical threshold. Nevertheless, it is likely that a single quality enhancer canuot "go it alone"; instead, a core of quality-enhancing users would be necessary to generate enough momentum to cffectuate change. 
acceptable nor unambiguously unacceptable. In this range, adding or subtracting a quality-enhancing user has a large effect on quality. This reflects the intuition that schools or neighborhoods that are in this marginal state are most susceptible to change, either for better or worse. Not only does each arrival or departure of a quality-enhancing user make a large difference on its own, but each arrival or departure is also likely to spur additional entry or exodus. Because users in a given pool will have varying tolerances for drops in quality, it is likely that a departing quality-enhancing user could drive the quality level below the minimum acceptable level for some additional user, thus triggering that user's departure as well. ${ }^{63}$ The second user's departure could, in turn, drop the quality level below the minimun that yet another user would find acceptable, thus spurring the third user's departure. ${ }^{64}$ The process works in the other direction as well. Each new quality-enhancing user improves the quality of the good, and this may drive the good above the minimum quality threshold of some additional quality-enhancing user, thus inducing her to enter the pool. That entry will likely spur further entries. ${ }^{65}$

If the curve depicted in Figure 1 natches up with reality in even a rough sense, this has important implications for local public goods. It means that the total utility generated by a set of user pools in a given community can increase or decrease depending on how the various heterogeneous users are distributed among user pools. While the question is an empirical one, our intuitions suggest that once a critical nuass of quality-enhancing users is achieved in a school or neighborhood, additional quality enhancers generate decreasing niarginal improvements. In contrast, the loss of each additional quality-enhancing user from a user pool that is quite close to falling below critical nuass produces a large increnent of harm. For example, a very safe neighborhood does not stand to gain nearly as much from the entry of an additional quality-enhancing family as does a marginal neighborhood.

Similarly, nost people intuitively recognize that having concentrated pockets of quality-detracting users is much different (and arguably much worse) than having quality-detracting users spread thinly among user pools. ${ }^{66}$

63. See id. at 96-99, 101-02 (describing such chain reactions in a variety' of contexts); $c f$. Thomas C. Schelling, Dynamic Models of Segregation, 1 J. MATH. SOC. 143, 181 (1971) (modeling neighborhood "tipping" with respect to race).

64. SCHELLING, supra note 57, at 96-99, 101-02.

65. Cf. id. at 101 (discussing "tipping in" and "tipping out"). The effects of increasing and decreasing quality on membership may not be symmetrical, however. For example, the quality level that triggers a person's exit may be far lower than that which would later be required to induce that same person's re-entry. HIRSCHMAN, supra note 3, at 7; Paul G. Mahoney \& Chris W. Sanchirico, Competing Norms and Social Evolution: Is the Fittest Norm Efficient?, 149 U. PA. L. REV. 2027, 2046-47 (2001) (providing an example in which a norm shift in one direction is much easier than a shift in the opposite direction).

66. Analogous concerns exist regarding concentrated pockets of poverty. See. e.g., Bradford \& Kelejian, supra note 47, at 586 ("To the extent that the probability of being poor is increased by the fact of growing up among poor people, any force increasing the concentration of poverty becomes 
In the latter case, spillover effects from quality-enhancing users may render the quality detractors harmless, or group norms and the threat of exclusion can operate to change the behavior of the quality-detracting users. As every elementary-school teacher knows, separating troublemakers from each other often results in a net reduction in trouble. Empirical work indicates that the achievement levels of students are sensitive to peer effects; that is, lowachieving students will do better if they are placed with higher-achieving students than if they are pooled with each other. ${ }^{67}$ Similar spillover effects have been documented in neighborhoods with respect to behavioral characteristics such as involvement in crime, drug and alcohol use, and unemployment. ${ }^{68}$

In other words, the shape of the curve in Figure 1 suggests that shifts of users among and between user pools is not a zero-sum game. ${ }^{69}$ If, instead, the relationship between the number of quality-enhancing users and the quality of the good were perfectly linear, a quality-enhancing user would add the same amount of utility to any pool she joined. In that case, any loss to the user pool from which a quality-enhancing user departs would be exactly offset by the gains to the new user pool which that same individual joins. ${ }^{70}$

While a relationship of perfect linearity seems unlikely, ${ }^{71}$ it is inportant to note that even a perfectly linear relationship between quality-enhancing users and the quality of schools and neighborhoods would not necessarily make us indifferent to how quality-enhancing users are distributed among pools. The reason for this becomes clcar if we recall the earlier distinction between consumption value and composite value. ${ }^{72}$ Figure 1 represents the

of interest for social policy."); Sampson \& Raudenbush, supra note 50, at 609-10, 625 (discussing problems associated with concentrated disadvantage and presenting a finding that "concentrated disadvantage is the single most important predictor of disorder in Chieago neighborhoods").

67. See, e.g., Henderson et al., supra note 42.

68. See Anne C. Case \& Lawrence F. Katz, The Company You Keep: The Effects of Family and Neighborhood on Disadvantaged Youtlis (Nat'l Bureau of Econ. Rescarch, Working Paper No. 3705, May 1991), available at littp://www.nber.org/papers/w3705.

69. See FISCHEL, supra note 30 (manuscript dated Oct. 2000 at $\$ 3-17$ ) (noting the possibility that there may be "beneficial peer-group effects from mixing rich and poor" which would keep migration from being a zero-sum game); Wilms \& Echols, supra note 57, at 439 (discussing the possibility that movement of students among schools may not be a zera-sum game and the potential that "movement of high-SES [socioeconomic status] pupils from low to high SES schools would lave little effect on popular schools, but dire consequences for schools losing their more able pupils").

70. See Gillette, supra note 1, at 1193 ("When a resident moves, the loss from membership in one community is offset by the gain in membership to another."); Hoxby, supra note 42, at 2 (noting that if peer effects were strictly linear, the situation becomes a zero-sum game, as "[i]n order to give one student a better peer, one must take that peer away from another studenl; the two effects exactly cancel").

71. While Hoxby's study did not find the spillovers from one peer's achievement level to that of another to be "generally non-linear," she questions the linear "baseline" model and suggests that the existence of channels other than achievement levels through which peer effects may occur could make overall effects nonlinear. Hoxby, supra note 42 , at 36 .

72. See supra text accompanying notes 13-27 (discussing these two sources of value). 
quality of a particular school or neighborhood and can be thought of as corresponding to the consumption value experienced by the users of that school or neighborhood. Arithmetically summing the consumption values associated with all pools captures only part of the picture. Each of these individual pools is also generating spillovers for the community at large, and these spillovers together make up composite value. While it nakes sense to think of each pool as generating spillovers commensurate with its own quality level, it could be the case that pools falling below a certain threshold of absolute quality will generate disproportionately large negative spillovers for the community as a whole. In other words, a single abysmal pool might generate negative spillovers several orders of magnitude greater than might a half-dozen somewhat below-average pools. ${ }^{73}$ Thus, we would want to be sensitive to the distribution of the quality-enhancing users, even in the case where a linear relationship exists between the number of quality enhancers and quality. Nevertheless, our concern with the distribution of qualityenhancing users is clearer and more pressing if we assume a nonlinear relationship like the one shown in Figure 1.

The curve shown in Figure 1 seems to suggest the desirability of policies that attempt to perform a sort of local-public-goods triage. If we assume that there are numerous competing user pools in a given metropolitan area with similar quality functions, these will have varying numbers of quality-enhancing users at any given time, placing them at different points on the curve. Quality-enhancing users can do the most good in the critical center range, where each additional participant makes a large contribution to quality and is particularly likely to spur the addition of more qualityenhancing users (either by attracting new quality-enhancing users or by transforming additional existing users into quality-enhancing users). Once an acceptable level of quality is assured in a given school or neighborhood, adding more quality-enhancing users to that pool will not generate significant gains. Instead, we might be better off if we (as a society) could convince additional quality-enhancing users to join a pool in which they could make a larger difference. ${ }^{74}$

The shape of the curve might also suggest that pulling qualityenhancing users from the schools that are in the worst shape (and where those users' efforts are essentially wasted) would also be a good idea. For obvious reasons of equity and distributive justice, this second suggestion is troubling. It is also unlikely to be a viable solution even from a more utilitarian standpoint, because schools and neighborhoods trapped in the "unacceptable" range are very likely to generate large negative spillovers for

73. It is also possible that a particularly outstanding school or neighborhood might generate disproportionately large positive spillovers for the community as a result of reaching a particular level of absolute quality, although this seems less likely.

74. This might not be the case if doing so meant forgoing large positive spillovers that could only be attained by reaching a particular level of absolute quality. See supra note 73. 
the rest of the relevant community. Instead, it might make more sense to undertake policy directions that would get all user pools past point $B$, where further gains will come relatively easily and where the dynamic will be set in motion for ultimately achieving a critical mass of quality-enhancing users.

But this is getting ahead of the story a bit. Before launching into a more formal gaine-theoretic analysis of the situation, I want to step back and consider how a focus on participation alters the exit-voice framework. I will start by showing how the idea of participation differs from the usual notions of voice, and then discuss how this enhanced notion of user influence changes our understanding of exit.

\section{Beyond Voice and Exit}

1. Beyond Voice.-It is important at this juncture to emphasize that users do influence quality through the exercise of voice, as well as through their everyday participation. Even mundane exercises of voice (complaining) can impact the quality of schools and neighborhoods, and voice writ large (political activism) may help to determine funding levels, which may be relevant to quality concerns. Nevertheless, a focus on voice as the exclusive quality-control mechanism available to current users misses mucl of the picture. A close look at the notion of voice, and its implicit limits and assumptions, shows why this is so. Hirschman defines voice as:

any attempt at all to change, rather than to escape from, an objectionable state of affairs, whether through individual or collective petition to the management directly in charge, through appeal to a higher authority with the intention of forcing a change in management, or through various types of actions and protests, including those that are meant to mobilize public opinion. ${ }^{75}$

Although this definition begins quite expansively, ${ }^{76}$ the list of voice alternatives contained within it reveals some conceptual limits. Most significantly, this notion of voice implies a distinction between consumers and "management": consumers voice their concerns either to the management directly, or to persons or institutions capable of influencing the producers. Voice focuses on communications from customers to those persons ostensibly in charge of controlling quality. ${ }^{77}$ Indeed, the term voice

75. HIRSCHMAN, supra note 3 , at 30 .

76. The first part of the definition, taken alone, would draw within its reach virtually any action taken by anyone in any context from which one is not actively flecing. For example, it would encompass playing solitaire on the job (instead of quitting), revising a mangled manuscript (instead of tossing it in the garbage), and distracting one's racquetball opponent when one is losing (instead of abandoning the game). These kinds of actions are indeed taken "to change, rather than to cscape from, an objectionable state of affairs," id., and they may indeed communieate something, but they are not what we would normally think of as voice.

77. See, e.g., id. at 4 ("The firm's customers or the organization's members express their dissatisfaction directly to management or to some other authority to which management is subordinate or througli general protest addressed to anyone who cares to listen... [and] [a]s a 
itself implies some listening other. ${ }^{78}$ Voice is, therefore, a fundamentally indirect method of controlling quality-as is exit. ${ }^{79}$

What users do on a day-to-day basis in their schools, neighborhoods, and parks does not fit comfortably within this notion of voice. ${ }^{30}$ One can, of course, argue that the term voice should be applied to anything that a user does, including such quotidian actions as paying attention in class or walking one's dog around the park. Yet forcing these sorts of user behaviors to fit into the "voice" box impedes analysis and reinforces the faulty assumptions that currently omit user participation from the quality equation. Because the term voice suggests that "users" and "producers" are mutually exclusive categories, one is led to assume that only the latter group is ultimately responsible for producing the good and determining its quality. This assumption, in turn, points to legal and policy solutions that ignore the real role of users in producing these goods.

The term voice, as it has been used in the literature, suggests that users are important to quality only insofar as they act as instruments for coercing action on the part of another party who is ultimately responsible for producing the good. Because the state can itself coerce the putative providers of local public goods, having users capable of performing this task might not seem very important. In fact, it might seem more efficient to have the state directly impose requirements on the local governmental entities in charge of providing local public goods, thereby taking the "micldleman" user out of the picture, along with the uncertainty surrounding the efficacy of voice at the local level.

Such a line of reasoning would miss what is perhaps the central feature determining the quality of local public goods-the day-to-day participation of the users. State coercion imposed upon the provider of the good cannot substitute for this participation, which arises endogenously. Because quality depends in large part on who the users are and what they are doing, a

result, management once again engages in a search for the causes and possible cures of customers' and members' dissatisfaction."); id. at 17 (discussing "the channels of communication between members and management in the public school systems") (emphasis added).

78. For example, it would make sense to speak of voice when an apartment dweller complains to management about faulty plumbing or leaky windows. It would make little sense to think of that apartment dweller as exercising voice when she cleans up the apartment or rearranges the furniture-even though the latter activities may have a much more profound influence on the quality of the apartment-dwelling experience.

79. Hirschman notes, correctly, that voicing one's views is a more direct communication than taking some action from whicl one's views might be inferred. See HIRSCHMAN, stpra note 3, at 16-17. Yet neither mechanism is as direct as influencing quality through one's own participatory acts.

80. To be sure, Hirschman's discussion of voice at times seems to edge close to my notion of user participation. See id. at 51 (discussing low people exiting from a given neighborhood "will be lost to the citizens' groups and commumity action programs that would attempt to stem and reverse the tide of deterioration"). However, to the extent Hirschman is referencing efforts to improve a school or neighborhood by cooperative behavior from within, the notion of "participation" better captures what is happening than does the term "voice." 
solution premised on state coercion of the "management" or the "producer" will be incomplete at best. Instead, user participation should be recognized as an important component of quality and a factor of production in its own right, separate and apart from the mechanism of voice.

Finally, some exercises of voice (for example, constant complaints and threats of litigation) may actually make other useful sorts of participation more difficult to sustain. Chubb and Moe's work on education supports this interpretation. In their study, effective schools were correlated with parental support, not with parental complaints and challenges:

Parents who unite behind a school, trust it to do what is best, and support its objectives and programs in the home can be a real asset to a school that wants to build an effective school organization. Parents who regularly challenge school priorities, frequently object to tracking policies or course assignments, and disagree with personnel decisions can cause real problems for the development of a coherent, ambitious, professional organization. ${ }^{82}$

Strong parental support is also likely to foster routine cooperation among the end-users of education-the students. Conversely, student cooperation inay be undermined by constant parental complaints. While an image of a school populated by obedient and unquestioning automatons is as repugnant as it is implausible, it is nevertheless true that schools cannot thrive without some minimal level of cooperative participation from most of the students, nost of the time.

2. Beyond Exit.-Just as voice does not fully capture all of the ways in which current users can impact the quality of a local public good, the term exit does not adequately convey what happens when a user decides to switch user pools. When viewed through the lens of user participation, such a decision has implications for the pool that the user joins, for the pool left behind, and for the larger community.

Conventional accounts suggest that exit-buying local public goods from a different supplier, either by physically leaving the jurisdiction or by opting for a private alternative-is analogous to switching to a different consumer product, such as a new breakfast cereal. The motivation in both cases is the desire to satisfy one's preferences or "tastes." two laudable things in this standard story. First, the exiting individuals are able to realize their consumer preferences more fully. Second, exit provides

81. Cf. Schwab \& Zampelli, supra note 40 , at 255 (discussing the role of residents' income levels in producing public safety); Manski, supra note 4, at 356-57 (noting the role of students in producing education).

82. CHUBB \& MOE, supra note 42 , at 147.

83. See Gillette, supra note 1 , at 1188 (observing that a decision to opt out of a publicly" provided level of service arises from the "desire to achieve one's preferences privately where one is unable to satisfy them through the political process" and noting that this desire appears, at least initially, analogous to preferring "full service restaurants to fast-food"). 
compelling market signals to the producer of the disfavored commodity and could spur product improvements. ${ }^{84}$ Relatedly, the threat of exit-that is, competition-is thought to provide market discipline and to prevent declines in quality.

For several reasons, this account of exit does not translate well to the local-public-goods context. First, it misapprehends the motives behind exit. Ordinary consumer motivations-paying for what one wants and getting what one pays for-are often attributed to people making decisions about where and how to consume local public goods. For example, James Buchanan observes that high-demand users (such as those with a taste for premium education) will readily opt out of a given consumption pool if they can realize higher net benefits consuming alone or consuming in some other pool. ${ }^{85}$ Exit is often formulated as a switch to a "better school" or a "safer neighborhood," with the school or the neighborhood conceptualized as a bundle of physical facilities and state-provided services. I contend that it is more fruitful to think of users as selecting among user pools rather than among exogenously provided products, and that this distinction has implications for the meaning of exit.

Here, it is helpful to consider how ordinary consumer goods differ from the local public goods under discussion. The former are exogenously produced, allowing one to decide in some meaningful way which lawnmower is "better" or which brand of cereal is more to one's taste, independent of what other consumers are doing. Because local public goods are largely endogenously produced, buying the best possible product means, in practical terms, joining the best possible user pool. ${ }^{86}$ People making decisions about local public goods are not motivated solely by a desire to avoid crosssubsidizing other users or by the desire to find an exogenously provided package that fulfills their preferences at the lowest cost. ${ }^{87}$ Rather, they are driven by the desire to join the best possible user pool. This means that mdividual decisions about user pools are interdependent.

Because of this interdependence, the nature and meaning of exit is different than it is for other consumer goods. Exit has financial impacts in the local-public-goods context, of course, just as it does in the context of other goods. When well-off taxpayers form new, autonomous pools or clubs

84. See HIRSCHMAN, supra note 3 , at 21 ("[B]y inflicting revenue losses on delinquent management, exit is expected to induce that 'wonderful concentration of the mind' akin to the one Samuel Johnson attributed to the prospect of being hanged.").

85. Buchanan, supra note 36 , at 5 (noting that "where the munieipality finances and provides a good that can be secured independently with hittle or no loss in efficiency, the shift of high-demand subgroups into their own purchase units cannot readily be forestalled while sharing gains are retained for remaining groups").

86. Cf. Schelling, supra note 63, at 145 ("To choose a neighborhood is to choose neighbors. To pick a neighborhood with good schools is to pick a neighborhood of people who appreciate schools (or of people who want to be with the kind of people who appreciate schools).").

87. See MiChAEL N. DANIELSON, THE POLITICS OF EXCLUSION 18 (1976) ("Higher taxes alone do not explain the flight of middle-income families and businesses to the suburbs, but they combine with poor schools, racial tensions, rising crime rates, and other problems in the older cities to accelerate the process."); $c f$. Oates, supra note 4, at 213 ("There is, 1 feel sure, a good deal more to local zoning policies than just keeping down local tax rates."). 
for consuming local public goods, this can pose a fiscal threat to the pool of consumers left behind. James Buchanan views this threat as so great that he recominends paying the high-demand users to stay put. ${ }^{85}$ But loss of tax revenue is not the only problem with out-migration. Exit imposes other sorts of costs as well, including costs which relate to the lost participation of the users. ${ }^{89}$ Recognizing these additional costs of exit makes an important analytic difference. If money were the only problem with exit, changes in the method and mode of taxing and financing public goods might offer real hope for deteriorating areas (assuming, for a moment, that the relevant political hurdles could be overcome). If lost participation is the real problem, nothing short of replacing or retaining that participation will prevent quality declines. ${ }^{90}$

The importance of lost participation becomes particularly clear if we consider exit to wholly private alternatives, which may not necessarily involve an immediate negative impact on the funding of local public goods. At first blush, opting out of public provision would seem, if anything, generous. For example, each child who is placed in a private school ostensibly reduces the financial burden on the public school system, while the child's parents must continue to contribute their share to a public school system from which they do not derive any consumption value. ${ }^{91}$ Not only does this picture ignore the well-recognized problem that exit may drain away voice (and ultimately money and service levels), ${ }^{92}$ but it also ignores

88. Buchanan, supra note 36, at 1 (arguing that "potentially-mobile central-city taxpayers who contribute to net fiscal surplus must be deliberately induced to remain in the sharing community by appropriate fiscal adjustments"); see also Gillette, supra note 1, at 1204-05 (discussing various "bribes" to retain individuals who would otherwise choose to opt out).

89. Hirschman recognized the costs associated with this dynamic. See HIRSCHMAN, supra note 3 , at 100 ("Parents who plan to shift their children from public to private school may thereby contribute to a further deterioration of public education."). For Hirschman, this detcrioration might be couched in terms of the loss of voice, although his observations are consistent with a broader understanding of the participation losses imposed by exit.

90. This does not mean that would-be exiters must necessarily be retained. As will be explained infra in subpart IV(A), there are two ways to obtain the necessary concentration of quality-enhancing users in a particular user pool-either by attracting and retaining qualityenhancing users or by transforming current users into quality-enhancing users.

91. Cf. Gillette, supra note 1 , at 1213 (providing an example in which private snowplowing reduces the costs that would otherwise be borme by taxpayers); see also id. at 1187 (discussing why people are willing to opt for private provision when they "must still pay for the publicly provided services of which they do not partake"). It sliould be noted that those who opt out while remaining within a given community are in fact still partaking of the composite value associated with the local public good, even if they cloose to obtain consumption value privately. Similarly, childless individuals receive composite value from their tax contributions to public education, even though they receive no consumption value from the public school systcm. Both sets of individuals are also affected by the capitalization of public school quality into property values. See FISCHEL, supra note 30 (manuscript dated Oct. 2000 at $\S 6-12$ ) (explaining that "no-kids voters" are motivated to support public scbool spending because good schools increase their property valuc); id. (manuscript dated Oct. 2000 at $\$ 6-14$ ) (presenting findings showing that home buyers take scliool quality into account).

92. See Gillette, supra note 1, at 1207-11 (discussing political costs that might be associated with decisions to opt for private provision). These effects could be particularly strong if the users who leave are the ones who would othenvise be the most vocal. See HiRSCHMAN, supra note 3, at 45-46; see also Liebman, supra note 3, at 294-99. Money would also be directly drained away from 
the costs that stem directly from the loss of a user who may be quite valuable and quality enhancing. Because of these costs, and as a result of the strategic dilemmas I will work through later in this Article,$^{93}$ it is indeed possible for collective-action problems-free-riding-to occur even when no financial support is withdrawn from the default pool.

Thus, when quality-enhancing users depart, real costs are imposed on those left behind that cannot be rectified by changing the way that the local public goods are funded or provided. People intuitively recognize that leaving the public school system or entering a gated community has consequences far greater than selecting a product from a supermarket shelf. The hostility that many people feel towards those who opt for such private alternatives likely reflects the intuition that making such choices is costly for those left behind, in a way that transcends mere dollars. ${ }^{94}$ The departure of quality-enhancing users from a default pool is particularly costly insofar as it sets in motion a chain reaction, both as to departures from the pool, and as to cooperation within the pool. ${ }^{95}$ A decline in the ratio of quality-enhancing users in the default pool spurs additional exits by quality enhancers. We can assume there is something like a "tipping point"-a point at which the ratio of quality-enhancing users drops below some critical threshold and triggers a mass exodus. ${ }^{96}$ There may also be negative behavioral shifts among those who stay within the pool. Even those users otherwise predisposed to qualityenhancing behavior may lose hope of making a difference, and may stop attempting to generate quality improvements from within. ${ }^{97}$

Moreover, in the context of local public goods, exit may not act as a viable feedback mechanism for spurring product improvements or as a source of competitive "market-discipline" benefits. Because the consumers are in large measure the product, people are not choosing or rejecting a product that can be easily improved exogenously; rather, they are choosing or rejecting each other. Exit in this context can be more accurately

the "losing" school to the extent that the departure of the student results in a withdrawal of any state or federal funding that is allocated on a per capita basis.

93. See infra Part II.

94. See Gillette, supra note 1, at 1190 (observing that "[t]he private institutions to which people seeking to opt out have migrated are consistently under attack as exclusionary and elitist, if not unconstitutional"); $i d$. at 1190-91 n.27 (collecting sources attacking residential community associations and other entities making use of private security forces).

95. See supra text accompanying notes $63-65$ \& fig. 1 .

96. Cf. Schelling, supra note 63, at 181 (defining "tipping" in the context of housing segregation). In Figure 1, the tipping point would occur somewhere to the left of point $\mathrm{C}$. Once $\mathrm{C}$ or greater quality enhancers are present, an unambiguously acceptable level of quality has bcen achieved. Because people have different tolerances for quality levels, any small upward or downward shift in the range between $B$ and $C$ could set in motion a chain reaction that could either drive the quality up to an unambiguously acceptable level or drive it down to a clearly unacceptable level.

97. See Daphna Lewinsohn-Zamir, Consumer Preferences, Citizen Preferences, and the Provision of Public Goods, 108 YALE L.J. 377, 392-99 (1998) (suggesting that "hopelessness" explains why people often fail to achieve collective goals). 
conceptualized as an elaborate "matching" exercise in which users match themselves up with other users, and in which each ensuing shift in user pools changes the product selections available to the remaining users. ${ }^{98}$ Because users are heterogeneous, matching equates to "sorting"-at least if exit is easy and if groups are able to use exclusionary devices (such as admissions criteria). The situation is not so much one of products competing for consumers; rather, it is more a matter of consumers competing with each other for spots in the best user pools. For this reason, exit cannot fully and simultaneously empower all consumers. Some users will find themselves unable to join desired user groups (because they are excluded), or, if exclusion is prohibited, other users will find themselves unable to consume their preferred product (which requires the ability to join with other qualityenhancing users and to exclude quality detractors).

A simple thought experiment demonstrates this point. Imagine a room filled with one hundred people, half of whom are excellent athletes and half of whoin are couch potatoes. Splitting the room randomly into two teams to accomplish soine physical task is likely to result in teams of roughly equal ability. Imagine instead that each person in the room is given a voucher to join either Team A or Team B, but that teams (as constituted at any point in time) can choose to vote would-be members in or out. One would expect a core group of athletes to quickly align themselves with one of the two teams and to apply exclusionary admissions criteria to any persons who wished to join. Other athletes, fearing that they might be left behind with the couch potato contingent, would be expected to rapidly seek admission to the "athlete" team. Couch potatoes might try to sneak onto the team as well, so as to free-ride on the talents of the athletes. But if admission is controlled by a current majority of athletes, the couch potatoes would not succeed in this ploy. At the end of the day, and barring any confounding interpersonal considerations or side payments, ${ }^{99}$ one would expect to see a team of athletes and a team of couch potatoes. The ability to join either team quickly becomes constrained and cannot produce favorable competition that would

98. For a discussion of other "matching" exercises, see Alvin E. Roth. The Evolution of the Labor Market for Medical Interns and Residents: A Case Study in Game Theory, 92 J. POLT. ECON. 991 (1984) (analyzing the matching game between medical students and hospitals); Stephen R. Heifetz, Efficient Matching: Reforming the Market for Law Review Articles, 5 GEO. MASON L. REV. 629 (1997) (analyzing the matching game between law reviews and authors). For goods like education and neighborhood security, the matching exercise is greatly complicated by the fact that quality is endogenously determined to a significant degree. In other words, one is not matching up with an entity that may have a relatively fixed set of traits (at least in the short run), but rather with a constantly changing group of fellow users.

99. If side payments were allowed, couch potatoes could try to recruit athletes to their team by offering them cash signing bonuses. Cf. Rothschild \& White, supra note 39, at 575-76 (discussing the use of scholarships to attract particularly desirable students who will generate positive externalities in higher-education settings). Giving less desirable user pools the wherewithal to attract and retain more desirable members is indeed one possible strategy for improving those pools. See infra text accompanying notes 160-69. 
"raise all boats" because the very means of competition is bound up in the tean's membership. ${ }^{100}$

This example illustrates the polar case in which members constitute the only relevant input. It is likely that other inputs have some significance in the context of education and security. Nevertheless, it seems unlikely that the exit mechanism can trigger the same sort of feedback loop for product improvement in the public-goods context as it does in the context of ordinary consumer goods. Unlike a manufacturer of a breakfast cereal who can use the data generated by exit to design something more to consumers' tastes, a local government or school district has relatively little ability to exogenously raise product quality; imstead, quality depends largely on the users themselves. This means that measures designed to spur market-like competition among providers-measures which would make perfect sense with ordinary consumer goods - may not work to improve quality in the local-public-goods context. ${ }^{101}$ On the contrary, the exit of quality-enhancing users takes away a principal means by which product improvements might be effectuated. ${ }^{102}$

This is not to say that competitive forces and the possibility of exit are completely irrelevant to quality. There is indeed empirical evidence suggesting that areas containing more schools and school districts have higher student-achievement levels, and economists have credited competition with these favorable outcomes. ${ }^{103}$ Assuming competition is really responsible for the gams, ${ }^{104}$ that competition may take the form of

100. One might object that in the long run the couch potato team could improve itself by undertaking an exercise regimen, cutting back on fatty foods, and the like. It is certainly true that endogenous cbanges among users within a pool can improve the quality of the public good-in this case, the team's performance. Indeed, I will argue that transforming users is onc of the most promising avenues for raising the quality of local public goods. See infra subpart III(C). The point here is that merely empowering users to choose among pools does not itself lead to uniformly improved public goods, but rather to sorting.

101. See infra subpart V(A) (discussing this point in the context of education vouchers).

102. In the consumer-goods context, the exit of too many users too quickly can drive a firm into bankruptcy before it has a chance to respond. HIRSCHMAN, supra notc 3 , at 24 (noting that "if the revenue decline exceeds a certain large percentage of normal sales volume, no recuperation ensues-beyond a certain point, losses will weaken the firm so badly that bankruptey will occur before any remedial measures can take effect"). In the local-public-goods context, the exodus necd not be so dramatic to prevent recovery; each exiting quality-enhancing user not only takes away revenue but also directly reduces the quality of the good, making it immediately less attractive to the remaining users.

103. See, e.g., FISCHEL, supra note 30 (manuscript dated Oct. 2000 at $\$ 6-8$ ) (collecting results of several studies that find better standardized-test scores in areas with more school distriets); Caroline M. Hoxby, Does Competition Among Public Schools Benefit Students and Taxpayers?, 90 AM. ECON. REV, 1209, 1236-37 (2000) (finding higher student achievement per dollar spent in areas with a large number of school districts); Michael L. Marlow, Public Education Supply and Student Performance, 29 APPLIED ECON. 617, 623-24 \& tbl.3 (1997) (presenting findings that areas with more schools and school districts have higher achievement-test scores).

104. It is possible that factors other than competition are responsible for some of these differences. For example, parents may fecl more empowered (or less trapped) where many schooldistrict choices exist; this empowernent may raise the quality of their participation. Or perhaps the 
endogenous competitive behavior among user pools rather than changes in the exogenous package provided by school administrators. For example, parents for whom exit from a particular school district is costly might pull together and undertake cooperative tutoring sessions to raise or maintain test scores. Their goal would be to make the school attractive to the "right" sort of peers, thereby safeguarding the quality of the school over the long run. ${ }^{105}$ This sort of user-centered competition depends upon the costlimess of exit for at least some portion of the user pool. In any event, it is clear that the threat of exit (or the threat of nonentrance of mensbers of a mobile population) ${ }^{106}$ operates somewhat differently in these contexts than it does for consumer goods, due to the role of users in producing the product and the relative ineffectiveness of exogenous imputs in raising quality.

Finally, and perhaps most importantly, exit is in an important sense not fully possible. ${ }^{107}$ While one can certainly opt out of a particular public school or political subdivision, one cannot avoid consuming the public good (or bad) that is produced through the composite consumption of all the users throughout the entire relevant community. Nor does the creation of ever smaller and more homogeneous "consuniption clubs" within the public sphere remove the members of such clubs from the effects of this composite public good (or bad) on the larger community. ${ }^{108}$ For this reason, all persons within the relevant community retain an interest in the quality of all local public goods within that community. ${ }^{109}$ For the same reason, law and policy have a potential role to play in structuring the provision of, and ensuring the quality of, these goods.

presence of many separately administered school districts yiclds a culture in which more conversations about education occur, with implications for attitudes and achievement levels. In other words, education may become more salient for the population as a whole when there are various educational approaches in the vicinity for perusal and comparison. To the extent more schools districts mean smaller schools, the independent impact of size should be taken into account as well. See Marlow, supra note 103, at 623 (citing a study by Eberts, Schwartz, and Stone on the imverse relationship between school size and student achievement); infra note 229 and accompanying text (discussing potential impact of size of user pool on collective action within the pool).

105. If we assume that test scores and other indicia of school quality are capitalized into property values, this would also be a way of protecting onc's investment in one's home. See FISCHEL, supra note 30 (manuscript dated Oct. 2000 at $\$ 6-14$ ) (discussing homeowner's stake in capitalization of test scores).

106. See id. (manuscript dated Oct. 2000 at $\$ 4-1$ ) (explaining that the notion of "exit" encompasses the failure to enter a particular community); see also id. (manuscript dated Oct. 2000 at \$3-12) (observing that the Tieboutian model of mobility is meaningful in assessing how people who move for reasons unrelated to pubhe services make choices among available communitics).

107. See HIRSCHMAN, supra note 3, at 100 (discussing situation in which "full exit is impossible" even after one stops consuming a particular product); id. at 101 ("The distinguishing characteristic of these [public] goods is not only that they can be consumed by everyone, but that there is no escape from consuming them unless one were to leave the community by which they are provided.").

108. Cf. Buchanan, supra note 36 , at 8 (describing out-migration into separate "fiscal cluhs" for joint consumption of goods).

109. See supra subpart I(A) (discussing composite value of publicly provided goods). 


\section{Choosing a User Pool}

Given the degree of interdependence between individual choices about local public goods, it makes sense to turn to game theory for guidance. ${ }^{110}$ The first collective-action problem highlighted by a focus on user participation involves making a choice among user pools. This choice can be simplified to the binary option of staying in a default user pool ("staying put") or choosing a private or other exclusive (e.g., suburban) alternative ("opting out"). Under current legal and institutional arrangements, opting out costs some nontrivial amount of money and is accessible only to some subset of the default pool population. For purposes of setting up the game, I will initially suppress this fact by assuming that all players are capable of opting out. Later, I will relax this assumption and consider the impact of current arrangements on the collective-action problem I have outlined.

\section{A. Cooperation and Consumption}

The Stag Hunt Game ${ }^{111}$ provides a good starting point for thinking about the strategic dilemmas involved in a quality-enhancing user's choice among user pools. David Lewis provides the following description of the dilemma:

Suppose we are in the wilderness without food. Separately we can catch rabbits and eat badly. Together we can catch stags and eat well. But if even one of us deserts the stag hunt to catch a rabbit, the stag will get away; so the other stag hunters will not eat unless they desert too. Each must choose whether to stay with the stag hunt or desert according to his expectations about the others, staying if and only if no one else will desert. ${ }^{112}$

There are some obvious parallels between the decision whether to opt out of a default pool and the decision whether to abandon the stag hunt to chase a rabbit. In both cases, the loss of participation makes things worse for those left behind. Expectations about what others will do influence one's choice: if one expects all the other quality-enhancing users to abandon a

110. CORNES \& SANDLER, supra note 8, at 132 (discussing the "important role for game theory" in developing public-goods models).

111. The Stag Hunt Game gets its name from a passage in Rousseau:

If a deer was to be taken, everyone saw that, in order to succeed, he must abide faithfully by his post; but if a hare happened to come within the reach of them, it is not to be doubted that he pursued it without scruple, and, having seized his prey, carcd very little, if by so doing he caused his companions to miss theirs.

JEAN JACQUES ROUSSEAU, ON THE ORIGIN OF INEQUALITY 349 (G.D.H. Cole trans. 1952), quoted in EDNA ULLMANN-MARGALIT, THE EMERGENCE OF NORMS 121 n.15 (1977). The payoff structure of the Stag Hunt Game is identical to one variation of the Assurance Gaine. See infra note 135; Lewinsohn-Zamir, supra note 97, at 392 n.40 (discussing two differcnt variations of the Assurance Game).

112. DAVID K. LEWIS, CONVENTION 7 (1969), quoted in ULLMANN-MARGALIT, supra note 111 , at 121 . 
particular user pool, one's best strategy is to do likewise. The local-publicgoods situation arguably resembles the stag hunt in a third respect as wellthe best outcome can be achieved if everyone cooperates by staying put. In the stag hunt, this greater good is the more filling stag meal. ${ }^{113}$ Coordination in the local-public-goods context might be expected to maximize the composite, community-wide value associated with a good like education, while also securing a consumption good of relatively high quality for each individual. In this sense, it can be said that we are all better off by cooperating.

It is easy to see that the parallel between the stories breaks down at this point. Unlike the superior good which one can enjoy only through cooperation in the stag hunt, the composite value associated with a safe or well-educated populace is enjoyed equally by those who contribute to its production by staying in the default pool and by those who opt for another alternative. In other words, one cares about the "stag" of community-wide safety or education being brought down, but one has no particular interest in participating in its demise. For one's own consunption purposes, the "rabbit"-a private or suburban education, for example-is preferred. Moreover, the goal of a safe or well-educated public can still be successfully achieved even if some percentage of players defects. In short, it is in everyone's interest to have these larger targets successfully pursued, but in nobody's interest to be in the hunting party that does the pursuing.

Another inajor difference concerns the heterogeneity of the participants in the local-public-goods "game." To put it into the language of the stag hunt, some participants are skilled hunters who can easily catch a rabbit or can contribute greatly to the killing of the stag-these hunters are the quality enhancers who also have the wherewithal to opt out of the default pool. Other participants lack the capacity to pursue rabbits, although they may be able to make contributions to killing a stag-these are quality-enhancing people who are unable to leave the default pool. Finally, there are participants whose presence threatens the success of the hunting party: not only are they inept at hunting - they also scare away stags and inay even lob stray arrows at their fellow hunters. These rogue hunters-quality detractors-provide yet another compelling incentive for quality-enhancing users to opt for rabbit hunting. ${ }^{114}$

Although the Stag Hunt Game helps to illuminate certain aspects of the local-public-goods dilemma, it is obviously not a perfect fit. This is so

113. If a better good were not possible through cooperation, the Stag Hunt would not present a coordination game at all; everyone would simply hunt rabbits from the outset and would be quite happy to do so. Likewise, if one accepts a privatization model for public goods, in which cveryone can do just as well providing for themselves as they can by coordinating, there would be no strategic dilemma presented at all.

114. Of course, those who opt out of a default pool do not truly "go it alone" as the rabbithunting image would suggest but instead join other, more exclusive groups-the equivalent of private hunting parties. 
because citizens receive a two-part payoff associated with the local public goods under discussion - one part corresponding to the consumption value (if any) they receive from consuming the good in question, and the second part corresponding to the composite value that is generated by the overall pattern of consumption of this good throughout the community. ${ }^{115}$ The first of these, consumption value, is directly determined by one's choice of user pools-for example, the school one chooses for one's children. The second part of the payoff, composite value, is sensitive to the overall pattern of choices that individuals throughout the larger community make about user pools.

One way to conceptualize the dilemma created by this two-part payoff is to think of the chooser as simultaneously juggling two roles: that of a consumer and that of a citizen. ${ }^{116}$ In her consumer role, she cares about the consumption value of the good: whether her children are getting a good education, or whether her family is safe in their neighborhood. In her citizen role she cares about composite value: whether all children are generally getting a good education, or whether all people are generally safe in community neighborhoods. Because of the role of participation and the fact that users are heterogeneous, these two roles may conflict with each other to some degree.

A helpful contrast is found in an example presented by James Buchanan-that of an inoculation against a serious communicable disease. ${ }^{117}$ In such a case, the private aspects of the good are in alignment with their public (spillover) aspects. ${ }^{118}$ By acting as a good consumer and getting a shot to protect oneself, one is also acting as a good citizen by helping to protect everyone else against the spread of the disease. One might initially think that the same thing would hold true for a good such as education. After all, by getting the best possible education for one's own children, one is certainly contributing in some degree to "an educated populace." However,

115. See supra subpart I(A) (discussing these two components of value); sle also TERRY $M$. MOE, SCHOOLS, VOUCHERS, AND THE AMERICAN PUBLIC 275 (2001) (noting that the decision of a parent as to whether or not to support vouchers "is made up of two components, one social and one personal-and the personal component may be quite influential in their thinking").

116. Terry Moe recently found this citizen-consumer framework to be descriptive of public school parents' judgments about education vouchers. See MOE, supra note 115, at 288 (explaining that parents making judgments about vouchers "appear to be combiming two roles: they are consumers, concerned about their own personal interests, and they are citizens, concerned about society as a whole"); see also Cass R. Sunstein, Social Norms and Social Roles, 96 CoLUM. L. REV. 903, 923-25 (1996) (positing that individuals may desire different outcomes and follow different norms in the role of a citizen than they do in the role of a consumer). Butt see Lewinsohn-Zamir, supra note 97, at 380-91 (criticizing the consumer-citizen distinction).

117. BUCHANAN, supra note 16 , at 181.

118. See id. (suggesting that distribution of a scarce inoculation drng based solely on its privategoods aspects will lead to an efficient result). In Buchanan's view, it is not possible to improve on the distribution produced by the market, since each person's consumption of the inoculation provides the same spillover benefits to the rest of the population (assuming the distribution pattern does not itself impact the spillover effects). Id. \& n.6. 
the dynamic of multiple user pools within a given community makes this analysis a bit too facile. In the case of local public goods such as education, one may find the best consumption value in a homogeneous enclave or in a private setting. But by withdrawing one's participation from the "default" educational setting, the quality of that default option diminishes, with deleterious long-term impacts on the composite value of the public good in question.

Because these two roles are in conflict, it matters how heavily each is weighted. I do not assume that the consumer role will automatically win out, but it is very likely to do so in the settings I am discussing here-education and neighborhood security. In these contexts, it is often the consumer's children (rather than the consumer herself) who will enjoy the direct benefits of consumption or who will bear the burden of consuming a substandard product. This is self-evident in the case of education. Moreover, one of the primary reasons people choose to move to a suburb (or a gated community) is for the perceived safety of their children. ${ }^{119}$ Any individual may operate under a number of different codes and may well be willing to sacrifice ordinary sorts of narrow self-interest to the public good. ${ }^{120}$ But one's role as a parent usually decisively overrides all other moral codes. ${ }^{121}$

In other words, concern for the community at large (composite value) will often pale next to concerns about one's own child (consumption value). Even so, it is likely that at least some people take an enlightened enough view of self-interest to recognize the significance of composite value to their own long-term well-being. Among people for whom a concern about composite value is sufficiently strong, a strategic dilemma evolves which may have the structure of a Prisoner's Dilemma. ${ }^{122}$ The next section formalizes this dilemma.

119. See, e.g., Roy Hayhurst, In Gates We Trust, DaLlas MORNING News, Mar. 29, 1998, at 9A (quoting a gated-community member who explains, "[w]c live in a gated community for comfort and security because we have four children"); Setha M. Low. The Edge and the Center: Gated Communities and the Discourse of Urban Fear, 103 AM. ANTHROPOLOGIST 45, 51-56 (2001) (presenting and discussing interview excerpts in which gated-community residents indicate that fear for their children was a primary factor motivating their residential decisions).

120. STRETTON \& ORCHARD, supra note 7, at 13.

121. See CHESTER BARNARD, THE FUNCTIONS OF THE EXECUTIVE 267-68 (1937) (describing a typical man with a stringent set of potentially conflicting moral codes, who will "kill, steal, cheat the government, rob the church" for the sake of his children), quoted in STRETTON \& ORCHARD, supra note 7, at 13; see also MOE, supra note 115, at 287-88 (finding, based on empirical data, that parents considering vouchers are not "driven mainly by naked self-interest" but that "self-interest is far more important than political science would lead us to belicve").

122. The Prisoner's Dilemma is based on a stock story involving the interrogation of two prisoners. Although the prisoners would do better jointly if both refused to testify against the other, each faces a payoff schedule in whicl he does better by testifying, no matter what the other prisoner does. As a result, the dominant strategy is for both to testify. The mathematician A.W. Tueker is credited with developing the model. See CHARLES J. GOETZ, LAW AND ECONOMICS: CASES AND MATERIALS 8-17 (1984). 


\section{B. The "Choice of Pool" Game}

To illustrate how the strategic dilemma might play out in the case of education, ${ }^{123}$ I will start with a two-person game modeling the decision whether to "stay put" in an inner-city public school or "opt out" to a private or suburban school or home-schooling alternative. ${ }^{124}$ Next, I will model a slightly more realistic multiparty game.

1. Two-Person Game.-The participants in our two-person game are two individual heads of household, Rudy and Carrie. Both have children, and must decide whether to stay put in the urban public school or opt out to a private school, suburban school, or home-schooling alternative. Both Rudy and Carrie are truly capable of opting out; this is neither forbidden by prevailing legal structures nor foreclosed to them due to financial pressures. ${ }^{125}$ Both are also relatively enlightened and other-regarding individuals. They care not only about the consumption value of education received by their respective children but also about the composite value of education throughout the larger community. In addition, I will make the following simplifying assumptions:

(1) Rudy, Carrie, and their respective children will be quality enhancers in whatever school they decide upon. In other words, their propensity to cooperate within the pool will not be affected by their choice of whether or not to stay in the pool.

(2) The preferences of Rudy and Carrie are identical and symmetrical. The decision of whether or not to opt out has only to do with matters of relative and absolute educational quality (as defined below), and not with other factors (such as a preference for religious training unavailable in the public schools). ${ }^{126}$

123. A similarly structured game might be developed to understand decisions about neighborhood security - that is, whether to "stay put" in an urban neighborhood or "opt out" to a private alternative (such as a gated community with a private security force) or another jurisdiction (such as a suburb). Cf. Abraham Bell \& Gideon Parchomovsky, The Integration Game, 100 COLUM. L. REV. 1965, 1991-93 (2000) (presenting three alternative game matrices modeling the "stay/leave" decision in the context of housing segregation).

124. The contrast I draw here between an "inner city" and a wealthy suburb is admittedly something of a stereotype and is certainly not descriptive of all modern urban situations. See generally ALEX MARSHALL, HOW CITIES WORK: SUBURBS, SPRAWL, AND THE ROADS NOT TAKEN (2000) (discussing the changing roles of cities and suburbs). In some places, the central city has become a locus of wealth where people affirmatively choose to live, while some suburban areas are occupied by those with less money and less choice. My reliance on this dichotomy stems only from its long familiarity as a shorthand way to refer to areas of relative advantage and disadvantage. The basic choice situation described here remains applicable, regardless of where tbe relatively disadvantaged and advantaged areas lie geographically.

125. It does not matter whether we think of opting out as costless or whether we simply view the payoffs given for opting out as being net of any costs associatcd with exercising that option.

126. To the extent these other factors account for a significant proportion of the opting out that actually occurs, this framework will be of less descriptive value. About twelve percent of schoolaged children in the United States attend private schools (a figure that has remained relatively stable 
(3) As in the real world, Rudy and Carrie will be able to adjust their own behavior based on the choice the other person has made. In other words, there are repeated rounds of play, the players take turns Inaking decisions, and each player can see what the other player has done during his or her latest turn. ${ }^{127}$

(4) Educational quality is rated "rotten," "decent," or "good." By these terms, I mean to designate not only the quality of academic programs and the associated educational outcomes but also other important factors that are predicates to achieving those outcomes (safety, discipline, and a good learning environment).

(5) Another dimension of educational value is designated by the term "exclusive." This offers a proxy for factoring in the importance of the perceived relative quality of education. ${ }^{128}$ People care not only about the absolute quality of their children's education but also about how that education stacks up to that received by relevant others. ${ }^{129}$

since 1940), and of these, almost eighty-five percent attend religiously affiliated schools. JOHN F. WITIE, THE MARKET APPROACH TO EDUCATION: AN ANALYSIS OF AMERICA'S FIRST VOUCHER PROGRAM 5-6 (2000). But it is unclear how inany parents sending their children to religiously affiliated private schools are motivated to do so by the religious cnvironment per se, rather than by other user-pool, curricular, or disciplinary considerations. The growing number of non-Catholies in Catholic parochial schools suggests that nonreligious motivations play a role. See Timothy Egan, The Changing Face of Catholic Education, N.Y. TIMES, Aug. 6, 2000, at 28, LEXIS, News Library, NYT File (reporting that the percentage of non-Catholics in Catholic schools has increased more than four-fold in the past 30 years, to 13.4 percent and obscrving that in the Archdiocese of New York, the figure is 20 percent). In any event, the vast majority of "opting out" involves a move to a suburban public school rather than to a private school. See Michacl Lewyn. Suburban Sprawl: Not Just an Environmental Issue, 84 MARQ. L. REV. 301,327 (2000) (noting that most parents prefer to "move to suburbia and send their children to "good" ... public schools for free" rather than "stay" in cities and spend thousands of dollars on private schools").

127. See Oliver et al., supra note 57, at 524-25 (discussing sequential decisionmaking and interdependence of decisions in contributions to public goods).

128. See generally Richard McAdams, Relative Preferences, 102 YALE L.J. I (1992) (discussing the inportance of preferences for a higher relative position). To the extent an exclusive private or suburban school gives its students a competitive advantage in further cducational or employment opportunities, it will be more highly valued, whether or not it is actually of higher quality in absolute terms. It is unclear whether such a preference for cxclusivity would be present to the same degree in the context of neighborhood security; if it were not, this might present a difference in the payoff structures and dominant strategies for the two local public goods.

129. In this two-person game, I am assuming the only relevant "other" for comparison purposes is the other player in the game (who can also opt out). If the two parties agree to cooperate, therefore, concerns about another party's gaining an advantage are climinated. In a more realistic multiparty game, there would be many "others" to be concerned about, and it would not be possible to eliminate concerns about relative position so easily. The attractiveness of the cooperative solution would drop aecordingly. Finally, a concem for relative position could cut tbe other way (leading quality-enhancing users to stay in the default pool) if they perceived the universe of relevant others as being limited to those within their own user pool (rather than all those viewed as relevantly like themselves throughout the larger community). See generally ROBERT H. FRANK, CHOOSING THE RIGHT POND: HUMAN BEHAVIOR AND THE QUEST POR STATUS (1985). Where important benefits (including intangible status rewards) are awarded based on one's position within a given user pool, this may well affect one's decision about which pool to join. See infra note 168 
Thus, in our two-person game, an education that is "good" in absolute terms can be "good and exclusive" (if only one player receives a good education) or "good and equal" (if both players receive a good education). ${ }^{130}$

(6) If both Rudy and Carrie stay put, their (and their children's) participation will ensure a good quality education in the default school. If only one or the other opts out, the remaining player will still be able to keep the school quality at the "decent" level. If, however, both opt out, the public school quality will fall to "rotten." In other words, I am assuming that some critical mass of quality enhancers will keep the public schools "good," and that some smaller number of quality enhancers is necessary to keep the schools "decent." 131

(7) Rudy and Carrie are quite enlightened and other-regarding, but they are also very concerned about the cducation of their children. They recognize that their decisions about whether to opt out or stay put will have consequences, and they further recognize that the "payoff" they receive froin the decision on this inatter will be inade up of two components: consumption value and composite value. I will assume (soinewhat arbitrarily, but not altogether implausibly) that their payoffs run as follows for these two components:

\section{Consumption Component}

Rotten education for iny child $=-2$

Decent education for iny child $=2$

Good (and equal) education for iny child $=5$

Good (and exclusive) education for my child $=7$

\section{Composite Component}

Rotten education throughout community as a whole $=0$

Decent education throughout the community as a whole $=2$

Good education throughout community as a whole $=3$

As this schedule indicates, I am assuming that the consumption and composite payoffs are independent of each other-in other words, that the

and accompanying text (discussing preferential college-admissions treatment for a top percentage of students in each high school).

130. In a multiparty game, matters get considerably more complex. I will assume that a good education achieved by opting out is made more valuable because of its exclusivity. The placement of the curve in Figure 3, infra, reflects this assumption. Likewise, I will assume that a good education achieved in the default pool will be rendered marginally "less good" by the fact that someone else is receiving an edueation that is more exclusive.

131. See supra text aecompanying notes 57-65 \& Fig. 1 . 
education Rudy's and Carrie's children receive will remain unaffected by the quality of the education received by others throughout the society. ${ }^{132}$ I have also made the possible payoff range for the consumption component larger than that for the composite component, which reflects the imtuition that people have a much larger stake in the former. In other words, my payoff structure assumes that people care a good deal more about what happens to their own kids than what happens with education in the commumity at large.

Those valuations, in coinbination with the other assumptions outlined above, yield the payoff grid shown in Figure 2.

Figure 2.

Payoffs for (Rudy, Carrie)

\begin{tabular}{|c|c|c|}
\hline & Carrie Stays Put & Carrie Opts Out \\
\hline \multirow{3}{*}{ Rudy Stays Put } & & \\
& 8,8 & 4,9 \\
& $(5+3,5+3)$ & $(2+2,7+2)$ \\
\hline \multirow{3}{*}{ Rudy Opts Out } & 9,4 & 5,5 \\
& $(7+2,2+2)$ & $(5+0,5+0)$ \\
\hline
\end{tabular}

Each payoff is the sum of two figures: one which represents the utility derived from consumption of education and another which represents the utility derived from the composite provision of education. The first set of numbers in each cell shows total payoffs for Rudy, and then for Carrie. I then repeat these payoffs in parentheticals, showing the two components of the payoff (consumption value + composite value).

The game, set up im this fashion, is a typical Prisoner's Dilemma. First, look at things from Rudy's point of view. No matter what Carrie does, Rudy is better off opting out. If Carrie stays put, Rudy can do better by opting out-he can reap both the benefits of a decent public school systein and a good (and exclusive) education for his own children (total payoff of 9). Staying put would reduce his payoff to 8 . Even though it would make the public school system "good" rather than merely "decent," his children would receive only a "good and equal" education rather than the "good and exclusive" education available by opting out. Of course, if Carrie is going to opt out, Rudy has an even greater incentive to opt out as well; otherwise, he

132. While this assumption seems plausible across some range, there would likely be a point where the low quality of the surrounding education would have such severe spillover effects as to effectively reduce the payoff associated with the consumption component-as well as to impose an additional set of costs on society not captured in the game as currently formulated. 
will be bearing the burden of keeping the public schools "decent," while downgrading his children's education to merely "decent." Meanwhile, Carrie gets the benefit of decent public schools while securing an exclusive education for her own children. While Rudy considers himself enlightened, he is not about to put the good of the community above the education of his kids.

Things look identical from Carrie's point of view. The result is that opting out is the dominant strategy for both, making the lower right-hand cell the equilibrium solution. In that cell, most kids get a rotten education, but Rudy's and Carrie's kids get a good education. ${ }^{133}$ The total combined payoff associated with the lower right cell is the lowest of the bunch. Rudy and Carrie could collectively do much better if they could agree to stay put (again, assuming enlightened preferences), but the temptation to defect is enormous. Opting out while the other stays in offers the best of both worlds and the highest individual payoff. The person who opts out is free-riding on the other participant's work on behalf of the public schools and can glean the community-wide benefits without contributing to them. All the while, the person who opts out is able to secure her kids an exclusive education and a competitive advantage in the lottery of life.

This game structure and the resulting dominant strategy depend on the specific payoffs I have built into the example, which depend in turn on a number of assumptions about the players that would not hold true for everyone. One could easily imagine different orderings of subjective valuations that would turn the game into Chicken, ${ }^{134}$ an Assurance Game, ${ }^{135}$ or a straightforward nongame situation. ${ }^{136}$ In addition, the payoffs can be

133. Notice that the payoff they receive in the lower right-hand cell is the "good and cqual" payoff. Since both players in the two-person game now receive the same education, it is arguably no longer "exclusive." In a multiparty game, of course, relatively large numbers of pcople could opt out before the benefits of exclusivity would start to erode.

134. "Chicken" gets its name from a dangerous automobile game in which two cars drive toward each other on a straight stretch of road. The first driver to swerve is a "chicken" and loscs the game. Of course, losing the game in this fashion is a better outcome, even for that drivcr, tban if neither driver swerved and the cars crashed into each other. See GILLETTE \& BAKER, supra note 3 , at 38 n.6.

135. The Assurance Game is identical to the Stag Hunt in that the best outcome for an individual occurs when the other party also cooperates. The worst outcome for an individual occurs when that individual cooperates but her opponent does not. The rank ordering of the other two outcomes (universal noncooperation and individual noncooperation while the other player cooperates) varies in different formulations of the game. See Lewinsohn-Zamir, supra note 97, at $392 \mathrm{nn} .39-40$ and sources cited therein (describing the Assurance Game and noting variations of it). Amartya Sen is credited with formulating the "Assurance Problem." Amartya K. Sen, Isolation, Assurance and the Social Rate of Discount, 81 Q.J. ECON. 112, 114 (1967).

136. If cooperative action cannot provide a joint higher payoff for the players, there is no possibility of gains through cooperation and thus no "game" at all. Instcad, there is only an obvious choice between ranked alternatives. For example, I attribute a large degree of enlightenment and other-regarding preferences to Rudy and Carrie. For many people, the consumption component of the payoff might so utterly dwarf the composite component as to make the latter irrelevant. In such a case, parties that could realize a higher consumption through opting out would simply do so; if their utility is not sensitive to composite value, no form of collective action could provide a greatcr joint payoff. 
affected by norms, laws, agreements, and other factors, as will be discussed presently; this can also transform the game from a Prisoner's Dilemma into another sort of game altogether. ${ }^{137}$ Nevertheless, the scenario set forth above demonstrates that under at least some imaginable circumstances it is possible even for people who care deeply about the community to find themselves in a situation where their dominant strategy is to opt out.

2. Multiparty Game.-Of course, games about goods such as education and security are never played between just two individuals; rather, they involve the interaction of relatively large groups of individuals. ${ }^{138}$ We can still assume that, at least within some range, individuals' decisions to stay put would have a positive impact on composite value, while decisions to opt out would have a negative impact. However, the quality of education likely does not depend in a directly linear fashion on the number of quality-enhancing persons making the cooperative choice of staying put. ${ }^{139}$ Across some portion of the continuum, one individual's cooperation or defection might add or subtract little or nothing in terms of quality, while at other points one individual's cooperation or defection might result in a rather dramatic change in quality. Figure 1 presented one possible way in which quality might correspond to the nuniber of quality-enhancing users. Figure 3, based on diagrams developed by Thomas Schelling, ${ }^{140}$ shows how this might translate into a framework for deciding whether to stay put or to opt out in a multiparty game.

Figure 3.

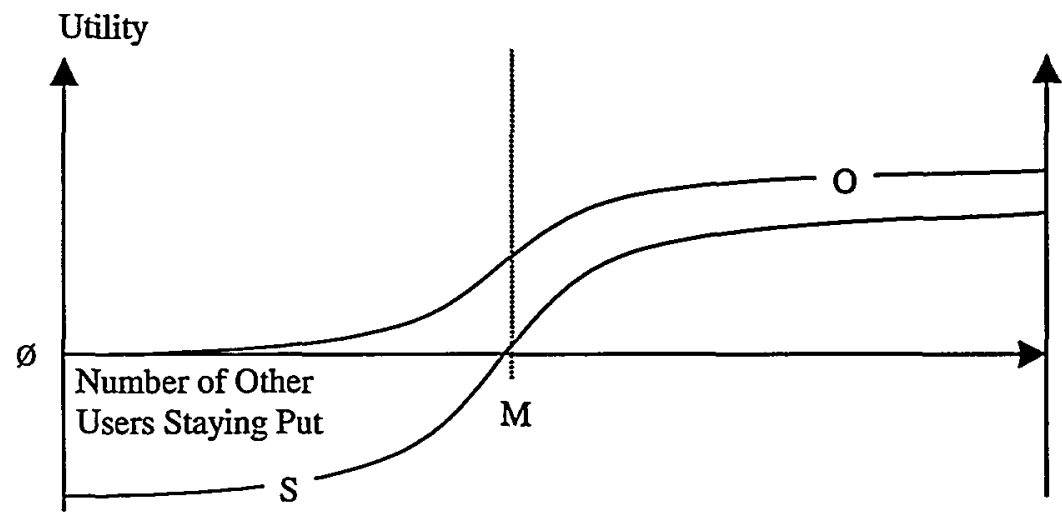

137. See infra subpart $\Pi(C)$.

138. It is important to clarify here that I am still discussing the "choice of pool" interaction, not the interaction among members of a given pool. The latter, which will become important later, see infra Part III, is being bracketed out of the analysis for now.

139. See supra Fig. 1 and accompanying text.

140. See SCHELING, supra note 57, at 220-43; see also JON ELSTER, THE CEMENT OF SOCIETY: A STUDY OF SOCIAL ORDER 27-30 \& fig.1.5 (1989) (discussing and applying Schelling's work). 
In Figure 3, the vertical axis represents utility, viewed from the perspective of an individual decisionmaker, Ingrid. I will assume that Ingrid shares all of the preferences that were previously attributed to Rudy and Carrie. ${ }^{141}$ The horizontal axis represents the number of other players who are making the cooperative choice-in this case, staying put. The curve marked O tracks Ingrid's utility if she opts out. As the upward path of the curve indicates, her utility increases as more players choose to stay put. This occurs because the people staying put are contributing to the composite value, which forms part of Ingrid's payoff. The curve marked $S$ tracks Ingrid's utility if she chooses to stay put. Again, the greater the number of other people staying put, the better she does. Because Ingrid's children are consuming education in the default pool under this scenario, the cooperation of others boosts not only the composite value that makes up part of Ingrid's payoff but also Ingrid's own consumption value. This results in a steeper slope for curve $S$, especially across the critical middle range.

As drawn, the graph depicts a typical multiparty Prisoner's Dilemma. No matter what everyone else does-that is, no matter how many others opt out and how many others stay put-Ingrid always does better by opting out. The utility gap is particularly large if few others cooperate, because this results in a markedly inferior education in the default pool. But even if everyone else cooperates (bringing the schools up to an acceptable level), Ingrid can still do a little better by opting out. This will enable her to obtain a slightly more exclusive education for her children, which will win them a competitive edge over those in the default pool.

Significantly, the payoff schedule shown in Figure 3 is based on the specific preferences and assumptions associated with Ingrid, which would not necessarily be shared by other quality enhancers facing the same choice. For example, I am assuming that Ingrid, like Rudy and Carrie in the earlier example, has no difficulty opting out-we can think of opting out as being costless for her, or we can simply think of the cost as already being netted out of the payoff schedule shown in Figure 3. Opting out is, of course, costly under current institutional arrangements and is not available to everyone. We might think of another individual who could not afford to opt out at all. For her, the $O$ curve would simply not appear as an option and she would face no game or dilemma. The decisions of others in the game would have an impact on this individual's utility, and her $S$ curve would slope accordingly, but she would be locked into the stay-put solution. For another person, opting out might be attainable but would come at a very high cost (perhaps he would have to work a second job or take out a loan with a very high interest rate). Because the $O$ curve reflects the net utility associated with opting out, that person's higher costs associated with opting out would shift the curve downward. ${ }^{142}$ This could make staying put his dominant

141. Presently, I will consider the possibility that individuals may have (or may develop) different sets of preferences.

142. The subsidy for a public-school education has the effect of reducing the cost of hoth the stay-put option and certain opt-out options (i.e., suburban schools). This would have the effect of 
strategy across the board, or it might become dominant once some number of other quality-enhancing users also decided to stay put.

I am also assuming that Ingrid assigns some importance to composite value. Indeed, this is what makes her utility responsive to changes in the number of other cooperators even when she is opting out. However, she also values consumption value fairly highly. In contrast, another individual might weight consumption value so much more heavily than composite value that composite value would not factor in at all. Such a person's O curve would be flat, because it would not depend to any degree on the number of other people remaining in the default pool. On the other hand, there are some individuals who weight composite value extremely heavily (or perhaps value signaling to the world that they weight composite value extremely heavily), so they would choose the stay-put option no matter what, even if this meant sacrificing consumption value. For example, one might think of President Carter's decision to send his daughter to public schools in the District of Columbia, despite the ready availability of alternatives that would (at least by some accounts) have offered higher consumption value. ${ }^{143}$ For such people, the $S$ curve would lie above the $O$ curve at all points.

In addition, I am assuming that Ingrid cares somewhat about her position relative to others. For this reason, she will choose to opt out even in the situation where enough other cooperators have raised the quality level of the default school into the acceptable range. Another individual might value membership in the diverse default community more highly than attaining a higher relative position than those in the default pool. For that person, the $O$ curve would drop down below the $S$ curve (nnaking staying put his preferred strategy) in the far right-hand portion of Figure 3, where many cooperators have ensured an acceptable default school. ${ }^{14}$ These are only a few examples of the many ways in which user heterogeneity might affect the collectiveaction problem. In addition to differences between users, it is also likely that changes in utility schedules may occur over time within the same user. Preferences may shift, perhaps as a result of positive or negative experiences in a given situation or with particular other users. At the point when an individual is making the decision of whether to stay put or opt out, the utility associated with the opt-out choice is really a prediction, just as the utility assigned to the stay-put option is a projection based on current information. To the extent financial circumstances play a role in the decision, this too may change for a given user over time.

placing the respective curves higher on the graph than they would otherwise be. I am making the simplifying assumption that there is a single opt-out opportunity available to a given individual. In reality, there are a variety of public and private altematives, as well as self-produced options such as hoine-scliooling - each of which would present a different mix of costs and benefits. In a more detailed depiction of the problem, one might include separate curves for each of these various options.

143. For more information on the Carters' decision, see Merrill Sheils, A School for Amy, NEWSWEEK, Dec. 6, 1976, at 61 .

144. In suclr a case, the situation would amount to an Assurance Game. See supra note 135. 
The poimt marked $M$ has special sigmificance. From Ingrid's perspective, this represents the number of other cooperators she would need to join up with in staying put to achieve a result that she would prefer to the outcome she would receive in a world where everyone opts out. ${ }^{145}$ In other words, an M-sized group acting together could generate a better outcome for Ingrid than the mass-defection option would generate for Ingrid. If we assume that there are at least $M$ others who face a payoff schedule similar to Ingrid's, the potential would exist for everyone in an M-sized group to better their lot by acting collectively. ${ }^{146}$ Yet there is little incentive to organize such a group, particularly if one suspects that some other coalition will form to do the same thing. Assuming such a cooperative coalition does exist, one clearly does better if one is not a part of it; the people opting out at point $M$ end up doing even better than those staying put. ${ }^{147}$ It is possible to think of the situation as a Chicken Game among all possible M-sized groups, in which the worst outcome for all concerned would be the one in which no Msized group stays put. But, of course, Chicken is won by precommiting not to provide the good in question. There is also the problem of how to get the M-sized group together in the first place. For any group smaller than $M$, members end up worse off than in a world where everyone opts out. ${ }^{148}$ Unless a mechanism exists to make cooperation contingent on obtaining the necessary group size, it may be impossible ever to form a sufficient coalition. And, of course, group heterogeneity further complicates coalition-building efforts.

One more point about Figure 3 bears mention. This Figure assumes that even in a world in which no quality enhancers cooperate by staying put, Ingrid can still do much better by opting out. No matter how horrible schools or neighborhoods may be in some places, those who remove themselves from those bad schools or neighborhoods can achieve some relief, even though they continue to be affected by spillovers in the form of lower composite value. At the extreme, this proposition might become empirically questionable. If there truly were neighborhoods and schools devoid of any quality-enhancing users, this could have such dramatic effects on the entire surrounding community that it would become increasingly difficult to wall

145. See ELSTER, supra note 140 , at 28 (identifying this as the point of "self-sustaining cooperation"). If one assumes that group members share homogeneous preferences, as Elster seems to do, it would be correct to say that this number of cooperators would each do better than they would do under a world of universal defection. If group members are heterogeneous, other group members might require a group of either more or less than $M$ other cooperators in order to make them better off than they would be in a world of universal defection.

146. See id. These other group members could either have a payoff schedule identical to Ingrid's, or they could have a payoff schedule in which even less cooperation yields them a better result than universal defection.

147. See id. (noting that even though cooperators will do at least as well in this situation as they would in a world of universal noncooperation, "[t]he noncooperators will, of course, do even better').

148. See id. at 29 (noting that even if a smaller group is "bound to each other with the strongest bonds of loyalty, they will perceive that cooperation is pointless-it is essentially dissipated among the noncooperators-and disband"). 
oneself off and achieve a higher consumption value in a private or suburban setting. For example, societal order might break down so completely that the crime and disorder spilling out of the worst neighborhoods and schools would make life unlivable for the entire relevant commumity. If this were the case, the $\mathrm{O}$ and $\mathrm{S}$ curves would actually meet at the far left-hand side of Figure 3, creating a game of Chicken with even higher stakes than the one just described.

Whatever the precise shape of the curves, society has a large stake in ensuring that some collective block of quality-enhancing individuals stays put. But few people have an imdividual interest in being among those who stay in the default pool. In the section that follows, I will explore some of the ways that legal rules and societal arrangements operate (or might operate) to achieve the desired result. For example, if opting out requires purchasing a market-rationed private alternative or paying the minimum housing price to join an exclusive suburb, financial barriers to exit will essentially "trap" a large segment of the population im any given default pool. If there are enough quality-enhancing users in this segment to ensure quality, society's worst outcome is avoided, albeit mequitably. It would be as if society had made lower- and middle-class quality enhancers the "designated swervers" in the incipient game of Chicken.

\section{Locks, Bribes, Norms, and Pacts}

There are several potential strategies which, alone or in combination, might solve the collective-action problem just outlined. These strategies fall into four broad and somewhat overlapping categories-locks, bribes, norms, and pacts. The first three of these can be viewed as altering the relative payoffs associated with the two options facing a quality-enhancing individual in the opting-out game, while the fourth involves addressing the dilemma through concerted action.

Figure 4 shows how mcreasing the utility associated with the cooperative solution would change the game:

Figure 4.

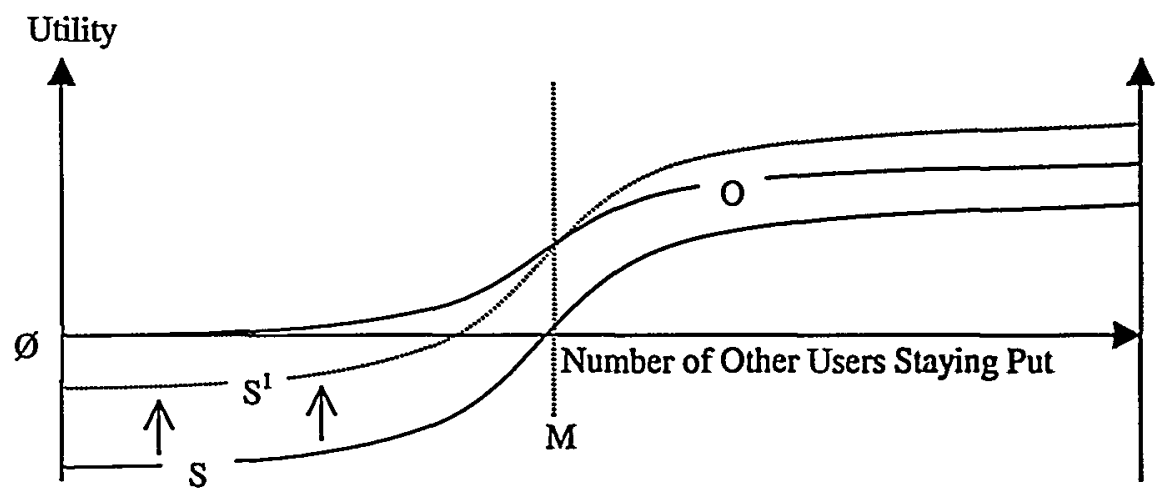


Recall that the $S$ curve represents the stay-put cooperative choice. If the utility associated with this choice were increased across the board for a given individual to $S^{1}$, that individual would find himself facing an Assurance Game rather than a Prisoner's Dilemma. In other words, the individual can do best by cooperating (staying put), provided at least $M$ other people also stay put. A policy or legal change that made opting out less attractive or more costly could have the same result, if it shifted the $O$ curve to a similar position relative to the $S$ curve. If the game's payoffs can be changed in this fashion so that cooperation is a dominant strategy, provided enough other people cooperate, the fourth strategy, pacts, could have an especially important role to play. While it might be possible for people to join together and act collectively even in a Prisoner's Dilemma situation, agreements are inore likely to offer a viable and stable solution where an Assurance Game is involved. Once the required number of participants are cooperating, there is no longer any temptation to defect.

1. Locks.-One obvious response to collective-action problems like the opting-out game is to lock the participants into the cooperative strategy-in other words, force them to stay put. A literal example of this principle was recounted by Thomas Schelling: In World War I, German soldiers were sometimes chained to their machine guns so that they could not act on an impulse to flee. ${ }^{149}$ Similarly, Edna Ullmann-Margalit has observed that two inortarmen ensnared in a strategic dilemma in which each has an incentive to desert would find it in their mutual interest to have mines laid around their area so that neither of them could desert. ${ }^{150}$ This obviously operates to change the payoff associated with deserting such that staying to fight becomes the dominant solution.

One might similarly think that somehow locking users into the default pool would be an obvious solution to the "choice of pool" problem. ${ }^{151}$ The most secure kind of lock-simply forbidding people to leave a given school

149. THOMAS C. SCHELLING, CHOICE AND CONSEQUENCE 196 (1984).

150. ULLMANN-MARGALIT, supra note 111, at 32 (observing that this solution "cffectivcly eliminates the possibility of desertion, and consequently each is happy to stay by his mortar and fight, knowing that the other has in fact no alternative but to fight too, with the result that the attack is repelled and they both stay alive").

151. Indeed, Hirschman and others have recognized that blocking exit is often the best way to ensure effective voice. HIRSCHMAN, supra note 3, at 79 ("Specific institutional barriers to exit can often be justified on the ground that they serve to stimulate voice in deteriorating, yct recuperable organizations which would be prematurely destroyed through free cxit."); id. at 45 (noting that if the most vocal customers are the first to leave, this suggests that "voice would be an effective recuperation mechanism only in conditions of full monopoly 'when the customers are sccurcly locked in"'); see also Liebman, supra note 3, at 302 (arguing that locking people into the public schools might be the most effective way of maximizing voice and thereby improving those schools). Whether or not it would also ensure effective participation is less certain; this will depend in part on the outcome of the second collective-action problem this Article addresses-the interaction within the user pool. See infra Part III. However, so that we can examine the locking mechanism as a solution to our first collective-action problem, I will assume for present purposes that qualityenhancing users will remain quality-enhancing users whether they are in the default pool voluntarily or whether they are locked into that pool. This assumption will later be relaxed. See infra Part IV. 
or neighborhood-is both out of bounds constitutionally and out of reach politically. ${ }^{152}$ But there are many other legal and structural features that operate, or potentially could operate, as locking (or at least "sticking") mechanisms for some subset of users. Perhaps the most important of these are the financial liurdles that individuals must surmount in order to opt for a private or suburban alternative. Exit from the default user pool is not costless under the present system and is not possible for a large subset of the population. One must either be able to afford the "entry fee" to a suburban life-which often requires spending more on housing-or one must be able to pay for a private alternative to the publicly provided good. Because not everyone has the resources to take advantage of either alternative, many who desire to leave will be unable to do so. Yet lowering the barriers to exit would have the effect of further decreasing the quality of the default option. Conversely, raising the barriers to exit would trap more quality-enhancing users in the default pool and raise the quality of the good. But there are other factors that make such barrier-raising problematic and mequitable. ${ }^{153}$

The current system of free public education works to subsidize the cooperative choice. Taxpayers must pay for this public option, whether or not they end up actually selecting it. At least to the extent people compare private alternatives with the public alternative available in the default pool, this subsidization will make the latter compare more favorably than it otherwise might. ${ }^{154}$ Such financial locks can alter the payoffs encountered by at least some of the players in the opting-out game, and thus, change their dominant strategy. If the cost of opting out becomes prohibitively expensive for particular players, they are no longer faced with a dilemma in any meaningful sense of the word (though they certainly may feel unhappy with the outcome). In such a case, their only option is to stay put.

Another set of lock-in possibilities would involve providing a mechanism whereby quality-enhancing users take turns in the default user pool. We might assume that everyone has a strong interest in keeping a sufficiently high ratio of quality-enhancing users in all user pools (including the default pool) but that everyone would personally prefer to opt for a different pool. If this is the case, the game is one in which everyone will try to free-ride on the participation of others and will likewise do everything

152. See Pierce v. Society of Sisters, 268 U.S. 510 (1925) (striking down as unconstitutional a law requiring public-sebool attendance). But see Liebman, supra note 3, at 307 (contending that Pierce migbt not rule out a compulsory public-school-attendance law if it were based on legislative findings, offered various "release time" and other options, and permitted those with bona fide religious objections to opt out).

153. See infra subpart IV(C) (discussing possible cooperation problems among users who are in a pool against their will).

154. See Liebman, supra note 3 , at $285-86$ (discussing impact of the implicit penalty that the current structure imposes on those leaving the public schools). Because public education is also "free" in exclusive suburbs, this subsidization factor would seem to be largely absent in the choice between urban and suburban public edueational opportumities. Howerer, if state school financing arrangements required the wealthier districts to help finance the poorer ones, resulting in a substantially heavier tax burd:n for suburbanites (relative to the education received) than that borne in the inner city, this would make opting out to the suburbs less attractive. 
possible to avoid being a "sucker" upon whoin others can free-ride. ${ }^{155} \mathrm{~A}$ "turnstile" mechanisin which allows everyone to be a free rider and a "sucker" in turn could provide a neat theoretical solution. ${ }^{156}$

It is hard to imagine how to implement a pure turnstile system consistent with constitutional and political constraints. ${ }^{157}$ But it might nevertheless be possible to structure incentives to approximate a "rotation" system among those who might otherwise opt out. This might be accomplished through a system of education-voucher credits that could be built up based on the number of years one attends an at-risk school. For example, a voucher equal to roughly half a year of private school tuition could be granted for every year a student spends in an at-risk school; the voucher could also be saved up and applied to tuition at a college or university. Families of limited means could thereby earn the right to rotate out of the default pool or, alternatively, could choose to save up credits to pursue future opportunities.

The possibility of earning voucher credits might help to retain more well-off quality enhancers within the pool, at least in the short run. For example, a family might decide to economize on costs by sending children to public school in grades one through eight, and then use the voucher credits to move the child to a private school for the high school years. Allowing the voucher credits also to be applied to higher education might cause some families to change their minds when the child reached high school age, provided that other quality-enhancing students in the same position were making the same "stay put" decision at that point. A similar program is conceivable in the neighborhood-security area: a tax credit could be provided for every year one stays in an at-risk neighborhood. This might simultaneously allow people of limited means to escape the neighborhood eventually, while encouraging them to stay put in the short run. If enough other people did likewise, this short-run decision might turn into a long-run solution.

Another possible way to lock users into the default pool would be to expand the default pool to encompass an entire metropolitan area or region. Annexation (and, more broadly, centralization) are strategies that can ensure that the financial burden is shared across an entire area. With monopoly power, a single provider can make entry of other providers more difficult and can reduce instances of opting out. ${ }^{158}$ But these techniques would not solve the participation dilemmas outlined here. Users can only interact at the individual neighborhood or school level. Therefore, designating an entire

155. See ANTHONY DE JASAY, SOCIAL CONTRACT, FREe RIDE: A STUdY OF tHE PUBLIC GOODS PROBLEM 63-64 (1989) (applying "free-rider" and "sucker" designations to the Prisoner's Dilemma).

156. See id. at 207-08 (discussing "turnstile" arrangements for moving between "frec-rider" and "sucker" subgroups).

157. But cf. Wilma Norton, Living in Harmony, ST. PETERSBURG TIMES, Apr. 16, 1989, at 1B (describing a plan of rotating school zones, in which neighborhoods "take turns" being bused).

158. See Gillette, supra note 1, at 1204 (discussing how centralization could deter opting out of public provision). 
metropolitan area as a single "user pool" is essentially meaningless. For participation purposes, the area would remain an agglomeration of separate subpools unless a mechanism were added to mix the users together in some manner. ${ }^{159}$

2. Bribes.-Another possibility is to focus not on trapping qualityenhancing users in the default pool, but on using incentives to attract and retain them. To put it pejoratively, this would mean bribing qualityenhancing users to stay put. ${ }^{160}$ One possible type of incentive has already been discussed-offering voucher credits or tax credits to people who stay within the default pool. Another controversial possibility is to focus mcentives on those who are most able to leave-the wealthy. James Buchanan suggested this strategy as a possible way to overcome the tendency for "high-demand" users to out-migrate from urban centers. ${ }^{161}$ Payment could involve, for exaniple, reducing tax burdens or providing a premium level of services to wealthier users. ${ }^{162}$ There are also more subtle ways of goimg about attracting or retaining the wealthy. For example, an urban center could subsidize goods that are disproportionately enjoyed by the wealthy (such as symphonies, museums, and operas). ${ }^{163}$ Yet such proposals raise egalitarian concerns, and some of the more blatant forms of discrimination in favor of the wealthy could run into legal barriers as well. ${ }^{164}$

Another troubling characteristic of such a strategy is its implicit assumption that all wealthy people are necessarily going to be quality enhancers. This is not the case. While there may be some correlation between wealth and quality-enhancing tendencies, there is not complete correspondence between these categories. ${ }^{165}$ Since opting out costs money,

159. See GERALD E. FRUG, CITY MAKING: BULLDING COMMUUNmES IVTHOUT BULDING WALLS 186-88 (1999) (discussing a plan to make school districts more heterogeneous by permitting students to attend schools anywhere within a metropolitan area when doing so would increase, rather than decrease, the diversity of the student body).

160. See Gillette, supra note 1, at 1204; Buchanan, supra note 36, at 11.

161. See Buchanan, supra note 36, at 4. Buchanan based his suggestion on the impact of outmigration on the tax base, but the additional impacts of lost participation would seem only to strengthen his argument.

162. See id. at 10 (discussing "bribes or side payments" to induce the well-off to remain in the collectivity, such as "tax-price reductions and/or budgelary changes"); id. at 15 (discussing "differential adjustments on the consumption services side" such as "special police details in highincome areas of cities"); see also John Conley \& Manfred Dix, Beneficial Ineguality in the Provision of Municipal Services: Why Rich Neighborioods Should Get Plowed First (June 2000), at http://www.cba.uiuc.edu/jpeonley/documents/public-finance/dirferential-access.pdf (making a similar argument for differential service levels).

163. See Buchanan, supra note 36 , at 14 (suggesting that "municipalities should listen more carefully to those who recommend fiseal support for art muscums, symphony orchestras, theaters, and parks").

164. See generally Charles $M$. HAar \& Daniel. W. Fessler. The WroNg Side of the TRACKS (1986) (discussing legal challenges to unequal provision of municipal services).

165. In the neighborhood-security context, the opposite may in fact be the case. Those who are not regularly employed may be invaluable in watching out for trouble in the streets. See JACOBS, 
however, wealthy quality enhancers are the quality enhancers most at risk of leaving the pool. Yet simply keeping the wealthy within the urban core may not necessarily solve the user-pool problems that are the focus of this Article. It is quite possible to live in a private gated community within a city and to send one's children to private schools.

Magnet schools offer a more targeted vehicle for attracting and retaining quality-enhancing users. ${ }^{166}$ Unlike incentive plans targeted only at the wealthy, magnet schools would theoretically attract people who value education. Likewise, incentives for home buyers in central cities might attract people who are interested in putting down roots and contributing to the community. In Washington, D.C., a $\$ 5000$ tax credit offered to first-time home buyers in the District has helped to spur an influx of new residents and a revitalization of the city. ${ }^{167}$

Not all incentives to keep users in a user pool are monetary, nor are they necessarily intentional. An interesting development in several state universities has been to adopt a policy of accepting a given percentage of top students froin each high school within the state. ${ }^{168}$ While this may have been motivated by a desire to maintain a diverse student body and equalize opportunities at the university level, the arrangement creates a powerful incentive for parents to keep their children in schools where they are likely to be user pool standouts-rather than in ones in which they will be surrounded by other high-achieving students. ${ }^{169}$ This mixing of user pools may well

supra note 49, at 282 (discussing contributions to safety made by people who are "hardly successes by most standards" and observing that "[t]he amount of time they devote to street watching and street management makes some of the rest of us parasites upon them"); see also VENKATESH, supra note 51, at 33-34 (relating a Chicago Housing Authority project manager's comment that mothers receiving government assistance were among the most effective leaders of tenant groups).

166. There is some evidence that magnet schools can effect changes in the student body. See Ryan, supra note 46, at 312 (observing that "magnet schools have shown some ability to attract suburban students to city schools"). But it is not clear that magnet schools can substantially boost performance through additional expenditures. For example, the lavish magnet school program in Kansas City, Missouri, which outfitted schools with such amenities as a planetarium, a robotics laboratory, and a working farm, and boosted per-pupil expenditures to nearly twice the state average, had rather underwhelming results. See id. at 290 (contrasting the increased student spending with mixed performance on national and statewide tests).

167. See Peter Behr \& Judith Evans, Revived District Joins the Region's Economic Boom; From Jobs to Housing, Nearly All Sectors Take Part, WASH. POST, May 31, 1999, at A01, LEXIS, News Library, WP File (reporting that $70 \%$ of all home buyers in the District in 1998 took advantage of the District's $\$ 5000$ first-time home buyer tax credit and that $40 \%$ of these new buyers came from outside the District).

168. See Paul Attewell, Mirage of Meritocracy, AM. PROSPECT, July 17, 2000, at 12 (noting that Florida guarantees a spot to the top $20 \%$ of each high school graduating class, California to the top 4\%, and Texas to the top 10\%); Patricia Kilday Hart, Imperfect Ten, TEX. MONTHLY, Apr. 1 , 2001 , at 52 (discussing impact of Texas's policy).

169. See Attewell, supra note 168, at 12 ("The percentage rules make the current clustering of professional families in districts with excellent schools highly disadvantageous. Middle-class kids would have a much better chance of getting into the colleges of their choice if their families moved down-market into more heterogeneous neighborhoods, where their kids would have a better chance of reaching the top 4 percent."). 
result in an even more fundamental equalization of opportunities than was originally envisioned.

3. Norms.-Game theorists have long recognized that intangible factors, such as social norms, can change the effective payoffs that the players experience. For example, notions of honor and disgrace powerfully alter the payoffs that soldiers experience when confronted with a collectiveaction problem. ${ }^{170}$ Hirschman suggests that decisions not to exit could at least in some imstances be explamed "by meinbers being aware of, and recoiling from, the prospective consequences of their exit." 131 To the extent people actually do resist exiting from a particular user pool out of concern over the impact on those left behind, it would suggest the presence of powerful social norms in favor of cooperative action that effectively change the payoffs in a manner analogous to the virtues of honor on the battleground.

Whether or not such norms exist in some circles, it is fair to say that they are not robust checks on exit froin schools or neighborhoods. Competing norms in favor of consumer choice seeln to dominate, and concerns about the side effects of individual decisions are often only vaguely apprehended. Nevertheless, the possibility remains that norms could be shifted in favor of collective action in this context. Such norm formation might involve focusing users on the consequences of abandoning the city's urban schools and neighborhoods, and on the benefits that will redound to their children if these schools and neighborhoods are instead reclaimed and improved. Because inost moves out of default pools are undertaken "for the children," such norm-shaping efforts should also focus on what is in the best interests of the children-with those interests viewed froin a broader perspective.

Indeed, merely reframing the collective-action problem may help to solve it. There is experimental evidence suggesting that people are more likely to contribute to a public good when the decision is presented as a choice of whether to make positive contributions to the well-being of others than when the decision is framed as whether to purchase a private good that will make others worse off. ${ }^{172}$ If this is so, merely convincing people that

170. See ULIMANN-MARGALT, supra note 111, at 37 (explaining that there is a "decrease in pay-offs, where being denounced as a deserter is involved, and [an] increase in pay-ofrs, in terms of esteem, reputation, prestige, and glory, where behaviour which is up to what is considered honourable is involved"); $c f$. TM O'BRIEN, THE THINGS THEY CARRIED 21 (Broadway Books 1998) (1990) ("Men killed, and died, because they were embarrassed not to.").

171. HIRSCHMAN, supra note 3 , at 100.

172. James Andreoin, Warn-Glow Versus Cold-Prickle: The Effects of Positive and Negative Framing on Cooperation in Experiments, 110 Q.J. EcoN. 1 (1995); see also Eun-Soo Park, WarmGlow Versus Cold-Prickle: A Further Experimental Study of Framing Effects on Free-Riding. $43 \mathrm{~J}$. ECON. BEHAV. \& ORG. 405, 406 (2000) (discussing framing literature and reporting further findings that "the negative framing has a most salient effect on the subjects who have individualistic 
private consumption choices about education and neighborhood security might have negative effects on others may be insufficient to foster cooperative norms. Recasting decisions about these goods as potential contributions to a valuable public good might be more useful. This line of reasoning also suggests that the rhetoric used to discuss these goods may have important real-world consequences and that viewing these goods as ordinary consumer items may have an insidious effect on the framing of the problem. ${ }^{173}$

The potential for norms to transform the collective-action problem in this setting depends, in part, on how quickly those norms might catch on and spread through the community. ${ }^{174}$ This may depend, in turn, on how much contact various subgroups within the community have with each other and on how strong the ties are among and between the individuals in these subgroups. For example, it is relatively easy to imagine a "public school" norm catching on in a close-knit neighborhood, where individuals live near each other and interact with each other daily, and where school-related decisions are the subject of talk among the neighbors. Likewise, people who interact with each other through their work might be susceptible to the attitudes of that reference group with respect to gated communities, suburban living, and private schools. However, it is also possible that people who strongly believe in pursuing their consumer preferences with respect to education and security will form isolated pools that are strongly resistant to these kinds of commumity-oriented norms.

4. Pacts.-If the premise of this Article is correct, one of the primary attractions of a given user pool is the other members within that pool. This suggests that one of the best retention techniques involves instilling confidence that other quality-enhancing users will also stay in the pool. Such confidence may be generated to some extent by the fact that it is costly to move out of a given pool. Finding ways to make the pool "stickier" would increase that level of confidence, yet mandatory lock-in mechanisms may create problems of their own. An alternative would be for users to form a pact to stay put or to otherwise find ways to reduce the risk that one will be harmed if others flee.

Taking a lesson from the FDIC, one might consider insurance as a way of overcoming tendencies to flee out of fear. The problem is in some sense an analogous one, at least with respect to neighborhoods. The effects of user pools on home values means that in the event of a massive out-migration from an urban core, people who move out first will do much better than those

value orientation, whereas the negative framing has a rather insignificant effect on the subjects who have cooperative value orientation").

173. See Frug, supra note 2, at 25-35 (criticizing consumer-oriented vision of local public goods).

174. See, e.g., Randal C. Picker, Simple Games in a Complex World: A Generative Approach to the Adoption of Norms, 64 U. CHI. L. REV. 1225 (1997) (modeling the spread of norms). 
who move out later. The strategic disadvantage of being the last to leave can lead to panic-selling in a changing neighborhood. Insurance plans which indemnify hoineowners for dropping home values due to neighborhood changes theoretically take away the incentive to leave too early. ${ }^{175}$

Another possibility is a conditional contract among users. This apphies a concept drawn froin a very effective fund-raising approach: contributions are inade contingent on the collection of enough other contributions and are refundable in the event the pre-established threshold is not met. ${ }^{176}$ In the user-pool context, one might imagine making a contract to stay in a particular neighborhood or school contingent on some critical mass of other qualityenhancing users also signing on. If a practical way of implementing this idea could be devised, it could keep the unraveling effect of out-migration from getting started; the user pool would be able to retain all those users who would stay if they expected almost everyone else to stay as well. Significantly, an agreement or pact to stay put might also help to develop norms supporting this choice (as well as specific substantive norms supporting quality-enhancing behavior within the user pool). If this effect were strong enough, it could lend stability to the cooperative solution by changing the payoffs enough to remove the temptation to defect. ${ }^{177}$

\section{Choosing Actions Within the User Pool}

The second collective-action problem highlighted by a focus on user participation involves the choice of action within the user pool. The preceding discussion of the "choice of pool" dilemma might seem to suggest that people are innately either quality enhancers or quality detractors and that a particular user pool's success depends on its capture of an adequate share of the former. Of course, this is not the case. Quality-enhancing behavior is the product of conscious choices; it is not an immutable personal attribute. Thus, the quality of a local public good will depend not only on who the pool's users are but also on what they are doing.

\section{A. Quality-Enhancing Behavior and Intrapool Spillovers}

Individual choices about whether to undertake quality-enhancing activities in a given user pool will have spillover effects within that user

175. See Bell \& Parchomovsky, supra note 123, at 2005-07 and sources cited therein (describing and analyzing home-equity insurance programs like the one implemented in Oak Park, Illinois).

176. See ELSTER, supra note 140 , at 42 ("Collective action problems can also be transformed if contributions are made conditional upon each other. The 'money-back' method stipulates that promises to contribute will be enforced only if a sufficient number of others promise to do the same.") (citations omitted). Empirical evidence suggests that the "money-back" method is a successful tactic for obtaining efficient provision of public goods from individual contributions. See, e.g., Mark Bagnoli \& Michael McKee, Volumany Contribution Games: Efficient Private Provision of Public Goods, 29 ECON. INQUIRY 351 (1991).

177. See supra Fig. 4 (showing the effects of raising the payoff associated with the cooperative choice). 
pool. Such choices will generate quality improvements that will benefit not only the individual undertaking the activities but everyone else within the pool as well. ${ }^{178}$ A neighborhood resident who makes the neighborhood safer by watching out for others increases both her own consumption value and the consumption value of everyone else in the neighborhood. ${ }^{179}$ Within the confines of the specific user pool, these quality-enhancing behaviors constitute a "public good"-everyone within the pool will share in the quality improvements that are generated for that particular school or neighborhood. This presents a collective-action problem, although its precise shape is not self-evident. Engaging in quality-enhancing behaviors may be costly or costless-an individual may find the incremental improvements generated by her efforts well worth the cost or not worth the cost. She may prefer to free-ride on the efforts of others, she may only find cooperation worthwhile if enough other people are also cooperating, or she may enjoy cooperating no matter what others do.

As these observations suggest, the game is greatly complicated by the fact that users are quite heterogeneous-both in how highly they value the various benefits associated with cooperation and in how heavily the costs of cooperation weigh upon them. For some users, certain forms of cooperation may be costless or may actually generate positive utility. For example, some students may find paying attention in class intrinsically rewarding, and some neighborhood residents may find it relaxing and healthful to take regular walks along neighborhood sidewalks and park paths. If this is so, then there is no "game" presented at all and no incentive to defect. If participation is its own reward, people will have an incentive to cooperate. ${ }^{180}$

For other users, cooperation may be costly-even prohibitively so. Some neighborhood residents are in no physical condition to make appearances on the street. Others, such as those working long hours, may have very high opportunity costs associated with contributing to neighborhood safety. Still others, such as those who make their living selling drugs or who are already engaged in gang activity, may find the cost of

178. Cf. CORNES \& SANDLER, supra note 8, at 235-36 (discussing maintenance activities in a club as providing public benefits within that club).

179. Making the individual neighborhood safer may also contribute in some measure to the overall composite public good of community-wide security. Whether it does so in a particular case will depend on the extent to whicl heightened safety in a given neighborhood actually reduces crime community-wide (as opposed to merely displacing it to other nearby neighborhoods). Importantly, individuals choosing actions within a user pool are typically not pulled in different directions by their interests in composite and consumption values, as they arc in the opting-out game. Instead, an individual's intrapool belıvioral choices will either move both components of value in the same direction or will at least improve consumption value while leaving composite value unchanged.

180. If participants view quality-enhancing activities as intrinsically valuable they will likely engage themselves in cooperative activities until the marginal benefits of doing so drop below the marginal benefits associated with some alternative activity (such as leisure). If all of the value associated with the cooperative activity is derived from engaging in it, there would be no temptation to free-ride. Cf. Réaume, supra note 41 , at 10 (observing that because public goods such as culturo are intrinsically enjoyed only as they are being produced, there is no free-rider problem). 
contributing to a safe neighborhood quite high indeed. In the education setting, cooperative behavior may involve good study habits and other forms of "school readiness" that are a function of factors in the home that are not within the control of the individual student. Students who are impoverished or who arrive at school froin disordered home environments cannot as easily engage in quality-enhancing behaviors as can privileged children from supportive homes. Because of these types of heterogeneity, behaviors that are costless or utility-producing for some people will be very costly or perhaps wholly out of reach for others.

One might object at this point that I am describing sociological phenomena rather than true collective-action problems-that these people are not "playing games" in any meanimgful sense but, instead, are doing what they are led to do by their environment, upbringing, and preferences. For example, it is often noted in the context of education that achievement is tied to certain relatively immutable characteristics of family backgroundeducation level and economic status. Since it is hard to do much about these characteristics through policy, one might think that there is no hope for usercentered quality improvements. ${ }^{181}$ It is certainly true that some behavioral patterns are entrenched and problematic. Couching the situation in terms of "payoffs" rather than in the more familiar language of socioeconomic disadvantage is nevertheless helpful. It leads us to consider the ways in which legal and policy structures might operate to change those payoffs. It also reminds us that choices are still, in fact, being made by individuals, even if those choices are highly constrained.

Moreover, certain kinds of troubling user heterogeneity are a function of group processes, and changes im user-pool dynamics could lave consequences for these processes. ${ }^{182}$ For example, some people receive a particularly large payoff from defecting within the user pool, not because they intrinsically enjoy defecting but because the social hierarchy within that particular user pool assigns social rewards to those who disrupt the school or the neighborhood. Likewise, some children are driven by peer pressure to avoid succeeding in school, ${ }^{183}$ and some neighborhood residents are kept off neighborhood streets by imtimidation tactics wielded by a subset of the neighborhood population. Sucli problems may be responsive to cooperative action within the user pool.

While there are inany kinds of cooperative behaviors for which costs will vary widely among users, some types of cooperation will be costly for almost everyone. A classic example is punishing unacceptable behaviors within the user pool. Ousting an individual from a school or from a

181. See Liebman, supra note 3 , at $260,266-277$ (discussing the assumption that factors such as student ability and family resources, which are closely linked to educational outcomes, are relatively insensitive to policy).

182. Id. at 293 (arguing that because of spillover effects from peers, combining students in different ways could yield improvements).

183. See Ryan, supra note 46 , at $288-89$ \& n.171 (summarizing and discussing anthropological studies about the peer pressure to avoid success in school that African-American students often face). 
neighborhood is obviously costly to those doing the punishing. ${ }^{184}$ More subtle forms of punishment, such as shunning or shaming, can also impose social or other costs on the punisher. ${ }^{185}$ While the benefits of punishing a particular individual are diffuse and spread across the user pool, the punished individual has a concentrated interest in avoiding the punishment and in making life miserable for would-be punishers. ${ }^{186}$ The result is a collectiveaction problem that carries some of the overtones of interest-group politics; the punishable individual is in roughly the same position relative to the punishment as an interest group is with respect to legislation that would disproportionately harm it while generating diffuse benefits. ${ }^{187}$

Whether or not a particular user pool can summon the will to oust a particular individual (or engage in lesser forms of punishment designed to deter quality-detracting behaviors) depends on the intrapool dynamics of cooperation or noncooperation. In the absence of collective action by those who stand to gain from the punishment, the punishment may not occur. Cooperation in this context can take the form of direct sanctions against wrongdoers or might instead involve actions and attitudes supporting official enforcement. ${ }^{188}$ For example, if students and parents exhibit their willingness to back up an administrative decision to oust a troublemaker, the decision is more likely to be made in the first place. Similarly, neighborhood residents might act cooperatively when they assist the police in apprehending a criminal. In contrast, parents who display their distrust of school administrators and residents who express animosity towards the police may implicitly encourage those in charge to turn a blind eye to problematic behavior.

In such cases, where cooperation is somewhat costly to the individual, but where the individual stands to gain from her own cooperation if enough others cooperate also, the interaction can be formalized as an Assurance Game. ${ }^{189}$ In such a game, the best payoff results from mutual cooperation. This cooperation can be expected if individuals are able to make cooperation pacts with each other. If each person's cooperation increases her own payoff, and if she believes others will also cooperate, there is no incentive to defect. We can see this both im a simple two-person interaction and in a

184. See ELSTER, supra note 140 , at 41 ("Punishment almost invariably is costly to the punisher, while the benefits from punishment are diffusely distributed over all menibers.").

185. See id. at 133 (observing that "expressing disapproval is always costly," requiring at least "energy and attention" and perhaps also "alienat[ing] or provok[ing] the target individual, at some cost or risk to oneself"). But see Richard H. McAdams, Cooperation and Conflict: The Economics of Group Status Production and Race Discrimination, 108 HARV. L. REV. 1003, 1028 n.95 (1995) (suggesting that "because people enjoy expression as an end in itself, expressing disapproval is not always costly" and observing that if this disapproval serves to "alienate the target" this is not a cost, but rather "the whole point").

186. ELSTER, supra note 140, at 41 (discussing punishment as a "public good").

187. See DANIEl A. FARBER \& PHIIIP P. Frickey, LAW AND PUBlic CholCE: A CRITICAl INTRODUCTION 23 (1991) (discussing the economic theory of interest-group influence).

188. Here, user participation begins to blur into certain varieties of supportive "voice." See supra subpart I(C) (distinguishing voice from participation).

189. See supra note 135 (describing the Assurance Game). 
multiparty interaction. In setting up the game to reflect a type of cooperation that is individually costly but beneficial for the group, I will use the example of taking part in a neighborhood watch effort.

\section{B. The Participation Game}

1. Two-Person Game.-Imagine that two people, Rita and Cedric, are living in a particular neighborhood that is neither entirely safe nor entirely unsafe. Each must decide whether to cooperate on a given evening by participating in a neighborhood watch or defect by staying inside and reading a book. ${ }^{190}$ If both participate in the neighborhood watch, neighborhood safety will definitely improve substantially. If only one participates, safety may improve a little, but the lone watchperson will find the experience terribly boring and perhaps also frightening. If neither participates, neighborhood safety will definitely suffer. The payoffs for Rita and Cedric are identical, as follows:

Much safer neighborhood: 150

Somewhat safer neighborhood: 50

Unsafe neighborhood: 0

Costs of doing the watch with another person: 50

Costs of doing the watch solo: 100

Figure 5.

Payoffs for (Rita, Cedric)

\begin{tabular}{|l|c|c|}
\hline & Cedric Does the Watch & Cedric Reads a Book \\
\hline Rita Does the Watch & 100,100 & $-50,50$ \\
\hline Rita Reads a Book & $50,-50$ & 0,0 \\
\hline
\end{tabular}

The net payoffs of Rita and Cedric appear in each cell of Figure 5. The best outcome for both players occurs if both do the watch. But if either player expects the other to defect, that player will choose to defect as well. The worst individual payoff occurs when the player does the watch solo,

190. A similar example is presented in GILLETTE \& BAKER, supra note 3, at 38, in which players must choose between patrolting a neighborhood and holding out. In Gillette and Baker's example, the payoffs are structured as a Chicken Game. The Patrolling Game makes only a brief appearance in a series of examples illustrating general principles of strategic interaction in the provision of public goods, but its content nieely underscores the role of user participation in the provision of neighborhood security. See id. at 37-38. 
because it generates only 50 in benefits but involves 100 in costs (half of this cost is due to the boredom and unease associated with doing the watch solo, while the other half relates to the energy expenditure that is always required to do the watch, whether alone or in tandem).

The obvious solution is for Rita and Cedric to agree that they will both do the watch. Given this payoff structure, neither of them will have an incentive to defect or a reason to suspect that the other person will defectdefecting would reduce the payoff for the defector, as well as for the other person. If they do not inake an agreement to cooperate, however, they may both end up defecting out of fear that the other person will defect.

2. Multiparty Game.-Matters become inore complicated when more than two players are involved. Figure 6 shows one imaginable way in which the situation just described might translate into a inultiparty gane:

Figure 6.

Utility

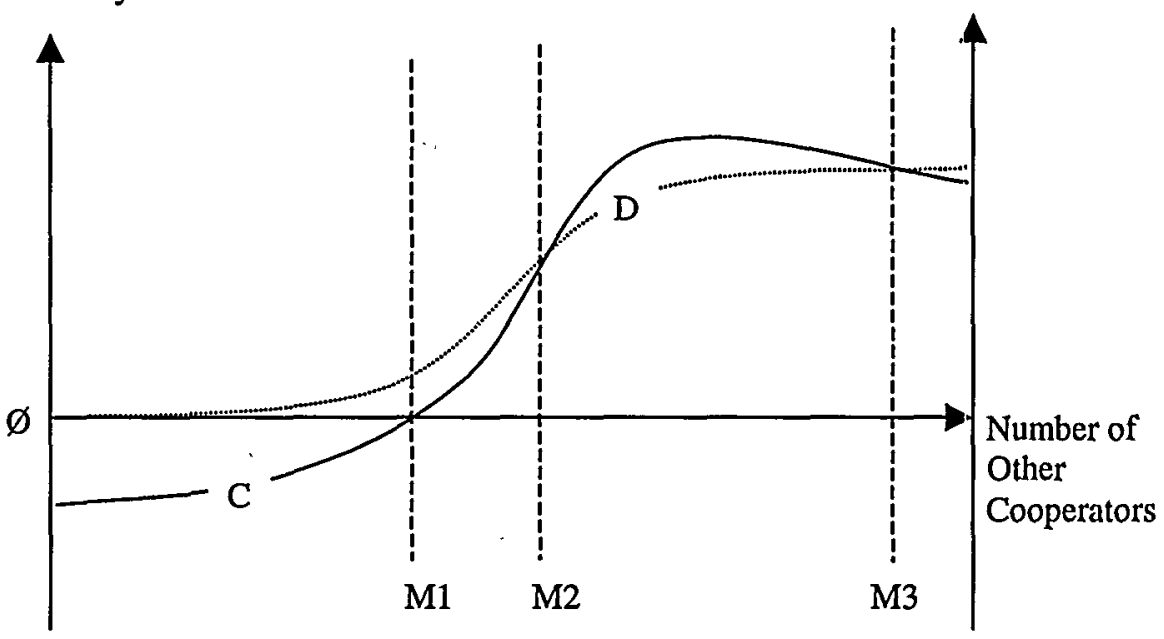

In Figure 6, the vertical axis represents utility, as viewed from the perspective of an individual decisionmaker, Irving. The horizontal axis represents the nuinber of cooperators-in our example, the number of people participating in the neighborhood watch. The $\mathrm{C}$ curve represents the utility associated with cooperation in combination with varying numbers of other cooperators. The D curve represents utility associated with defection when varying numbers of cooperators are present. The shapes of these curves and their relationship to each other are empirically unknown and may vary greatly depending not only on the kind of cooperation involved but also on the preferences and resources of the particular individual confronting the choice. 
This basic situation, as drawn, constitutes an Assurance Game. If Irving expects at least M2 other people to cooperate, he will do best by cooperating as well. Yet beyond point M3, the additional gains produced by further cooperation are so minimal that additional cooperators incur net costs by cooperating. If there are at least M3 cooperators, Irving would do better to free-ride on their efforts. This is not particularly problematic unless it leads to resentunent on the part of others and an unraveling of the cooperation pacts that the others have inade. Defection begins to be tempting if cooperation levels fall below M2. To the left of point M1, cooperation is not selfsustaining. In other words, it takes at least M1 cooperators to do better than everyone would do in a world of universal defection. If Irving expects less than M1 other people to cooperate, he should definitely defect. Unless at least this minimum number can agree to work together, the group will remain in the far left-hand portion of the graph, where defection is the dominant strategy and where there are insufficient cooperators to adopt a different strategy.

Figure 6 might seem to inspire optimism. After all, an Assurance Game is a nuch easier type of collective-action problem to solve than a Prisoner's Dilemma. But user heterogeneity adds an important wrinkle to this picture. In our simplified two-person game, both people were fully capable of cooperative action; they shared identical preferences and symmetrical payoffs. These same preferences and capabilities were then ascribed to Irving, the individual decisioumaker in the multiparty game presented in Figure 6. But not all of the players in a given multiparty game will confront the same payoff schedule that Irving faced. Due to differences in capabilities and preferences, the game may look quite different from other perspectives. In fact, the intrapool cooperation game is only an Assurance Gaine for some of the participants. If those participants recognize that most others view defection as an unambiguously dominant strategy, they may lose hope of getting enough other cooperators to achieve the quality improvements they seek. ${ }^{191}$ Likewise, if some users are incapable of cooperative behavior, a high-quality public good can be provided only if enough other capable and willing users in the pool actually cooperate.

For example, consider how this saine decision (whether or not to participate in a neighborhood watch) might appear to three additional fictitious decisionmakers: Greta (a gang member), Horace (a homebound man), and Josie (an associate at a law firm). For Greta, the sanction for participating might range from social ostracism to overt violence, while the benefits of a safer neighborhood are of no value to her. For Horace, participation is virtually impossible (assuming he cannot conduct surveillance froin his rear window). Horace has a real interest in a safer neighborhood-it would raise his home's value, which he plans to borrow

191. See Lewinsohn-Zamir, supra note 97 , at $392-99$ (discussing hopelessness as a risk in an Assurance Game). 
against to cover his mounting health-care costs-but there is no feasible way for him to participate in bringing it about. For Josie, participation might mean dropping the ball in the middle of important litigation or sabotaging her billable-hours target for the month. Because Josie can afford to take a taxicab home every might, lives in a building with a doorman, and plans to move as soon as her student loans are paid off, ${ }^{192}$ she does not have a particularly strong interest in the safety of the neighborhood as a whole.

In all three cases, though for vastly different reasons, the costs associated with participating in the watch are prohibitively high relative to the perceived benefits. Horace is willing to participate but is unable to do so; Greta and Josie are physically able to participate but are unwilling to do so. While Horace, Greta, and Josie may seem like hard cases, one can imagine their abilities and preferences changing over time so that participation would become a viable strategy. In the next section, I will consider some possible mechanisms through which users might be transformed into cooperating, quality-enhancing users.

\section{Strategies for Improving Intrapool Outcomes}

In the face of user heterogeneity, obtaining the necessary quantum of participation is no simple matter. We will want to consider ways of changing perceived payoffs to make cooperation a viable or dominant strategy for as many users as possible. The best solution is to make cooperation valuable in itself, rather than costly, for most users. This would turn the situation into a nongame in which enhancing quality is an automatic byproduct of maximizing one's own utility. This is already the case for certain kinds of "participatory goods" such as culture, which can only be enjoyed through participation. ${ }^{193}$ It can be made the case for goods such as neighborhood security as well, if neighborhoods can be structured in ways that make "patrolling" the neighborhood not a chore but an unconscious by-product of going about one's daily life and enjoying ordinary neighborhood interactions. As Jane Jacobs explaims, "The safety of the street works best, most casually, and with least frequent taint of hostility or suspicion precisely where people are using and inost enjoying the city streets voluntarily and are least conscious, nonnally, that they are policing." ${ }^{194}$ Here, we might think about the ways that neighborhoods and schools can be made more "userfriendly" - that is, more conducive to quality-enhancing cooperative use. ${ }^{195}$

192. Expected mobility is likely to matter a great deal in individuals' assessments of the perceived benefits of cooperative action. See infra text accompanying notes $236-48$ (discussing the role of stability and expectation of future interactions in determining intrapool cooperation levels).

193. See Réaume, supra note 41, at 10-11 (discussing "participatory goods").

194. JACOBS, supra note 49 , at 36.

195. See infra text accompanying notes $285-87$ (discussing this point in the context of zoning); see also Frug, supra note 1, at 1090-92 (discussing potential to transform communities along the lines urged by the "new urbanists"). 
In some crime-riddled neighborhoods, of course, casual use of the streets is not costless and cannot immediately be made so by design. In such a case, cooperative action among residents may first be necessary to reduce the costs of using the streets and to establish and reinforce norms that effectively raise the price of engaging in quality-detracting behaviors. ${ }^{196}$ This may require concerted efforts that transform otherwise uninvolved residents into active quality-enhancing participants. In Chicago, there have been a number of successful grassroots efforts to imcrease citizen participation in neighborhood security. ${ }^{197}$ Such efforts do their work through social norms-encouraging cooperation among law-abiding citizens and discouraging aberrant behaviors. ${ }^{198}$ For example, faith-based initiatives, such as prayer vigils, have been used to reduce crime in neighborhoods on Chicago's South Side. ${ }^{199}$ These vigils help to support and legitimize community policing efforts and serve as "a visible display of community solidarity against crime." ${ }^{200}$ As Dan Kahan explams, such vigils also encourage cooperative behavior among neighbors:

[T] he vigils foster trust and habits of cooperation among law-abiding residents themselves. Crime and social alienation reinforce each other: Rampant crime breeds distrust among neighbors; distrust weakens citizens' willingness to watch out for each other's interests and to contribute to the maintenance of the community institutions that conventionally transmit law-abiding norms; these conditions lead to more crime. ${ }^{201}$

Other community-based efforts have also been successful in breaking this cycle-agaim by engaging users directly and fostering intrapool cooperation and quality-enhancing behaviors. Sone of Chicago's "CAPS" (Chicago Alternative Policing Strategy) programs, such as "Operation Beat

196. It is likely that another form of collective action-gang activity-greatly mises the cost of such efforts in some neighborhoods. See WESLEY G. SKOGAN \& SUSAN M. HARTNETT, COMMUNTYY POLICING, CHICAGO STYLE 174-75 (1997) (describing a community's "March for Peace," which drew ridicule from gang members and which some residents avoided, fearing gang retaliation). Chicago's gang-loitering ordinances have attempted to raise the cost of such illicit collective activity. The original gang-loitering ordinance was struck down as unconstitutionally vague, see City of Chicago v. Morales, 527 U.S. 41, 51 (1999), but a new, more narrowly tailored ordinance has simce been enacted. See Fran Spiclman ct al., City's Hands Tied on Gangs; Police Struggle with Loitering Crackdown, CHI. TRIB., July 21, 2000, at 1, 2001 WL 6686678 (reporting enforcement difficulties associated with the new ordinance). See generally TRACEY L. MEARES \& DAN M. KAHAN, URGENT TIMES: POLICING AND RIGHTS IN INNER-CITY COMMUNITIES (1999) (discussing the gang-loitering law and other crime-control techniques implicating constitutional rights).

197. See Dan M. Kahan, Privatizing Crininal Law: Strategies for Private Norm Enforcement in the Inner City, 46 UCLA L. REV. 1859, 1865-72 (1999) (describing prayer vigils in Chicago).

198. See id. at 1860 (recognizing the power of social norms as an altemative approach to reducing crime).

199. Id at 1865 (discussing Tracey Meares's work).

200. Id.

201. Id. (citations omitted). 
Feet," work by "organizing large numbers of law-abiding citizens to occupy the streets of disorderly neighborhoods during times when those streets might otherwise have been expected to be the center of criminal activity."202 Because these initiatives directly involve community members, they can draw on recognized sources of legitinlacy within the community and avoid the tensions that would be associated with a heightened police presence. ${ }^{203}$ To the extent these and other measures foster and reinforce informal social controls within families, peer groups, and schools, they have great potential to address delinquency. ${ }^{204}$

In the education context, transforming users might mean providing parents in troubled areas with the resources and skills that they need to help their children become quality-enhancing participants in their schools. One of the most hopeful empirical findings is that attitudes and behaviors in one family can "rub off" on other families through peer contacts in schools. ${ }^{205}$ This dynamic multiplies the effect of each positive (or negative) change in user behavior. School policies and institutional choices (themselves the product of voice or of prior collective action) may also affect the cost of cooperation within a given user pool. ${ }^{206}$ In a highly disciplined school setting with few distractions, for example, students may find it less costly to pay attention. Likewise, if learning can be made intrinsically rewarding for students, intrapool cooperation would yield positive benefits and would be pursued for its own sake.

Parents and other user-pool members can also be organized to develop and reinforce relevant quality-enhancing norms in schools (as well as in the streets) and to present a united front against disruptive conduct. The notion of accountability could be widened-by the pool members themselves-to apply to the actions of parents and students, not just to the actions of teachers and administrators. For example, the Chicago public schools are experimenting with report cards which rate parents on such criteria as getting the child to school on time, preparing the child for the school day, and having the child turn in homework. ${ }^{207}$ While it is likely that parents would view

202. Id. at 1869 (discussing these programs and citing empirical work in SKOGAN \& HARTNETT, supra note 196).

203. See id. at 1869, 1871-72; Sampson \& Raudenbush, supra note 50, at 612 (discussing the importance of informal social control in controlling neighborhood disorder).

204. See ROBERT J. SAMPSON \& JOHN H. LAUB, CRIME IN THE MAKING: PATHWAYS AND TURNING POINTS THROUGH LIFE 96, 119 (1993) (discussing the family's role in providing informal social control in preventing delinquency and noting the significance of the social processes of family, school, and peers in explaining delinquency).

205. See Liebman, supra note 3, at 293 (noting that "a fourth to a third of the effect of socioeconomic status [on academic outcomes] comes not from the wcalth and educational attainments of Jane's and Johnny's own parents but from the wealth and attainments of their classmates' parents").

206. Because of user heterogeneity, however, wbat works to induce cooperation within one user pool may not be equally effective with a differently conposed user pool.

207. See Michael Martinez, Parents Will Get Own Report Cards, CHI. TRIB.. Sept. 22, 2000, at 6, 2001 WL 3711687. 
these report cards with animosity if they were received from teachers or administrators whon they already view with suspicion, ${ }^{205}$ similar concepts imitiated by the parents themselves could carry real clout. Being given a "bad grade" by a teacher whom one neither likes nor trusts might merely replicate the parents' own negative school experiences; receiving a "bad grade" from one's neighbors and peers could amount to a powerful social sanction that could reinforce quality-enhancing norms. ${ }^{209}$

Another possibility is to provide direct incentives for quality-enhancing behaviors among students. A growing trend has been to reward desirable student behaviors (attendance, attentiveness, good grades, and so on) with prizes such as food, outings, and even relief from final examinations. ${ }^{210}$ Some local businesses have gotten into the act by awarding various sorts of food prizes and merchandise discounts for good grades on student report cards. ${ }^{211}$ While these tactics remain controversial, the basic idea of seeking to transform user behavior by altering perceived payoffs makes good sense. Arguably, it might be better to try to effect this transformation through norms or social rewards. Yet it is possible that some of these prizes catch the attention of the truly relevant norm-forming group-other children or teenagers-and perhaps help to encourage a norm towards achievement.

In sone contexts, there may be practical problems with identifying and rewarding quality-enhancing behaviors. For example, if much of the qualityenhancing behavior that occurs in neighborhoods is largely unconscious and involves simply being out and about on the streets, ${ }^{212}$ there would be no nieaningful way to measure and reward individual contributions to neighborhood safety.

Where measures can be devised that work to induce increased intrapool cooperation, this might be expected to have a snowball effect on quality. First, cooperation within the pool is likely to spur more cooperation among

208. The parental report cards in Chicago have indeed been criticized on this ground. See, e.g., id. ("Critics contend the checklist could create hostility between parents and teachers...."); John Simmons, A Recipe for Alienating Already-Alienated Parents, CHI. TRIB., Aug. 20, 2000, at 19, 2001 WL 3708767 ("Until we find a way to bridge the gulf of fear, distrust, cultural differences, limited English proficiency and education levels, any 'evaluation' is likcly to be seen by parents as just another barrier to participating in their children's education.").

209. See Kahan, supra note 197, at 1872 (discussing "private shaming" as a potential tool for altering norms and behavior).

210. See, e.g., Linda Perlstein, The Sweet Rewards of Leaming; Teachers Motivate Students with Tokens for Candy and Fries, WASH. POST, Nov. 14, 1999, at Al, 1999 WL 23314700; St. Vincent Program Encourages Good Grades; Catholic School Youngsters Who Eam an A in Academic Subjects Will Receive Pizzas, Zoo and Museum Tickets, INDLANAPOLS STAR, Sept. 19. 2000; at D3; Kellie Patrick, A Bribe Offered to Boost Learning; For Attendance, Boca Principal Would Ax Finals, SUN-SENTINEL (Fort Lauderdale), Mar. 24, 2000, at Al, 2000 WL 5648377.

211. See, e.g., Elizabeth Kelleher, Good Deals as Easy as A-B.C; Some Stores IVill Let You Cash In on Your Report Card, WASH. POST, Nov. 3, 2000, at C13, 2000 WL 25425951.

212. JACOBS, supra note 49 , at 36. 
existing pool members. ${ }^{213}$ Second, as quality increases, more qualityenhancing users are inclined to enter the pool and to stay there, even when they have the opportunity to leave. ${ }^{214}$ This second effect means that the outcome of the intrapool game has real implications for the "choice of pool" game. As this suggests, neither the "choice of pool" problem nor the "choice of action within the pool" problem operates in isolation. It is necessary to examine the interactions not only within these games but also between the games.

\section{The Interdependence of Interpool and Intrapool Decisions}

The two collective-action problems just described-the first involving choices among pools $\mathrm{s}^{215}$ and the second involving intrapool choices ${ }^{216}$-are linked im important ways. The most important and overarching link is that the outcome of both strategic interactions affects the total number of qualityenhancing users and the quality of the local public good they are producing. However, the two games are not played independently and their results merely summed arithmetically-instead, they interact with each other. Therefore, addressing one collective-action problem may make the solution of the other collective-action problem either easier or more difficult. For example, one of the best ways of heading off potential intrapool collectiveaction problems may be to find ways to employ signaling and screening devices so as to "pool up" with like-minded persons who are both capable of and committed to cooperation. But such devices will have a sorting effect, with implications for the "choice of pool" problem. Conversely, measures designed to address the "choice of pool" problem may have unintended consequences for user-pool characteristics such as size and stability, and may thereby decrease the amount of cooperation occurring within a pool.

\section{A. Achieving a Critical Mass}

Figure 7 reproduces the quality curve that appeared in Figure 1 and adds some numeric benchmarks; it brings us full circle to the place our analysis began.

213. See generally Robert Sugden, Reciprocity: The Supply of Public Goods Through Voluntary Contributions, 94 ECON. J. 772 (1984) (discussing the theory that people will reciprocatc when other people contribute to the provision of a public good); id. at 783 (reporting "some experimental evidence that people are induced to contribute more to public goods and charitable activities by seeing other people contributing") (citing J.H. Bryan \& M.A. Test, Models and Helping: Naturalistic Studies in Aiding Behaviour, 6 J. PERSONALITY \& SOC. PSYCHOL. 400 (1967)).

214. For example, in the absence of attrition, neighborhoods and school districts can bo expected to "grow" a middle class over time. JACOBS, supra note 49, at 282 ("[C]ities necd not 'bring back' a middle class ... and carefully protect it like an artificial growth. Cities grow the middle class.").

215. See supra Part II.

216. See supra Part III. 
Figure 7.

Quality

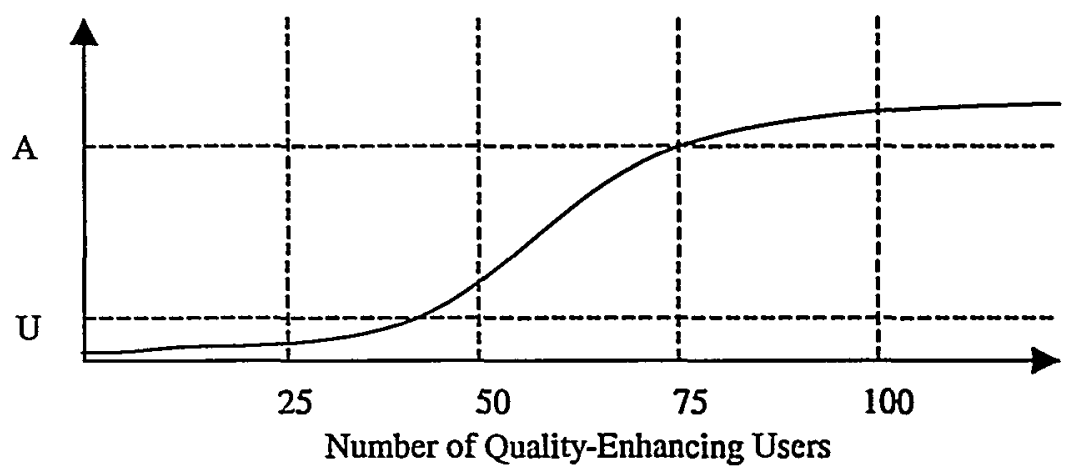

Just as in Figure 1, the horizontal axis in Figure 7 represents the number of quality-enhancing users, the vertical axis represents the quality of the local public good, and the curve represents one possible relationship between these two factors. The area above the top dashed line represents an unambiguously acceptable level of quality, and the area below the lower dashed lines represents an unambiguously unacceptable level of quality. Between these two lines, opinions vary with tastes. The vertical lines marked $25,50,75$, and 100 correspond to the number of quality-enhancing users-that is, users who are both willing and able to cooperate. On this graph, obtaining an unambiguously acceptable level of quality requires assembling at least seventy-five quality-enhancing users in the pool. As the preceding discussions suggest, this can be done in two ways-either by attracting or retaining people who are already quality-enhancing users or by transforming current users into quality-enhancing (cooperating) users.

The outcoines of the interpool and intrapool games described in Parts II and III will affect the number of quality-enhancing users. Because achieving the inagic number of quality-enhancing users is the goal, it would not seem to inatter how many of these quality-enhancing users are lured into the pool froin without and how many are "grown" from within-any combination of quality-enhancing users froin any source whatsoever would seem to do the trick. This is technically true, but a little inisleading. The fact that a person is a quality-enhancing user (or not) in one user pool does not inean that same user will also be a quality-enhancing user (or not) in a different user pool. A student who makes wonderful contributions in a relatively sheltered, nurturing classroonr environment inight be cowed into silence if inoved to a new user pool; likewise, a student who is pressured into underachieving in one user pool inight quickly become a quality-enhancing user if switched to a different setting dominated by different internal norms.

Simply adding more users who are currently quality enhancers in their own user pools inay have unintended consequences, either by triggering changes in those users (e.g., they stop being quality-enhancing after being 
switched to a new user pool) or in the pool itself (e.g., by changing the size, stability, or other pool characteristics which bear on the ease with which pool members cooperate with each other). Every change in the membership and dynamics of a given user pool will have an impact on the intrapool dynamics, including the prevailing norms within the pool. ${ }^{217}$ These intrapool dynamics will, in turn, influence quality and thereby affect the decisions people make when choosing among user pools. Those choices will, in turn, change the internal dynamics within the pool, and so on.

For example, a user pool might start off with fifty quality-enhancing users, might then lose half of these to suburban or private alternatives, and then might undertake intensive programs to turn more of the current users into quality enhancers. Twenty current users might form a pact to engage in quality-enhancing behaviors, bringing the total back up to forty-five. This might improve quality enough to attract ten new quality-enhancing users. However, three of the newly attracted quality-enhancing users might have trouble adapting to the new environment and might cease to cooperate, and the influx of new people might change intrapool dynamics enough to make two of the home-grown quality-enhancing users stop cooperating. Meanwhile, the successful new quality enhancers might cause norms to reach a tipping point, resulting in social pressures that would transform a inajority of users into quality enhancers. ${ }^{218}$ These fluctuations would likely unfold over a period of years. In the meantime, membership in the user pool will be influenced by other factors as well, such as changes in local economic conditions.

In the next two sections, I consider two sets of relationships between the "choice of pool" game and the "choice of action within the pool" game. In subpart B, I note that expectations about cooperation levels within various pools play a role in the "choice of pool" game, and I consider ways that quality-enhancing users might engage in signaling and screening behaviors to sort themselves into pools with other people whom they expect to be quality enhancers. In subpart C, I consider how various characteristics of user pools-all of which might be impacted by efforts to solve the collectiveaction problem presented by the "choice of pool game"-may affect the levels of cooperation within the user pool.

\section{B. Signaling and Screening}

An individual will choose to opt out of a default pool only when she expects to realize a higher consnmption value in some other pool. ${ }^{219}$ That mdividual's expected payoff froin opting out will depend in large part on her

217. See Robert C. Ellickson, The Market for Social Norms, 3 AM. L. \& ECON. REV. 1, 24 (2001) (discussing how change in group membership can affect group norms).

218. See id. at 34 and sources cited therein (discussing the "tipping point" for norms).

219. In Part II, supra, the game I constructed assumed that a higher payoff was available by opting out. 
perceptions and predictions about the alternative user pool. ${ }^{220}$ In effect, she will be trying to determine whether this is a pool with a high proportion of cooperative, quality-enhancing users. ${ }^{221}$ By the same token, a decision to leave the default pool will be influenced by one's perceptions and predictions about the default user pool. It is therefore helpful to consider the ways in which people obtain information about the likely intrapool interactions, since their perceptions about these interactions will often drive their decisions about user pools. Willingness to cooperate in a user pool is a private attribute that is not readily verifiable. However, people may use techniques of signaling and screening to increase their chances of "pooling up" with other cooperators. ${ }^{222}$ These techniques may contribute to the sorting of users into stratified user pools.

Because not all users are equally well-equipped to cooperate, players in the "choice of pool" game might scan the available pools for a proxy characteristic such as wealth that is thought to be correlated with at least the ability (if not necessarily the inclination) to cooperate. An individual might also look for a track record of excellent outcoines associated with past cooperative behavior (high test scores or low crime rates). More interestingly, a person might look for pools of users who are signaling that they are not only able but are also willing to cooperate. It is possible that by expending substantial sums to join exclusive pools, users are signaling that they are persons who value education or security very highly. 223 person who places a high valuation on these goods may be more likely to cooperate as a quality-enhancing user within that user pool. ${ }^{224}$ It is often noted that the

220. Expected payoffs will, of course, also be affected by perceived differences in exogenous factors-the qualifications of the teachers or the number of police officers, for example.

221. I do not mean to suggest that individuals put the matter in quite these terms. The task is probably perceived more vaguely as "finding a good school" or "finding a safe neighborhood." But this inquiry will necessarily require considering and making predictions about user pools.

222. See generally DOUGLAS G. BAIRD ET AL,, GAME THEORY AND THE LAW 122-58 (1994) (discussing signaling and screening as mechanisms for conveying and obtaining otherwise nonverifiable information).

223. See Liebman, supra note 3, at 274 (arguing that both suburban and private schools "are populated by parents and students who, in the clearest possible way-cash on the barrel head, and a lot of it-have manifested well-developed tastes for education"). A person who does not value education highly could also engage in high spending on education, but because this would presumably yield her a lower utihty payoff than alternative expenditures for something she does value highly (such as a nice automobile), she would be less likely to do so than somcone who genuinely values education. However, it is possible that there are other benefits associated with high spending on education (such as the status associated with telling people that your child attends a particular school), that might yield enough utility to make high spending on education worthwhile for some who do not value the education itself. If so, this would make high spending on cducation a less reliable signal of one's private valuation of education. In addition, some people who valuc education very highly simply lack the funds to signal this preference.

224. For example, a person who highly values education would be expected to highly value the results of cooperative action undertaken to improve education, and might also be expected to experience low or negative costs in engaging in quality-cnhancing behaviors relating to education. In other words, for such a pesson the benefits of cooperative action would decisively outweigh the costs, making her very likely to cooperate. 
gates and guards around private communities are relatively ineffectual against crime. ${ }^{225}$ One reason why these communities may remain popular despite this lack of efficacy is that the decision to live in a gated, guarded community is a powerful signal of being a security-minded individual. Of course, unless this security mindedness is expressed in some cooperative action (such as watching out for others in the neighborhood) the results may be objectively no better than those achieved in a more randomly formed user pool, such as an urban neighborhood. ${ }^{226}$

Another way of signaling a commitment to cooperation (and hence to quality) would be to construct precommitment devices that will require future cooperation, or to create screeming devices that will limit entry. Manageinent might add these devices as a result of an exercise of voice, or the ineasures might be impleinented by the users themselves. Either way, such devices may have the effect of structuring intrapool cooperation and inay therefore affect the "choice of pool" decision. Some exclusive pools have embedded mechanisms for enforcing cooperation within the pool. These can also be thought of as exclusion mechanisms designed to ensure a high ratio of quality-enhancing activity (and a low or nonexistent ratio of quality-detracting activity) within the user pool. For example, private schools may require that students exhibit a certain demeanor and level of achievement or risk being expelled. Gated communities may prohibit certain behaviors that are thought to detract from the quality of the neighborhood atmosphere. 227

Suburban public schools and neighborhoods also employ screening devices. Zoning regnlations often operate to maintain a price of admission to the suburbs (the cost of housing) that is outside the reach of a large proportion of the population. To the extent wealth is correlated with qualityenhancing behaviors, this screening mechanism may operate as a rough proxy for the inore direct exclusionary mechanisins that private user pools employ. ${ }^{228}$ Of course, all user pools have some exclusion mechanisms, insofar as bad actors inay ultimately be expelled from school or incarcerated for committing crimes in a neighborhood. How well these exclusion inechanisms will work in practice depends on the other users within the pool.

225. See Low, supra note 119, at 53-54 (presenting interview excerpts in which members of gated communities acknowledge that the security provided by the gates and guards is largely illusory).

226. It is possible, however, that the illusion of safety enjoyed in a gated community contributes to actual safety to the extent it encourages law-abiding people to make use of the community's sidewalks and public spaces. See supra text accompanying notes 49-54.

227. See SIDNEY BROWER, GOOD NEIGHBORHOODS: A STUDY OF IN-TOWN \& SUBURBAN RESIDENTIAL ENVIRONMENTS 70-71 (1996) (discussing privatized living arrangements in whiel1 "[g]atekeepers, doormen, or concierges are used to screen outsiders" and in which "[t]hcre is a scrious effort to avoid internal conflict by ensuring that residents conform to common norms").

228. See Frug, supra note 2, at 30 (observing that "the current feel of a prosperous suburban high school is more like that of a private school than that of a central city high school" and noting that "exclusive' quality is simply maintained through zoming rather than an admissions office"). 
Because these exclusion mechanisms often operate rather weakly and may completely fail to ensure a critical concentration of quality-enhancing users in the pool, they are unlikely to operate as strong signals of cooperation unless the users take concerted action with respect to their enforcement. Examples of such concerted action might include ubiquitous "We Call Police" signs in the windows of imdividual homes or various sorts of "zerotolerance" policies adopted in the school setting. ${ }^{229}$

\section{Pool Characteristics and the Dynamics of Cooperation}

The size, composition, and stability of user pools may also have important implications for the degree of intrapool cooperation and the resulting amount of quality-enhancing behavior. Each of these factors may be affected by the legal arrangements governing the "choice of pool" decision.

1. Size.-Where a user pool is small, cooperation might prove easier. ${ }^{230}$ On the other hand, small shifts in behaviors or membership will have a larger impact in a small group, for good or ill. Size may also be correlated with other factors which could have an independent impact on quality, such as the range of class offerings available in a school, the amount of mdividual attention that students receive, or the housing density in a neighborhood setting. Thus, it is likely that changes in user-pool size may have an impact on both cooperation and quality, but it is not obvious in which direction these changes would go.

The user pools under discussion here-neighborhoods and schools-do have some functional size limits. As discussed above, ${ }^{231}$ a strategy of expanding the default pool to encompass the suburbs as well would not really succeed in creating a unitary user pool. Doing this would centralize administrative functions and financing (which might well have impacts on quality), but it would not cause users to interact as one oversized user pool. Instead, users would continue to interact at the local school and neighborhood level. Within these functional bounds, however, the size of the

229. There may be independent normative reasons that a policy like "zero tolerance" in the schools would be undesirable. To the extent administrators feel constrained by such policies to punish trivial violations, it can result both in unfair punishments and a loss of legitimacy for administrators. See Margaret Graham Tebo, Zero Tolerance, Zero Sense, A.B.A. J., Apr. 2000, at 41.

230. See OLSON, supra note 22, at 53-57 (discussing the advantages of small groups). James Buchanan has argued that "[o]ther things [being] equal, the smaller the number of persons with whom a person interacts, the higher the likelihood that he will seem to behave in accordance with sontething akin to the Kantian generalization principle: in our terminology, that he will provide public good in his clioice behavior." James M. Buchanan, Markets, States, and the Extent of Morals, 68 AM. ECON. REV. 364, 365 (1978). It is unclear whether this supposition is empirically true. See Paul Pecorino, The Effect of Group Size on Public Good Provision in a Repeated Game Setting, 72 J. PUB. ECON. 121 (1999).

231. See supra text accompanying notes $158-59$. 
user pool may be determined in part by applicable law and policy governing the formation of user pools.

2. Homogeneity and Diversity.-The legal arrangements governing the formation of user pools for schools and neighborhoods will have some impact on the degree of homogeneity or diversity of those pools. For example, zoning ordinances often maintain residential homogeneity along socioeconomic lines. Some have suggested that groups that are homogeneous will be able to cooperate with greater ease. ${ }^{232}$ It is clear that some kinds of homogeneity, such as having common goals and interests, would unambiguously promote cooperation (at least with respect to those common goals and interests). Indeed, some of the heterogeneous preferences and costs discussed earlier could create barriers to cooperative action. It is less clear whether other kinds of homogeneity would independently promote heightened cooperation. Many imdividuals have preferences of some sort with respect to homogeneity (in some cases desiring it and in other cases assigning negative value to it). ${ }^{233}$ These preferences may impact both their "choice of pool" decisions and their actions within the user pool.

Even if homogeneity promotes cooperation in the short run, people who learn to cooperate with heterogeneous others will likely prove more reliable cooperators across the broad range of cooperative situations they will encounter throughout life. In other words, early cooperative interactions may have positive spillovers for later cooperative interactions with different partners. In a general sense, this is what socialization is all about. To the extent preferences for certain kinds of homogeneity are based on ignorance and prejudice, these preferences could be changed through successful cooperative experiences with others. ${ }^{234}$ Because education has a special role in attempting to turn children into life-long cooperators, it would make sense in the education context to shun any short-term cooperative benefits associated with homogeneity in favor of fostering the more socially valuable skill of cooperating with heterogeneous others.

For these reasons and others, many view diversity as valuable for its own sake. Not everyone agrees, of course. Some would maintain that the

232. See NELSON, supra note 33, at 39-40 (contending that "[a] well-defined set of community objectives and a feasible plan for achieving them are much more likely to emerge when the community population is homogeneous"); Sugden, supra note 213, at 783 (conjecturing that "the more homogeneous a community is in respect of incomes and tastes, the more closely it can approach Pareto efficiency, and the greater will be its success in producing public goods through voluntary activity").

233. There is an increasing disdain for homogeneity in many communities, with diversity working as a positive selling point. See FISCHEL, supra note 30 (manuscript dated Oct. 2000 at $\$$ 3-17) (observing that "many affluent buyers are eager to avoid the modern stigma of living in a white-bread suburb"). This attitudinal trend could help to solve the "choice of pool" problem to the extent that it eliminates any extra increment of value associated with exclusivity (as opposed to quality). See supra subpart II(B).

234. See Bell \& Parchomovsky, supra note 123, at 1988-99 and sources cited therein (discussing possibility that preferences may shift as a result of integration). 
better way to foster diverse ways of life and to best meet the diverse preferences of heterogeneous individuals is to facilitate the development of many different kinds of communities. ${ }^{235}$ I will not attempt to resolve these issues here. It is simply important to note that the way in which user pools are formed will have implications for diversity and homogeneity. Diversity and homogeneity may, im turn, have implications for the utility people experience within the user pool and for the degree of cooperation they can achieve in that setting and in others.

3. Stability.-Another important factor is user-pool stability over time. It makes intuitive sense that a stable user pool will not only be more cohesive than one in which turnover is high but will also become better at working together and will therefore be able to achieve better results. Members of a stable group can learn what to expect from each other and can develop bonds of trust that will enhance their ability to achieve common goals. ${ }^{236}$ Empirical evidence suggests that members who interact as repeat-play "partners" rather than as one-shot "strangers" are significantly more willing to contribute to a public good benefiting the group. ${ }^{237}$ In addition, subjective expectations about the length of future interactions appear to affect one's willingness to cooperate. ${ }^{238}$ These findings provide another reason to question whether a market model featuring the ability to switch effortlessly among competing "products" will produce optimal results. However, enforced stability (locking in users) may not achieve the desired results either; the level of cooperation within a given pool may depend, in part, on whether users are im that pool by force or by choice.

Locking people into a particular user pool in the local-public-goods context is tantamount to locking them into a particular collective-action game-the one played within that user pool. Some empirical work on

235. See ROBERT NOZICK, ANARCHY, STATE, AND UTOPLA 309 (1974) (arguing that "if there is a diverse range of communities, then (putting it roughly) more persons will be able to come closer to low they wish to live, than if there is only one kind of community"); NELSON, supra note 33, at 43 (discussing the view that the best model for society is one "in which people with a wide diversity of views and behaviors may coexist in separate communities" and citing NozıCK, supra).

236. Sampson \& Raudenbush, supra note 50, at 612 (positing that "the shared willingness of local residents to intervene for the common good depends... on conditions of cohesion and mutual trust among neighbors" and defining the "collective efficacy" of a neighborhood by reference to "shared expectations" regarding neighborhood social control).

237. Claudia Keser \& Frans van Winden, Conditional Cooperation and Voluntary Contributions to Public Goods, 102 SCANDINAVIAN J. ECON. 23, 31 (2000) (presenting empirical work showing that there is nuch inore cooperation in contributing to public goods among small groups working together in repeated games than there is among small groups whose menbership is constantly changing).

238. See id. at 32-33 (presenting enipirical results which "suggest that cooperation is dependent on the subjects' perception of future interaction" and that "[t]he tendency to cooperate is greater when subjects anticipate prolonged interaction with others as members of a group"). Because it is the expectations that matter, even overly optimistic predictions about one's ability to leave a default pool could have an effect. See JACOBS, supra note 49, at 271 ("The key link in a perpetual slum is that too many people move out of it too fast-and in the meantime dream of getting out."). 
Prisoner's Dilemma games suggests that when both players are forced to participate in the game, there will be higher defection rates than when one or both of the players affirmatively choose to participate in the game. ${ }^{239}$ But the higher defection levels shown in the experinental setting may not reflect a behavioral change in reaction to the indignity of being forced to play a game against one's will: the defector may have been a dyed-in-the-wool defector all along who simply would have removed herself from the game otherwise. ${ }^{240}$ In contexts like education and neighborhood security, exit from the default pool does not inean avoiding strategic interactions altogether, but rather choosing to "play the game" within some other user pool. In such a situation, the people leaving the default pool are not particularly likely to be incorrigible defectors; instead, it is likely that the "super-cooperators" will want to exit if it is possible to find another user pool in which mutual cooperation is assured. ${ }^{241}$ It is unclear whether a super-cooperator locked into a default pool would be inore likely to defect in that setting. Nevertheless, it remains possible that the conditions under which one participates in interactions with others may affect the character of those interactions.

Another interesting finding from the same study was that more cooperative interactions occurred in "unilateral choice" games (in which the interaction takes place at the option of just one party and the other party cannot choose to exit froin the interaction) than in "inutual choice" games (which are played only with the assent of both parties). ${ }^{242}$ One possible interpretation of this result would be that the presence of willing participants in a given interaction has positive spillovers influencing the cooperation levels of those who are in the game involuntarily. At the same time, the fact that some participants are unable to leave may provide a level of security and stability that is conducive to cooperation. If this is so, the presence of some locked-in participants would not necessarily have negative results and might even lead to more cooperation than would occur in a world where everyone can costlessly opt out.

Whether or not mandatory lock-in mechamisms would decrease cooperation within user pools probably does not matter very much, given the constitutional and political barriers to implementing such mandatory locks.

239. See Esther Hauk \& Rosemarie Nagel, Choice of Partners in Multiple Two-Person Prisoner's Dilemma Games: An Experimental Study (July 2000) (presenting empirical work suggesting that forcing participants to participate in a Prisoner's Dilcmma game yields higher defection rates within the game than exist when participation in the game depends on the assent of one or both players), at http://www.econ.upf.es/deehome/what/wpapers/postscripts/487.pdf.

240. See id. at 14 (observing that "[i]ntending defectors are more likely to opt out than intending cooperators").

241. Indeed, the discussion in the preceding Part describes bow such super-cooperators might succeed in "pooling up" with each other. See supra subpart IV(B).

242. See Hauk \& Nagel, supra note 239 , at 9,17 (concluding that cooperation may not arise if mutual agreement is necessary). 
Yet even when "softer" locks are in place, such as financial barriers to exit, the fact that people are in a particular pool against their will may have an influence on the level of cooperation. This is particularly true where people view escape from a given user pool as imminent. For exaunple, it has been hypothesized that renters might avoid forming social attachments or having children if they expect that they will eventually purchase a home in a different neighborhood, so as to minimize later adjustment costs. ${ }^{243}$ This lack of investment in the social network might be expected to reduce their propensity to cooperate with neighbors to raise the quality of the local neighborhood and schools.

Likewise, to minimize transaction costs, people might choose to rent rather than buy if they expect to move again soon. Renters, unlike homeowners, do not have the value of their largest financial asset tied to the success of the local neighborhood and schools and may therefore be less inotivated cooperators. ${ }^{244}$ A person who buys a home, in contrast, might be more likely to "put down roots" in the community, and these roots would increase her attachment to the home and to the neighborhood. ${ }^{245}$ She will also sink significant transaction costs into the house purchase. Both the attachment and the transaction costs will make her less likely to leave. In this sense, hoineownership itself might be thought of as a type of lock, albeit one assumed voluntarily. A homeowner who plans to stay will be motivated to cooperate, both to maximize her family's consumption value and to protect her investment in her home. ${ }^{246}$ For these reasons, well-intentioned policy changes which have the effect of burdening the home-ownership decision (such as bans on home sales or a steep tax on home sales in changing neighborhoods) ${ }^{247}$ may be counterproductive.

Stability might more usefully be promoted through changes in the design of neighborhoods or in prevailing norms. For exainple, a norm in favor of loyalty to one's school or neighborhood might serve as a stabilizing force. ${ }^{248}$ Such a norm would offer a powerful counterbalance to marketoriented rhetoric which suggests that switching to a new school or neighborhood is an appropriate and even laudable exercise of consunier sovereignty.

243. Mark Dynarski, Residential Attachment and Housing Demand, 23 URB. STUD. 11, 19 (1986).

244. See FISCHEL, supra note 30 (manuscript dated Apr. 2001 at $\$ 1-2$ ) (discussing capitalization of local public services into home prices and noting that the home is the largest single asset of most individuals).

245. See Dynarski, supra note 243 , at 19.

246. See FISCHEL, supra note 30 (manuscript dated Apr. 2001 at $\$ 1-5$ ) (contending that homeowners are motivated to participate in local politics because of the impact of local-government action on their property values).

247. See Bell \& Parchoinovsky, supra note 123, at 2009-11 (discussing the possibility of deterring exit through the imposition of a steep tax on home sales in neighborhoods experiencing high turnover).

248. See HIRSCHMAN, supra note 3, at 76-105 (presenting a theory of loyalty). 


\section{User Pools and Legal Rules: Two Examples}

Understanding the significance of user participation leads to policy prescriptions with a much different focus than those which have recently dominated the debate. Vouchers and other market-oriented programs purport to improve the world by focusing on demand-side impacts on what are conceptualized as exogenously provided goods. The idea is that granting consumers sovereignty and choice will force product improvements in much the same way as it might for a consumer good like a lawnmower. "Choice" has therefore been touted as a panacea. ${ }^{249}$ The analysis in this Article suggests that product improvements must come, in substantial part, from within the user pool. This understanding of local public goods suggests a different policy focus: improving the user pool in each and every school and neighborhood.

If user pools are the key to the quality of local public goods such as education and security, and if society at large has an interest in keeping the quality of these goods above some minimum threshold, legal rules should be structured to give all user pools the best chance of achieving that quality. ${ }^{250}$ Sorting mechanisms that stratify users into pools based on criteria such as income and ability are unlikely to achieve this result. On the contrary, they are likely to result in some very troubled user pools at the bottom of the ladder, resulting in negative spillover effects throughout the relevant community. Precisely how sorting occurs under various legal rules, and precisely what the impacts of such sorting are for the affected user pools, are empirical questions that I cannot resolve here. What I can do is offer a caution, based on the theoretical observations I have outlined.

To make this caution more concrete, I will briefly discuss two controversial legal measures that affect the way user pools are formededucation vouchers and residential zoning. Each of these topics enjoys an exhaustive literature which this Article cannot even begin to plumb, and a thorough exploration of the notion of user participation as it relates to either of these topics would require another article. These final pages merely introduce some important and timely applications of the ideas in this Article.

\section{A. Education Vouchers}

The premise of education vouchers is very appealing-grant purchasing power to all families and make the schools compete for the student-

249. See, e.g., CHUBB \& MOE, supra note 42, at 217 ("Without being too literal about it, we think reformers would do well to entertain the notion that choice is a panacea."). John Witte writes of the dominance of what he terms "choice theater" in current policy debates about education. WITTE, supra note 126, at 172.

250. I am assuming that communities cannot afford to have even one abysmal user pool in their midst without suffering serious negative spillover effects-in other words, that the goal just outlined is defensible on utilitarian grounds. From the perspective of social justice, the case for working to improve all user pools is even more clear. 
customers. ${ }^{251}$ The idea resonates not only with those who believe in consumer autonomy and free-market choice but also with those who are troubled by the inequities built into the current system of education delivery. ${ }^{252}$ Allowing only the wealthy to opt out of troubled public schools seems deeply unfair and offends basic notions of equality of opportunity. ${ }^{253}$ Thus, vouchers occupy an odd space in the public discourse: they seek to reduce the ability of the wealthy to acquire a "better" education on the open market, but they attempt to do so by expanding, rather than contracting, the role of the market in allocating educational opportunities. This seeming paradox is explained by voucher proponents' faith in the power of competition to improve the quality of education.

Schools will have to improve under a voucher system, we are assured, or they will simply go out of business like any other shoddily run enterprise. ${ }^{254}$ At least as told in its purest form, this story casts school administrators into a role not unlike that of competing providers of an exogenously provided good like long-distance telephone service. When telephone companies compete to provide long-distance service to customers, their goal is straightforward-subscribe as nany customers as possible. The personal characteristics of the customers (aside from the threshold question of solvency) have no impact on the good itself. Therefore, long-distance service providers are not selective about whom they sign on. The architecture of nationwide long-distance service is such that there are no immediate limits to the number of subscribers who can be added. In this context, competition for customers works very well, and there is indeed every incentive for the providers to try to offer the best product at the lowest price.

251. See, e.g., Martha Minow, Reforming School Reform, 68 FordHAM L. REv. 257, $263-72$ (1999) (setting forth and critiquing eight assumptions about competition that underlic the schoolchoice movement); Trebilcock et al., supra note 2, at 209 (discussing voucher supporters' argument that "the threat of exit will induce supphiers to produce goods and services that are highly responsive to citizen preferences and to do so in the most efficient manner").

252. I do not mean to suggest that these are mutually exclusive categories, only that some rather surprising alliances have emerged in the debate over education vouchers.

253. See, e.g., Jay Mathews, Group Pushes for Vouchers, WASH. POST, Dec. 19, 2000, at http://washingtonpost.com/ac2/wp-dyn/A26599-2000Dec19?language=printer (last visited Oct. 17, 2001) (arguing that "it is hard to imagine how any affluent parent, blessed with the ability to choose private or pubhic [schools], could in good conscience tell a D.C. shop clerk she can't have a voucher"); Jodi Wilgoren, Young Blacks Turn to School Vouchers as a Civil Rights Issue, N.Y. TIMES, Oct. 9, 2000, at Al (disenssing the pro-voueher campaign launched by a new national organization, the Black Alliance for Educational Options).

254. See, e.g., Ronald A. Cass, Privatization: Politics, Law, ond Theon, 71 MARQ. L. REv. 449,460 (1988) (discussing the assumption that, under vouehers, "any school, public or private, that did a good job of educating children at a reasonable price would flourish ... while schools that did a poor job would go out of business, sell out to better managers or take other steps to improve their performance in order to attract voucher dollars"); Minow, supra note 251, at 264, 266-67 (questioning the assumption that good schools would cxpand and bad schools would shut down under a voucher system). 
As should be apparent by now, schools diverge in important respects from this model. For one thing, schools are finite structures that can only accept a limited number of students; thus, maximizing the number of customers cannot be their central goal. More important, schools' success is bound up in their students-those important coproducers of the educational product. In other words, to succeed, a school requires a sufficient pool of quality-enhancing users. Indeed, a school will seek to pack its ranks with quality-enhancing students and to exclude any students who would have a negative impact on the school's quality. ${ }^{255}$ The reason for this is simple. A pool filled with quality-enhancing users will be very easy to serve because the students, in large part, help themselves learn. Good teachers and administrators could be expected to flock to such a school and to accept much lower pay than they might demand to teach a harder-to-serve segment of the population. Supported by helpful parents and attentive, smart, wellbehaved students, schools can easily achieve excellent educational outcomes. In a pure market setting, this would enable the school to charge a premium price and also maintain the selectivity that will ensure continued excellence.

Under a voucher system, the school's ability to ration spots on the basis of price will likely be partially or fully suppressed. ${ }^{256}$ In order to fulfill the market-oriented promise of vouchers, however, the school must be granted some selectivity in admissions. If schools can exercise this selectivity freely, the result would be a stratified ladder of user pools sorted by ability. ${ }^{25 ?}$ Despite this sorting effect, will there also be laudatory competition among schools that will "raise all boats"? It is certainly possible that schools would compete based on inputs (adding teachers or building more and better buildings), but it is unclear how efficacious these inputs would be in

255. See Cass, supra note 254 , at $487-88$ (discussing incentives to serve "the low-cost, highdemand segment of consumers"); Trebilcock et al., supra note 2, at 212-13 (discussing the risks of "cream skimming").

256. See WITTE, supra note 126 , at 82 (noting that the Milwaukee program rcquired schools to admit students randomly and were therefore unable to "cream-skim"); Liebman, supra note 3, at 287-92 (detailing the ways in whicl voucher programs disable market mechanisms).

257. See Liebman, supra note 3 , at 284-87 (describing the stratification that might be expected under a voucher program). Empirical work in Europe indicates that school-choice plans do tend to increase stratification. See John S. Ambler, Who Benefits from Educational Choice? Some Evidence from Europe, in MARKET APPROACHES TO EDUCATION: VOUCHERS AND SCHOOL CHOICE, supra note 24, at 353, 372 (concluding, based on the European results, "that the primary negative effect of school choice is its natural tendency to increase the educational gap betwcen the privileged and the underprivileged."). Similar empirical results have been observed in New Zealand, where an across-the-board scbool-choice plan was recently implemented. See generally EDWARD B. FISKE \& HELEN F. LADD, WHEN SCHOOLS COMPETE: A CAUTIONARY TALE (2000) (presenting results of this empirical study). Although the New Zealand schools were not permitted to expressly ration spots by price, there was a good deal of sorting by income based on (1) access to transportation to reach the school of one's choice and (2) various sorts of activity fees which were attached to desirable curricular and extracurricular programs in the top schools. See id. at 208-09. In addition, oversubscribed schools were allowed to select students, with the result that students were often competing for the schools rather than the other way around. Id. at 222-23. While more students were able to attend better schools after the choice plan's inception, the schools (and students) at the very bottom of the ladder were made worse off. Id. at 231-34. 
improving education except to the extent they succeed in attracting qualityenhancing users. Such inputs cannot solve the problem of stratified user pools that results when quality-enhancing users pool together. However, as I suggested earlier, users who are in a pool from which they cannot easily exit may indeed make an effort to raise quality endogenously in order to attract or retain other quality-enhancing users. This sort of competition, which mvolves the participation of the users themselves, might well have laudatory effects across the board. But what happens if exit becomes costless? Will the few quality-enhancing users in a troubled user pool work for endogenous change in the hope of attracting more quality enhancers? Or will they seek to abandon the troubled user pool and enter into competition with other qualityenhancing users for the coveted spots in "better" user pools?

Of course, it is possible to call a program a "voucher" program and yet allow schools no power to ration seats either by price or by other admissions criteria. Where there is inore demand for a given school than the available supply of seats, rationing might be done by lottery or in accordance with soine administrator's sense of the optimum mix of students. Some of the "controlled-choice" and other pilot voucher programs in the United States follow one of these strategies. ${ }^{258}$ But it is hard to understand why any school would bother to "compete" under such a constrained voucher system beyond the minimum level required to keep its seats filled. If quality is largely determined by the concentrations of quality-enhancing and quality-detracting users in a given pool, there is nothing to be gained by attracting additional entrants who will be administratively or randomly selected. The suppression of the price mechanisin ineans that no matter how popular the school becomes, per-pupil revenue will not increase; moreover, removing the ability to ration spots on other criteria eliminates the possibility of reducing costs by selecting only easy-to-serve students. ${ }^{259}$

To be sure, the mix of user pools that results from this type of controlled-choice scheme may be normatively desirable and may generate some important benefits. Indeed, my analysis has attempted to show that reconfiguring user pools may result in real improvements. But such improvements cannot accurately be attributed to competition. The irrelevance of competition under these conditions becomes clear if we consider higher education, where "customers" similarly serve as inputs. ${ }^{260}$ If colleges and universities were suddenly forbidden to ration seats based on admissions criteria or on price and were instead assigned students through a lottery or administrative assignment program (based on the students' "wish

258. See FISK \& LADD, supra note 257, at 302-05.

259. See Liebman, supra note 3 , at 288 (discussing the loss of market discipline that occurs when the ability to compete on the basis of price is removed); Trebilcock, et al., supra note 2, at 218 (questioning whether "an intensively government-managed form of competition is likely, in practice, to yield the efficiency properties that economists often claim on behalf of unconstrained competitive markets").

260. See generally Rothschild \& White, supra note 39. 
lists"), the resulting array of educational products and student pools would not be the result of competition among the schools in any meaningful sense.

Empirical work on the effectiveness of existing, limited voucher programs in improving student performance has yielded mixed and contested results. ${ }^{261}$ But even where evidence indicates that granting students vouchers to transfer from deteriorating public schools to good private schools results in improvements in performance, this does not establish that competition is responsible for the improvements or that the programs would be successful if implemented on a broad scale. These improvements would also be consistent with a user-participation model, in which the private school receiving the new entrants has high concentrations of quality-enhancing users. These users are producing a high-quality educational product that is then consumed by the new entrants. In other words, one might expect an executive edict mandating the same transfer of a student from a "bad" school to a "good" school to do just as well at raising that student's performance. ${ }^{262}$

Some might argue that if there is any evidence that vouchers are working for some students, never mind the reason, we should eagerly embrace them. One response is that there is something very troubling about touting a program that succeeds for reasons entirely different from those proffered. A more pragmatic response is that the illusion that vouchers are "working" cannot be sustained on a large scale. If vouchers were universalized, we would expect to see one of two negative outcomes. One possibility is that the rhetoric of market competition will be taken seriously, and schools will accordingly be allowed some ability to select among students. This can be expected to result in the sorting of students into strata, with significantly deleterious effects on the sector of society that ends up at the bottom (and ultimately, these negative effects will be experienced by the community as a whole). The other alternative would require abandoning the idea of "choice" altogether, and bureaucratically orchestrating student placements to achieve the sort of user mixes that will avoid the problem of leaving behind the lowest rung in the sorting game. Given the perceived

261. See, e.g., WITTE, supra note 126, at 119-43 (presenting and discussing empirical work on student outcomes under the Milwaukee voucher program and questioning the validity of prior findings that vouchers led to improved performance); Jay Mathews, Scores Improve for D.C. Pupils With Vouchers, WASH. POST, Aug. 28, 2000, at A1, 2000 WL 25412776 (reporting study results); William Safire, Editorial, Vouchers Help Blacks, N.Y. TIMES, Aug. 31, 2000, at A25, LEXIS, News Library, NYT File (discussing results of a three-year study in Washington, New York, and Dayton by Professor Paul E. Peterson et al.); Jay Mathews, Some Researchers Question Voucher Study, WASH. POST, Sept. 19, 2000, at B4, 2000 WL 25416854 (reporting controversy over voucher study results showing gains for children in Washington, New York, and Dayton); D.W. Miller, The Problem with Studying Vouchers, CHRON. HIGHER ED., July 13, 2001, at 14, LEXIS, News Librury, CHEDUC File (discussing difficulties in designing voucher studies that are free of distortions).

262. This might not be the case if the students participating in voucher programs are selfselected and hence more motivated than a randomly chosen student. Even in that case, however, the gains would stem from the user and the user pool rather than from market discipline. 
interference with individual freedom that the latter solution would involve, and the fact that it would run directly counter to the "choice" rhetoric einployed by voucher supporters, we might expect any widespread voucher plan to contribute to further deleterious sorting among user pools.

Using voucher programs to consciously "disperse" the poor into better neighborhoods and schools presents its own risks. The notion of dispersal reflects both an awareness that users influence the quality of these goods and a blind spot about the logical implications of the policy prescription. For "dispersal" - the outflow of impoverished residents from the inner city-can only be successful if it is matched with an influx or retention of qualityenhancing users within that urban core. ${ }^{263}$ The best candidates for dispersal will be those persons who will show the largest gains as a result of moving to a better neighborhood or school. Because these candidates are likely to be the best quality enhancers within their current user pools, their dispersal can only further degrade the goods being consumed by those remaining in the default user pool.

In short, the notion that vouchers can instantly transform education through the simple operation of competitive market forces is illusory. ${ }^{264}$ What voucher success stories mstead demonstrate is that moving a student froin an environment dominated by quality-detracting users into an environment dominated by quality-enhancing users can do wonders for that student's achievennent. ${ }^{265}$ Moving a family from an unsafe neighborhood into one filled with quality-enhancing consumers of neighborhood security may well produce an analogous outcome for the lucky family making the move. ${ }^{266}$ In each case, it is not the effect of competition that produces the gains for the newcomers but rather the influence of the other users on the public good in question.

A user-participation model suggests that we should find ways both to encourage and to facilitate the optimal mixing of users and also to assist

263. I am assuming here that total dispersal-the removal of everyone from an inner-city neighborhood or school-would be both infeasible and undesirable. While it is possible that an inner-city school could be closed and all its students sent elsewhere, the notion of a residential core without a local school does not seem like an appealing long-term solution.

264. See, e.g., Trebilcock et al., supra note 2, at 232 (arguing that the idea that vouchers offer "an escape from the messy and unprincipled compromises of politics and the frailties of voice as a disciplining mechanism is largely an illusion").

265. See Ryan, supra note 46 , at $297-98$ and sources cited thercin.

266. See Leonard S. RUbinowitz \& James E. Rosenbaum, Crossing the Class and COLOR LINES: FROM PUBLIC HOUSING TO WHITE SUBURBIA (2000) (assessing the effects of the court-ordered Gautreaux program in Chicago, which assisted the relocation of several thousand families from inner-city neighborhoods to middle-class suburbs); id. at 189 ("While the studies discussed in this book showed that families' experiences were very complex, they supported the basic premise of the concept of 'geography of opportunity'-people who move to better areas can improve their opportunities and attainments."); see also Lawrence F. Katz et al., Moving 10 Opportunity in Boston: Early Results of a Randomized Mobility Experiment, 116 Q.J. ECON. 607 (2001) (discussing improvements in well-being experienced by recipients of housing vouchers in the Boston area). 
more people in becoming quality-enhancing users. Markets are not designed to do either of these things. ${ }^{267}$ Instead, market-oriented voucher programs can stratify users and may thereby generate undesirable results. Limited "choice" programs which prohibit schools from screening by ability or income might offer benefits for some students but would still entail risks for the students left behind. ${ }^{268}$ It is also important to recognize that any gains associated with these constrained programs would be the result of government-selected policy choices and user participation, not the operation of competition. ${ }^{269}$

\section{B. Residential Zoning}

Focusing on user participation also has some interesting implications for a longstanding mechanism for structuring the delivery of local public goods-zoning. ${ }^{270}$ Zoning is usually thought of as a set of regulatory exclusions that keep out the disfavored uses, and this is certainly accurate. But in a metropolitan area, a pattern of zoning regulations may also operate to trap less well-off users in a particular user pool by erecting financial barriers to exit. ${ }^{271}$ Zoning thus fences users into certain user pools, even as it fences them out of other user pools. In order to understand how zoning affects the formation of user pools, it is necessary to look at what is happening on both sides of that fence.

1. Zoning as Exclusion.-On the exclusionary side of the fence, zoning facilitates the creation of stable, stratified communities. Zoning allows

267. This should not be surprising given that a public good, and hence cooperation, is involved. See Liebman, supra note 3, at 313 \& n.269 ("One thing markets are not good for is allocating public goods, and an educated public is just that.").

268. See Liebman, supra note 3, at $291 \&$ n. 145 (pointing out equity concerns associated with stratification by parental sophistication); Minow, supra note 251, at 281 (discussing risk of stratification by degree of parental concern and involvement under school-choice plans); Levin, supra note 24 , at 44 (explaining that because "[t]he ability to use educational choiee effectively depends heavily upon occupational experience, education, and other resources such as the capacity to obtain and interpret information in a useful way," school-choice plans "will tend to favor more advantaged families").

269. The design details associated with voucher programs are critically important and are likely to be both complicated and controversial. See Trebilcock et al., supra note 2, at 232 ("Onee wc move beyond mere aphorisms or sloganeering, the detailcd design of voucher systcms raises technically complex and normatively contentious issues."); Ryan, supra note 46, at 312 (observing that "the details will make all the difference" for education vouchers); Isabel V. Sawhill \& Shannon L. Smith, Vouchers for Elementary and Secondary Education, in VOUCHERS AND THE PROVISION OF PUBLIC SERVICES 251, 260-69 \& tb1.9-2 (C. Eugene Steuerle et al. eds., 2000) (discussing various voucher programs and emphasizing that the "[d]evil is in the [d]etails").

270. There are many kinds of zoning regulations, which vary both in intent and effect. 1 wiil focus here on zoning rules that exclude certain kinds of housing types or sizes from particular residential neighborhoods.

271. It is true that poor people could lcave the metropolitan area entirely and scek affordable housing elsewhere, perhaps in a rural setting. But if we assume that the metropolitan area is attractive for social, familial, and employment reasons, the choice to remain in the inner-city portion of that metropolitan area may be something of a non-choice. 
communities desiring premium services to effectively charge admission to the community in the form of minimum housing-consumption requirements, which translate into minimum property-tax contributions. ${ }^{272}$ In this manner, zoning can ensure that every family is bearing a relatively equal share of the tax burdeu required to fund local public goods like neighborhood security and education. Were it not for zoning, the argunent runs, the poor could "free ride" on premium local goods and services by moving into inferior housing units in a wealthy neighborhood. ${ }^{273}$ With zoning in place, the world can work in a reliably Tieboutian fashion, with various jurisdictions offering various packages of goods and services from which individuals can select based on preferences.

While this justification for zoning makes sense, a focus on user participation suggests a much more deep-seated attraction to zoning: it enables one to prescreen meinbers of one's user pool. ${ }^{274}$ This might, in part, reflect a desire to realize certain associational preferences. The analysis in this Article suggests, however, that there are additional instrumental reasons why one might wish to control entry into one's user pool. If wealth is positively correlated with being a quality-enhancing (or cooperative) user, then a wealth requirement would help maintain the desired concentrations of quality-enhancing users in the user pool..$^{275}$ So zoming not only permits groups of individuals to procure the goods and services they desire (without free riders encroaching on the deal) but also allows them to decide who can consune those goods and services with them. ${ }^{276}$ Because consumption is (in

272. See Bruce W. Hamilton, Zoning and Property Taxation in a System of Local Governments, 12 URB. STUD. 205 (1975).

273. See id. at 205 (explaining that in the absence of constraints such as zoning. "the Tiebout Hypothesis seems to be a formula for musical suburbs, with the poor following the rich in a neverending quest for a tax base"); Oates, supra note 4, at 204 ("We can thus envision a process in which wealthy households establish a community with high levels of public outputs only to find themselves 'invaded' by lower-income families seeking the pecuniary advantages of the large tax base-a continuing game of hide-and-seek with no stable solution.") (footnote omitted).

274. The idea that zoning might be motivated not only by fiscal considerations but also by concerns about the effects of population characteristics on public goods has been convincingly presented by Wallace Oates. See Oates, supra note 4, at 201-19.

275. Wealth is not a perfect proxy for quality-enhancing potential. It is clearly underinelusive, screening out large numbers of quality-enhancing users of nore modest means. But while this underinclusiveness is troubling on social-justice grounds, wealth may remain a serviceable screening criterion as long as enough wealthy quality enhancers exist to form a viable pool. On the other hand, if a wealth requirenent allowed many quality detractors to slip past, it would not be a useful screening device. Private user pools typically add other admissions criteria to the wealth requirenent to guard against just such a possibility. Nevertheless, if the degree of overinclusiveness is not large and enough other quality enhancers exist in the user pool, this is unlikely to create serious problems for the user pool. Most inportant, perhaps, is the widespread belief that wealth maps fairly reliably onto quality-enhancing potential. If most quality enhancers believe that a wealth requirement does a good job of screening out quality detractors, they will be attracted to user pools that have wealth requirements (perhaps straining their budgets considerably to get in), and this will enhance the user pool's ability to address any quality-detracting behasiors that seep in.

276. See Oates, supra note 4. 
important respects) production, having control over one's co-consumers means having control over the quality of the local public good.

Of course, zoning is not the only way in which people can form exclusive consumption commumities. Robert Nelson has argued that if zoning is ruled out, wealthy mdividuals might form communities with few or no public services to eliminate any incentive for the less wealthy to enter. ${ }^{277}$ The wealthy could then simply obtain their services privately. ${ }^{278}$ The formation of separate commumities in this story reflects the reality that the cooperation of other users is required to produce certain goods, like neighborhood security. An individual wealthy homeowner could hire bodyguards, erect fences, and set various alarms in any neighborhood, but no real sense of security can be obtained in an isolated fortress. Certain elements of security, such as the ability to move freely about one's neighborhood and to allow one's children to play on local sidewalks, cannot be purchased by an individual family - these require the cooperation of a user pool. ${ }^{279}$

Recognizing this reality, Nelson (writing in 1977) somewhat presciently noted that "[p]olice protection might even be provided privately to some extent as the wealthy congregated $\mathrm{m}$ large privately managed developments with guards, entry gates, and other protections paid for by the residents." 280 Today, millions of Americans live in gated enclaves with private police forces, and such arrangements are on the increase. ${ }^{281}$ Since these communities are not given tax rebates but still must contribute financially to the public goods being provided by the municipalities in which they are located, the impetus seems to be the choice of a user pool rather than a desire for fiscal advantages. Thus, eliminating zoning could not keep people from forming stratified user pools, unless the law were to limit the ability of private commumities to exclude users. ${ }^{282}$ Eliminating or changing the nature

277. NELSON, supra note 33, at 41 . Nelson notes that funding services at the state or federal level would preclude this maneuver but would necessarily make spending less responsive to local preferences. $I d$. at 42 .

278. See id. at 41 .

279. An outlandishly wealthy individual could theoretically hire a user pool and live in a neighborhood resembling a movie set with numerous paid cmployees acting as neighbors. Aside from the implausibility of this solution, it would likely conflict with other values that the person might be seeking in life-such as sense of life's being authentically lived. Jane Jalcobs describes a less extreme example of a hired user pool in residential Park Avenue. She notes that "if its rents were to slip below the point where they could support a plentiful hired neighborhood of doormen and elevator men, it would undoubtedly become a woefully dangerous street." JACOBS, supra note 49 , at 40 .

280. NELSON, supra note 33 , at $41-42$.

281. See David A. Sklansky, The Private Police, 46 UCLA L. REV. 1165, 1173 (1999) (discussing the "surge in walled-off, gated housing developments, which commonly use homeowner fees to pay for patrols by private seeurity guards").

282. For two perspectives on the appropriate degree of judicial intervention into the affairs of residential associations, compare Clayton P. Gillette, Courts, Covenants, and Commumities, $61 \mathrm{U}$. CHI. L. REV. 1375 (1994) (suggesting that judicial deference might be appropriate to protect 
of zoning would, however, remove local government support for stratified communities. ${ }^{283}$ The extent to which this would result in a reduction in userpool stratification would depend, in part, on the respective amounts of stratification currently attributable to fiscal considerations and to other considerations relating to the choice of a user pool. ${ }^{284}$ It would also depend on the overall cost differentials associated with moving to a private alternative, given the fact that consumers of private alternatives must continue to pay taxes for publicly provided goods. At a minimum, eliminating zoning would raise the cost of forming exclusive user pools.

Froin a user-pool perspective, there are problems with stratification and good reasons for wanting to reduce governmental support for it, even if the stratification cannot be eliminated altogether. Zoning may have at least two other negative effects on user pools. First, the existence of exclusively residential zones may actually reduce the safety of those areas. Much of what inakes a neighborhood safe is the presence of "eyes" out and about in the streets. ${ }^{285}$ Having a mixture of residential and commercial activity on a given block will tend to naximize the number of people who will be moving to or from some legitimate errand at any given time. ${ }^{286}$ The presence of people out on the streets tends to attract more eyes and more activity, and thus enhances safety. ${ }^{287}$

Second, zoning patterns across a community may foster user-pool instability. If zoning restrictions result in fine gradations of housing size and type, a person will be forced to move from neighborhood to neighborhood

residential-association autonomy), with Gregory S. Alexander, Dilemmas of Group Auronomy: Residential Associations and Community, 75 CORNELL L. REV. 1 (1989) (arguing that excessive judicial deference to residential-association autonomy could compromise the ideal of community).

283. As Frug writes, law plays a central role in maintaining current patterns of suburban residential homogeneity:

To achieve any significant level of homogeneity, suburbs need state-granted autonomy: the right to incorporate as a separate municipality; immunity from annexation by the central city; the privilege of cngaging in exclusionary zoning; the ability to legislate and provide services solely in their own self-interest; the authority not only to tax the real property located within city boundaries but to spend the revenue collected solely on local residents.

Frug, supra note 1 , at 1070.

284. It is difficult to know to what extent zoning in a given area is "fiseal zoning" (that is, motivated by fiscal considerations) as opposed to "pubhic-goods zoning" (that is, motivated by the desire to regulate population fiows and hence to affect the quality of public service). See Oates, supra note 4, at 212 (observing that "there is a real problem of collinearity in distinguishing betwcen the extent of fiscal and of public-goods zoning"); Vicki Been, Comment on Professor Jerny Frug's The Geography of Community, 48 STAN. L. REV. 1109, 1111 (1996) (noting the "vast hiterature about the fiscal zoning thesis that provides evidence that fiseal motivations are one of the most important reasons that people move to the suburbs and choose income-homogeneous communities when they make that move").

285. See generally JACOBS, supra note 49, at 35-42 (discussing the importance of eyes on the street).

286. See id at 36-37 (explaining how public places, stores, restaurants, and bars promote safety by getting people out on the streets and by adding the eyes of storekeepers).

287. See id. at 37 (noting that "the activity generated by people on crrands, or people aiming for food or drink, is itself an attraction to still other people"). 
during a typical life cycle to keep pace with changing life circumstances. An individual might perhaps start out as a single person in an apartment in one part of a large metropolitan area, move to another neighborhood filled with two-bedroom cottages upon marrying, and then move to a suburb dominated by four-bedroom houses after having children. The person might later move to a "better" suburb or gated community, to a smaller home once the nest is empty, or to a retirement community. ${ }^{288}$ To be sure, mobility is increasing generally and certain forms of it-such as company transfers from one metropolitan area to another-cannot be readily eliminated. However, adding a high degree of movement within a metropolitan area over the life cycle serves to further destabilize user pools. If housing types were mixed within a given neighborhood, it might be possible for our hypothetical individual to live in the same general neighborhood (even if not in the same home) throughout her life. ${ }^{289}$

At this point, it is important to emphasize that zoning need not be used to generate narrow, stratified, homogeneous residential zones-although it has often been used in this way. ${ }^{290}$ It is fully possible to zone for mixed uses and for mixed types and sizes of housing. ${ }^{291}$ If used in this way, zoning might still be a mechanism for keeping out certain nuisance-like uses and would have continuing vitality for that reason. William Fischel's work points to another important function that such heterogeneous zoning might continue to serve-that of providing stability and predictability and thereby protecting the value of the largest single investment of most homeowners: their house. ${ }^{292}$ When zones yield a predictable, even if heterogeneous, mix of homes, it is possible for the value of local public goods such as education and neighborhood security (net of the taxes for these goods) to be capitalized into home values. ${ }^{293}$ This avoids the unstable scenario in which the poor continually attempt to free-ride on premium services and the wealthy continually depart as the tax base erodes. ${ }^{294}$ It is not necessary for everyone to consume the same amount of housing for this to work, as long as the stock of each type of housing is limited by zoming. ${ }^{295}$ When such capitalization occurs, people who live in smaller houses may pay less tax while receiving

288. See id. at 139-40 (discussing the instability problems associated with homogeneous neighborhoods).

289. Id. at 139 (noting that people who "live in diversified, rather than monotonous, districts" can "stay put" despite changes in jobs, family size, and interests and can thereby contribute to neighborhood stability).

290. See FISCHEL, supra note 30 (manuscript dated Oct. 2000 at $\S 3-16$ ) (discussing viability of zoning for heterogeneous communities).

291. See id. (manuscript dated Oct. 2000 at $§ 3-17$ ) (deseribing "private planned 'new towns"' containing "a mix of building types to appeal to a heterogeneous market").

292. Id. (manuscript dated Oct. 2000 at $\$ 3-7$ ) (explaiming how eapitalization of public services into home values depends upon zoning to create inelasticity of supply).

293. See id. (manuscript dated Oct. 2000 at $\$ 3-16$ ) (explaining how zoning regulations can limit the supply of various types of housing stock to facilitate capitalization).

294. See supra note 273 and accompanying text.

295. FISCHEL, supra note 30 (manuscript dated Oct. 2000 at $\S 3-16$ ). 
the same services, but they will end up paying a premium for their home that equals the value of this property-tax "bargain."296

It is plausible that heterogeneous zones might provide the stability and predictability of zoning while avoiding the unfortunate results of stratification. The time inay be right for such a shift in zoning practices: many people no longer crave hounogeneity and are expressing preferences for more heterogeneity. ${ }^{297}$ Whether or not this result would be politically achievable is a question beyond the scope of this Article, but one that will likely be heavily impacted by user-pool concerns.

2. The Other Side of the Fence: Zoning as Forced Inclusion.-By blocking certain opportunities to exit from a given user pool, zoning may also have the effect of "trapping" some users in that pool. If zoning restrictions were eased so that inore users could afford to enter suburban areas, inner-city default pools might be further depleted of quality-enhancing users. Housing vouchers, if adopted on a sufficiently large scale, could have the same effect.

One way to answer this concern is to note that the suburban areas largely became attractive in the first place because of their ability to exclude lower-income users, and that their reason for existence would disappear if that exclusionary power were stripped away. While this would be an excellent argument for never allowing exclusionary zoning to get started in the first place, there is no guarantee that removing zoning would return peopie to the default pools they initially left behind. Higher density housing might begin to make inroads into previously exclusive suburbs, but the response among those already living in those suburbs would likely be to either stay put or move to a private gated enclave that would be protected against any future encroachments. A family living in the suburbs would probably not choose to inove into the inner-eity default pool, which would at that point be even further depleted as a result of the easing of zoning restrictions.

The work of zoning would only be fully undone if the decision to inove to the suburbs in the first place could be undone-that is, if the flow of people from city to suburbs became bi-directional. This does not necessarily require luring current suburbanites in from the suburbs; rather, unobility for other reasons results in a steady influx of new families to a given urban area, who will then be in a position to choose anong communities. But without some incentives or unique attractions associated with the inner city, an influx into that area seems unlikely. Without measures designed to ensure that the expected additional outflow from the city would be matched by an inflow to

296. See id:; Bruce W. Hamilton, Capitalization of Intrajurisdictional Differences in Local Tax Prices, 66 AM. ECON. REV. 743, 744 (1976).

297. See FISCHEL, supra note 30 (manuscript dated Oct. 2000 at $\S 3-17$ ) (discussing the possibility that heterogeneity may increase home values). 
the city, lifting zoning could have unintended negative consequences for the user pool left behind. Put another way, lifting zoning might amount to another instance of the "dispersal" fallacy. Dispersing the poor among wealthy neighborhoods can only result in a pocket of residual poor unless measures are taken to make the dispersal coinplete and mandatory (which presents its own serious probleins) or the dispersal is matched by an inflow into the previously troubled areas.

This line of analysis is admittedly troubling. Recognizing the utility of zoning as a means of forcing mclusion in a given user pool raises obvious social-justice issues. Also, there are other valid objections to retaining zoning solely to trap quality-enhancing users into a given pool. First, there is a concern that a user who is in a particular user pool against his or her will is unlikely to be as quality-enhancing (cooperative) as a user who is there by choice. Second, a user who does not expect to stay in a given user pool is likely to be a less cooperative user. Many quality enhancers currently trapped in troubled pools doubtless expect to soon gain the financial wherewithal to exit that user pool. Nevertheless, by raising barriers to exit, zoning may help to avoid the worst societal outcomes. If this is so, then zoning is an even more effective tool of the well-off than has previously been recognized. It not only furthers the consuniption interests of the well-off by enabling thein to form exclusive communities but also helps to maintain the composite value of local public goods by keeping a core of quality enhancers in the default pool. This enables the well-off to defect in the "choice of pool" game described earlier, safe in the knowledge that there will be enough other cooperators to avoid a disastrous outconie.

The situation is patently unjust, mirroring concerns of voucher proponents: Why should low-incone quality enhancers be forced to stay in troubled user pools while high-inconie quality enhancers always have opportunities to opt for better user pools? The role of exclusionary zoningand hence of law-in contributing to this state of affairs should generate discomfort among thinking people. Maybe it is time for the voucher proponents and the opponents of exclusionary zoning to converge on the solution of easing zoning restrictions, perhaps by moving towards more heterogeneous zones. This would provide low-income people with a broad, meaningful range of choice as to both education and public safety, ${ }^{298}$ but it would also present certain risks, including the risk that inner-city user pools would become dangerously depleted. ${ }^{299}$ To avoid this, the zoning changes

298. See id. (manuscript dated Oct. 2000 at $\S 3-11$ ) (noting that most people in the United States live in metropolitan areas that offer a choice of a significant number of local-governnental cntities).

299. Any drastic change in current zoning practices affecting existing housing stock also runs the risk of working an unfairness on those who paid a premium to buy into an exclusive zone. See William A. Fischel, Equity and Efficiency Aspects of Zoning Reform, 27 PUB. POL'Y 301, 311-12 (1979); see generally Harold M. Hochman, Rule Change and Transitional Equity, in REDISTRIBUTION THROUGH PUBLIC CHOICE 320 (Harold M. Hochman \& George E. Peterson eds., 
could be coupled with other measures designed to improve default user pools: for example, incentives to attract and retain users, and programs designed to inobilize and transform users.

\section{Conclusion}

The problems I have explored in this Article are complex ones, for which no easy solutions exist. Everyone senses that users have a profound influence on locally provided goods like education and neighborhood security. Yet nobody knows quite what to do with this fact. Too often the users' influence is shunted aside as something that is too resistant to policy to be confronted head-on. The result has been wrong-headed policy prescriptions that treat these goods as if they were ordinary consumer goods. Of course they are not. Education and neighborhood security are in large ineasure endogenously produced by those who consume them. Moreover, users of schools and neighborhoods are producing true public goods (or bads)-froin which no one in the larger community may exit.

Understanding goods such as education and security as user-produced public goods inakes it possible to identify and begin to work through the collective-action problems associated with the provision of these goods. A user-centered approach also allows a clearer view of legal and policy alternatives. For example, the user-participation model shows why competitive solutions that might make sense for exogenously produced goods may fail for goods that are largely user-produced. It also calls into question the exclusive focus on fiscal impacts that often dominates analyses of interjurisdictional dilemmas. A focus on users as producers of the goods suggests that these dilemmas are not just about financial obligations, but also and more importantly about participation.

Refocusing on the user's role in producing these public good offers an interesting new perspective for legal scholars and suggests some potentially promising directions for policy. Instead of seeking to improve these "products" through the inanipulation of exogenous factors, we should redirect our attention to the user pools themselves. The ideas that I outline in this Article are only starting points, but I hope that they suggest the promise associated with a user-focused approach to local public goods.

1974) (discussing equity concerns that accompany rule changes). Given the positive value many now associate with heterogeneity, however, it is unclear whether opening the door to additional housing types and kinds of uses would actually decrease home values. See supro note 297 and accoinpanying text. 